\title{
LEVANTAMENTO DE INSETOS EM PLANTAS DANINHAS NA ENTRESSAFRA DAS CULTURAS DA SOJA E DO MILHO EM JABOTICABAL (SP)
}

\section{MARINA REGINA FRIZZAS \\ Engenheino,Agrônomó}

Orientador: Prof. Dr. SINVAL SILVEIRA NETO

\begin{abstract}
Dissertação apresentada à Escola Superior de Agricultura “Luiz de Queiroz”, Universidade de São Paulo, para obtenção do título de Mestre em Ciências, Área de Concentração: Entomologia.
\end{abstract}

\author{
PIRACICABA \\ Estado de São Paulo - Brasil \\ Outubro - 1998
}


Dados Internacionais de Catalogação na Publicação (CIP)

DIVISĀo DE BIBLIOTECA E DOCUMENTAÇĀO - Campus "Luiz de Queiroz"/USP

Frizzas, Marina Regina

Levantamento de insetos em plantas daninhas na entressafra das culturas da soja e do milho em Jaboticabal (SP) / Marina Regina Frizzas. - - Piracicaba, 1998.

102 p. : il.

Dissertação (mestrado) - - Escola Superior de Agricultura Luiz de Queiroz, 1998. Bibliografia.

1. Entomologia agricola 2. Entressafra 3. Inseto 4. Milho 5. Planta daninha 6. Soja I. Título

CDD 633. 34

632.58 
"O homem que venceu na vida é aquele que viveu bem, riu muitas vezes e amou muito; que conquistou o respeito dos homens inteligentes e o amor das crianças, que preencheu um lugar e cumpriu uma missão; que deixa o mundo melhor do que encontrou, seja com uma flor, um poema perfeito ou o salvamento de uma alma; que procurou o melhor nos outros e deu o melhor de si.” 
Aos meus queridos pais,

Benedito Frizzas e Maria da Graça, exemplos de dedicação, doação e sobretudo de amor, por me mostrarem que mais importante que a vitória ou a derrota, é jamais desistir de lutar pelos meus ideais,

carinhosamente

\section{DEDICO}

Aos meus irmãos,

Andréa, Patricia e Amauri, por plantarem em meu coração a amizade, a alegria, a dedicação e o amor

E ao meu sobrinho, Thiago 


\section{AGRADECIMENTOS}

À DEUS, pelo dom maravilhoso da vida, por iluminar e guiar passo a passo meu caminho me fazendo entender que o conhecimento é mensagem de vida e que esta é um livro aberto que ensina a quem deseja aprender.

Ao Charles Martins de Oliveira, pela imensurável ajuda, apoio, incentivo, companheirismo, confiança, amizade e por preencher minha vida de amor, alegria, carinho e serenidade.

Ao Prof. Dr. Sinval Silveira Neto, pela orientação amiga, pelo convivio generoso e pelo incentivo e apoio.

À Profa Dra Nilza Maria Martinelli, pela contribuição valiosa no desenvolvimento deste trabalho, pela amizade e exemplos de dedicação e profissionalismo.

Aos professores e funcionários do Departamento de Defesa Fitossanitária da FCAV/Jaboticabal, Raquel Matassa de Assis, Maria Isabel Vitale, Reinaldo Aparecido Longo, Rodrigo Boarini, Luciana dos Santos, Natalina D.C. de Andrade, Aracyara M.S.A. de Faria, Rosângela T. dos S. Souza, Jurandir de Oliveira, Gilson José Leite e em especial a Dionísio Celso de Figueiredo Neto pela grande ajuda na condução do experimento e amizade.

Aos Professores do Departamento de Entomologia da ESALQ/USP, pelos ensinamentos.

Ao Prof. Dr. Ricardo Pereira Lima Carvalho, pela amizade, pelas oportunidades, incentivos e sugestões.

À Dra Marinéia Lara Haddad e em especial à Regina Célia Botequio de Moraes, pela valiosa colaboração na análise faunistica e pelo constante auxílio. 
Ao Prof. Dr. Celso Omoto pela correção do Summary, pelos ensinamentos, sugestões e pela amizade.

À grande amiga, Rosangela Cristina Marucci, pelo companheirismo e pelo convivio gostoso de todos esses anos, pelas alegrias e tristezas que já passamos juntas.

Aos amigos, Cláudia Maria Toffanelli, Mônica Josene Barbosa Pereira, José Lino Neto, Jorge Anderson Guimarães, Teresinha Augusta Giustolin, Silvia Monteil Gomes, Maria Aparecida Bittencourt (Cidoca), Lusinério Prezotti, Rogério Biaggioni Lopes (Fito) e Elton Lúcio de Araújo pelo convivio e pelos momentos de descontração pois, o verdadeiro amigo é aquele que nos faz melhor do que somos.

Aos funcionários do Departamento de Entomologia da ESALQ/USP, em especial à Regina, Ana Gabriela, Solange, Cibele, Edilma, Neide, João gorá, Carlinhos e Tutú.

À CAPES, pela concessão da bolsa.

Às bibliotecárias, Eliana Maria Garcia Sabino e Kátia, pela correção das referências bibliográficas e colaboração.

À todos os colegas do CPG - Entomologia da ESALQ/USP.

$\mathrm{E}$ a todos que direta ou indiretamente ajudaram na realização deste trabalho pois, no final o que a gente leva é o que a gente faz. 


\section{SUMÁRIO}

Página

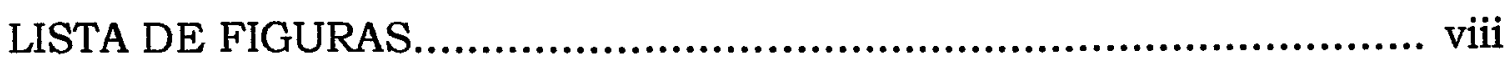

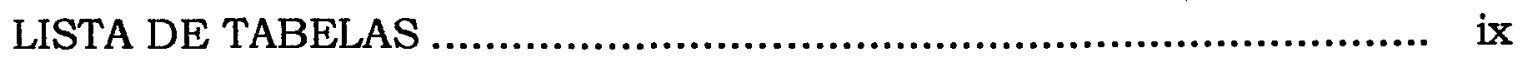

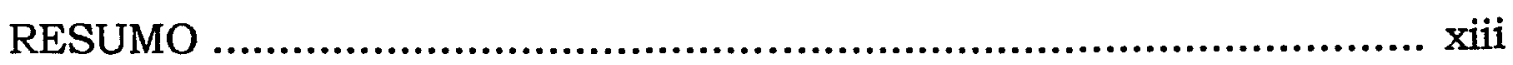

SUMMARY

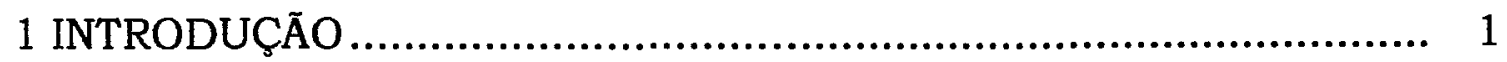

2 REVISÃO DE LITERATURA ……........................................... 3

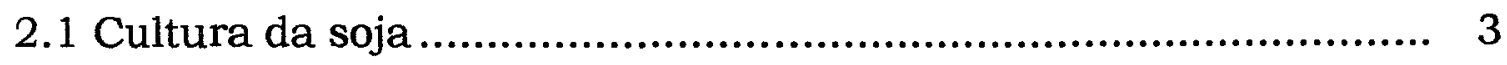

2.1.1 Artrópodes da cultura ...................................................... 3

2.1.2 Plantas daninhas na cultura ............................................... 5

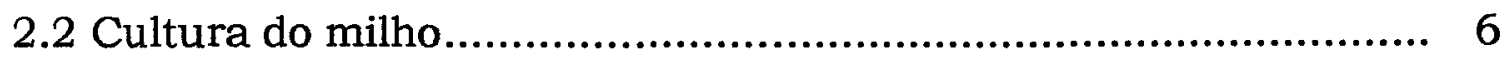

2.2.1 Artrópodes da cultura ........................................................ 7

2.2.2 Plantas daninhas na cultura ................................................ 7

2.3 Influência das plantas daninhas sobre as culturas e insetos........ 8

2.4 Plantas daninhas hospedeiras de insetos-praga........................... 10

2.5 Plantas daninhas hospedeiras de inimigos naturais .................... 14

2.6 Plantas daninhas hospedeiras de insetos na entressafra ............. 18

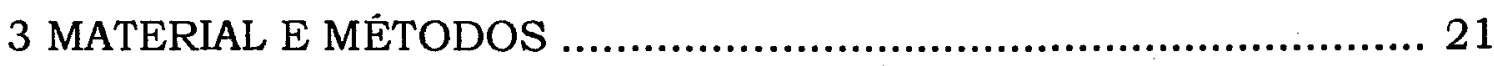

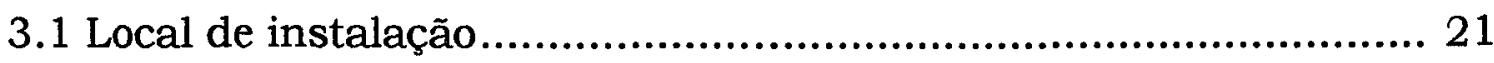

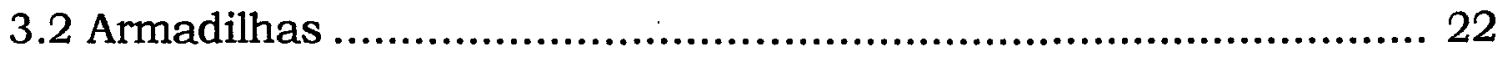

3.3 Avaliações e levantamentos de insetos....................................... 26

3.4 Identificação e coleção dos insetos............................................... 27

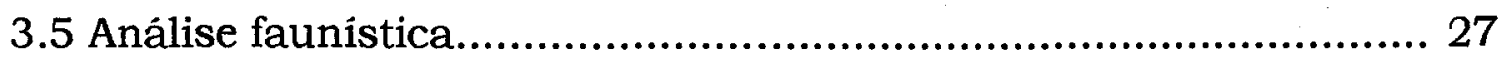

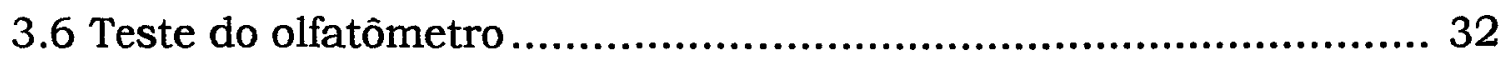

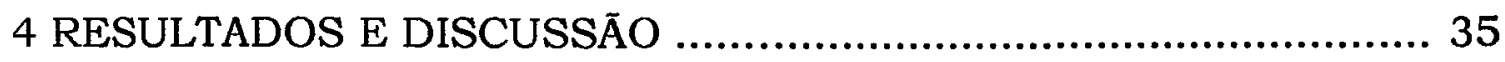

4.1 Comunidade de insetos nas áreas de soja e milho ........................ 35

4.1.1 Espécies coletadas .............................................................. 35

4.1.2 Caracterização das comunidades............................................ 40 
4.1.3 Delimitação das comunidades ........................................ 44

4.2 Levantamento de insetos em plantas daninhas na área de soja ... 45

4.2.1 Espécies de plantas daninhas ......................................... 45

4.2.2. Análise faunistica..................................................... 47

4.3 Levantamento de insetos em plantas daninhas na área de milho ................................................................................. 64

4.3.1 Espécies de plantas daninhas ...................................... 64

4.3.2 Análise faunistica................................................... 65

4.4 Comparação das áreas de soja e milho com relação aos insetos coletados nas plantas daninhas ......................................... 80

4.5 Teste do olfatômetro .......................................................... 83

4.5.1 Lagria villosa................................................................. 83

4.5.2 Paranapiacaba significata............................................. 84

4.5.3 Diabrotica speciosa.................................................... 86

4.5.4 Piezodorus guildinii......................................................... 87

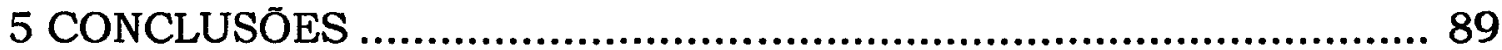

REFERÊNCIAS BIBLIOGRÁFICAS .......................................... 91 


\section{LISTA DE FIGURAS}

Página

1 Armadilha de Malaise ......................................................... 23

2 Armadilha luminosa modelo INTRAL..................................... 24

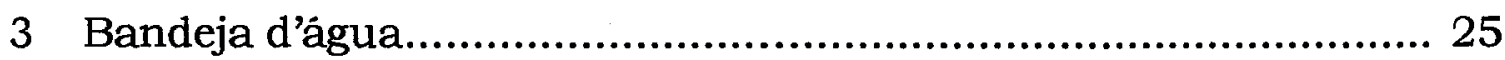

4 Olfatômetro ........................................................................ 33

5 Porcentagem de insetos coletados durante a entressafra nas áreas de soja e milho. Jaboticabal, SP, 1997 e 1998 ................. 43 


\section{LISTA DE TABELAS}

Página

1. Espécies coletadas e resultados da análise faunistica dos insetos capturados com armadilha luminosa, armadilha de Malaise e bandeja d'água na entressafra da soja de 1997 e 1998 em Jaboticabal, SP

2 Espécies coletadas e resultados da análise faunistica dos insetos capturados com armadilha luminosa, armadilha de Malaise e bandeja d'água na entressafra do milho de 1997 e 1998 em Jaboticabal, SP

3 Relação das espécies de plantas daninhas encontradas na entressafra da cultura da soja de 1997 e 1998 em Jaboticabal, $\mathrm{SP}$

4 Espécies coletadas e resultados da análise faunística dos insetos coletados em guizo-de-cascavel com rede e cone entomológicos na entressafra da soja de 1997 em Jaboticabal, SP

5 Espécies coletadas e resultados da análise faunistica dos insetos coletados em anileira com rede e cone entomológicos na entressafra da soja de 1997 e 1998 em Jaboticabal, SP

6 Espécies coletadas e resultados da análise faunística dos insetos coletados em guanxuma com rede $e$ cone entomológicos na entressafra da soja de 1997 e 1998 em Jaboticabal, SP 
7 Espécies coletadas e resultados da análise faunística dos insetos coletados em crotalária com rede e cone entomológicos na entressafra da soja de 1997 e 1998 em Jaboticabal, SP

8 Espécies coletadas e resultados da análise faunistica dos insetos coletados em losna-branca com rede e cone entomológicos na entressafra da soja de 1998 em Jaboticabal, $\mathrm{SP}$

9 Espécies coletadas e resultados da análise faunística dos insetos coletados em apaga-fogo com rede e cone entomológicos na entressafra da soja de 1998 em Jaboticabal, $\mathrm{SP}$ 60

10 Espécies coletadas e resultados da análise faunística dos insetos coletados em capim-amargoso com rede e cone entomológicos na entressafra da soja de 1998 em Jaboticabal, SP 62

11 Relação das espécies de plantas daninhas encontradas na entressafra da cultura do milho de 1997 e 1998 em Jaboticabal, SP.

12 Espécies coletadas e resultados da análise faunística dos insetos coletados em rabo-de-foguete com rede $\mathrm{e}$ cone entomológicos na entressafra do milho de 1997 em Jaboticabal, SP. 
13 Espécies coletadas e resultados da análise faunistica dos insetos coletados em guanxuma com rede e cone entomológicos na entressafra do milho de 1997 e 1998 em Jaboticabal, SP 68

14 Espécies coletadas e resultados da análise faunistica dos insetos coletados em apaga-fogo com rede $\mathrm{e}$ cone entomológicos na entressafra do milho de 1997 e 1998 em Jaboticabal, SP

15 Espécies coletadas e resultados da análise faunistica dos insetos coletados em carrapicho-de-carneiro com rede e cone entomológicos na entressafra do milho de 1998 em Jaboticabal, SP.................................................................

16 Espécies coletadas e resultados da análise faunistica dos insetos coletados em falsa-serralha com rede $\mathrm{e}$ cone entomológicos na entressafra do milho de 1998 em Jaboticabal, SP.

17 Espécies coletadas e resultados da análise faunistica dos insetos coletados em nabiça com rede e cone entomológicos na entressafra do milho de 1998 em Jaboticabal,SP

18 Espécies coletadas e resultados da análise faunística dos insetos coletados em anileira com rede e cone entomológicos na entressafra do milho de 1998 em Jaboticabal, SP 
19 Média ( \pm DPM) do número de insetos da espécie Lagria villosa encontrados nas plantas daninhas através do teste do olfatômetro, Jaboticabal, SP, 1998

20 Média ( \pm DPM) do número de insetos da espécie Paranapiacaba significata encontrados nas plantas daninhas atravês do teste do olfatômetro, Jaboticabal, SP, 1998

21 Média $( \pm \mathrm{DPM})$ do número de insetos da espécie Diabrotica speciosa encontrados nas plantas daninhas através do teste do olfatômetro, Jaboticabal, SP, 1998

22 Média $( \pm$ DPM) do número de insetos da espécie Piezodorus guildinii encontrados nas plantas daninhas atravês do teste do olfatômetro, Jaboticabal, SP, 1998 


\title{
LEVANTAMENTO DE INSETOS EM PLANTAS DANINHAS \\ NA ENTRESSAFRA DAS CULTURAS DA SOJA E DO \\ MILHO EM JABOTICABAL (SP)
}

\author{
Autora: MARINA REGINA FRIZZAS \\ Orientador: Prof. Dr. SINVAL SILVEIRA NETO
}

\section{RESUMO}

Com o objetivo de conhecer as espécies de insetos diretamente relacionadas com as plantas daninhas, que comumente se desenvolvem em culturas de milho e soja, e atravês de uma análise faunistica, selecionar as espécies predominantes no periodo de entressafra nestas culturas, além de comparar áreas de milho e soja com base nas espécies de insetos que ocorrem em diferentes plantas daninhas, foram realizados levantamentos na Fazenda da FCAV de Jaboticabal (SP) em áreas de soja e milho durante os meses de maio a setembro de 1997 e 1998. As avaliaçōes foram realizadas semanalmente através da coleta dos insetos nas plantas daninhas durante a entressafra por meio de rede e cone entomológicos, armadilha de Malaise, armadilha luminosa e bandejas d'água. Após a coleta dos dados foi feita a análise faunística através do cálculo dos indices de constância, dominância, abundância, freqüência, diversidade, similaridade e porcentagem de similaridade e para 4 insetos-praga considerados predominantes foi realizado um teste de preferência às plantas daninhas através do olfatômetro. Os resultados obtidos permitem concluir que embora as áreas de soja e milho tenham 
apresentado indices de diversidade semelhantes, elas tem baixo índice de similaridade em relação as espécies encontradas. Durante a entressafra da soja, as pragas predominantes nas plantas daninhas são Diabrotica speciosa Germ., Lagria villosa Fabr., Paranapiacaba significata (Gahn.), Xerophloea sp., Scaphitopius sp., Alydus sp., Piezodorus guildinii West. e Thyanta perditor (Fabr.) e os inimigos naturais são Cycloneda sanguinea (L.), Delphastus sp., Eriopis connexa (Germ.), Hyperaspis notata (Muls.), Geocoris sp., Polybia sp. e Chrysoperla externa (Hagen). Já durante a entressafra do milho, as pragas predominantes nas plantas daninhas são $D$. speciosa, L. villosa, P. significata, Bucephalogonia xanthophis (Berg), Diedrocephala continua Sakakibara \& Cavichioli e Xerophloea sp. e os inimigos naturais são $C$. sanguinea, Delphastus sp. e Geocoris sp. Os insetos $L$. villosa, $P$. significata e $D$. speciosa tem preferência por determinadas espécies de plantas daninhas através do olfatômetro. Dos insetos coletados durante a entressafra da soja e do milho, a maioria são insetos-praga e destes, D. speciosa é a única espécie predominante em todas as plantas daninhas avaliadas. 


\title{
SURVEY OF INSECTS IN WEEDS DURING THE OFF-SEASON OF SOYBEAN AND CORN CULTURES IN JABOTICABAL (SP)
}

\author{
Author: MARINA REGINA FRIZZAS \\ Adviser: Prof. Dr. SINVAL SILVEIRA NETO
}

\section{SUMMARY}

With the objective to know the species of insects directly associated with the weeds, that commonly inhabit in corn and soybean crops, and to select the predominant species in the off-season period in these cultures by using faunistic analysis, besides comparing corn and soybean areas based an the species of insects that occurr in different weeds, a survey was conducted in the experimental station of Jaboticabal (SP) in soybean and corn areas during the months of May to September of 1997 and 1998. The evaluations were taken weekly through the collect of the insects in the weeds by using net trap, clam trap, Malaise trap, light trap and erminelime trap. After collecting the samples a faunistic analysis was performed through the estimation of the indexes of constancy, abundance, frequency, diversity, similarity and percentage of similarity and for 4 insect-pests considered predominant a preference test to the weeds was done with the use of an olfactometer. Although the results of index of diversity were similar in areas of soybean and corn, they have low index of similarity in relation the species meeting. During the off-season soybean, the predominant pests in the weeds were Diabrotica speciosa Germ., Lagria villosa Fabr., Paranapiacaba significata (Gahn.), Xerophloea sp., Scaphitopius sp., Alydus sp., Piezodorus guildinii West. and Thyanta perditor (Fabr.) and the natural enemies were Cycloneda sanguinea (L.), Delphastus sp., 
Eriopis connexa (Germ.), Hyperaspis notata (Muls.), Geocoris sp., Polybia sp. and Chrysoperla externa (Hagen). During the corn off-season, the predominant pests in the weeds were $D$. speciosa, $L$. villosa, $P$. significata, Bucephalogonia xanthophis (Berg), Diedrocephala continua Sakakibara \& Cavichioli and Xerophloea sp. and the natural enemies were C. sanguinea, Delphastus sp. and Geocoris sp. The insects $L$. villosa, $P$. significata and $D$. speciosa showed preference to certain species of weeds through the olfactometer test. Among the insects collected during the off-season of the soybean and corn, most of them were insect-pests, $D$. speciosa was the only predominant species in all weed species evaluated. 


\section{INTRODUÇÃo}

Desde que o homem deixou de ser nômade, para cultivar seu alimento, até os dias de hoje, das 250 mil plantas conhecidas ele concentrou em não mais que uma centena de espécies a garantia do seu sustento. Ao mesmo tempo, um grupo quase três vezes mais numeroso passou a ser chamado de plantas daninhas, invasoras ou oportunistas. Elas competem com as espécies cultivadas, que são muito produtivas, mas incontestavelmente mais frágeis e dependentes do seu controle. Assim, os herbicidas são utilizados em maiores quantidades que qualquer outra classe de pesticida. Dos produtos fitossanitários empregados no Brasil, $30 \%$ são aplicados na cultura da soja, sendo que $44 \%$ dos herbicidas e $24 \%$ dos inseticidas consumidos no País são destinados a essa cultura, fazendo desta a maior consumidora nacional de herbicidas (Matuo, 1997).

As plantas daninhas são consideradas plantas indesejáveis por hospedarem insetos-praga, patógenos e por reduzirem as produções das culturas. Entretanto, certas espécies podem ser consideradas benéficas para o agroecossistema, por auxiliarem o sistema de manejo de pragas e fornecerem alimentos subsidiários como pólen, néctar e presas alternativas para insetos entomófagos, melhorando assim, o controle biológico de certas pragas (Souza, 1991).

As plantas daninhas podem servir como um reservatório de pragas na entressafra, abrigando-as quando a cultura não se encontra no campo, e a manipulação da abundância e da composição destas 
plantas na entressafra pode ter grande implicação sobre a população de insetos presentes (Altieri et al., 1977). Dessa forma, outras práticas agricolas podem ser adotadas, como o controle destas plantas antes do plantio da cultura. Por outro lado, a possibilidade de se manter uma associação especifica de plantas daninhas em áreas cultivadas, desde que respeitados os períodos de interferência, têm sido discutida por vários autores.

Embora em outros paises existam uma série de trabalhos ressaltando a importância que as plantas daninhas exercem na bioecologia de muitos insetos, no Brasil as informações são escassas, principalmente durante o periodo da entressafra das culturas.

Com base nestes fatos, este trabalho visou conhecer as espécies de insetos diretamente relacionadas com as plantas daninhas que comumente se desenvolvem na entressafra de milho e soja e através de uma análise faunística, selecionar as espécies predominantes neste periodo e, comparar áreas de milho e soja com base nas espécies de insetos que ocorrem em diferentes plantas daninhas. 


\section{REVISÃO DE LITERATURA}

\subsection{Cultura da soja}

A cultura da soja (Glycine max L. Merr.), desde a sua introdução no Brasil, tem sido conduzida com alto nivel técnico em todas as suas operações, desde o preparo do solo até a colheita. Em função de possibilidades de mercado, a cultura tem se expandido desde a regiāo Sul-Sudeste até o norte do país. A soja é hoje a segunda lavoura em área plantada no Brasil e, no âmbito mundial, somos o segundo maior produtor dessa leguminosa proveniente da China (Deuber, 1997).

Entre as culturas anuais, após o milho, a soja é a mais explorada no Estado de São Paulo, sendo este, o sexto maior produtor nacional. Os principais cultivos estão localizados na região Mogiana (Nordeste) e Vale do Paranapanema (Sudoeste) (Tanaka, 1997).

\subsubsection{Artrópodes da cultura}

A comunidade de artrópodes da cultura da soja, especialmente as pragas, está sujeita a constantes mudanças em função de um ou da combinação dos seguintes fatores: mudanças nas práticas culturais, tais como métodos de plantio, rotação de culturas, época de plantio, espaçamento, utilização de cultivares precoces, tardias etc.; modificação na eficiência dos inimigos naturais, sejam eles nativos ou introduzidos; efeitos da aplicação dos defensivos agricolas sobre os 
insetos visados $\mathrm{e}$ sobre os inimigos naturais, incluindo os microorganismos entomófagos; mudanças na avaliação do impacto econômico causado pelas pragas, com conseqüente ajuste no nível de dano econômico (NDE); alteração da associação com o hospedeiro e por conseguinte, melhoria da sanidade da cultura (Kogan \& Turnipseed, 1987).

Ainda de acordo com Kogan \& Turnipseed (1987), logo após a emergência da cultura pode ocorrer o ataque da lagarta rosca (Agrotis ipsilon, Hufnagel) e da broca do caule (Elasmopalpus lignosellus Zeller) nas plântulas. Durante o restante da fase vegetativa e em alguns casos, até o início da fase reprodutiva, há a ocorrência da lagarta da soja (Anticarsia gemmatalis Hūeb.), falsa medideira (Rachiplusia nu Guen.) e da broca das axilas (Epinotia aporema Wals.). Com o início da fase reprodutiva surgem os percevejos (principalmente Nezara viridula L. e Piezodorus guildinii West.) que causam danos desde a fase de formação das vagens até o final da fase de desenvolvimento dos grãos ou sementes.

De modo geral, as lagartas desfolhadoras, juntamente com os percevejos sugadores de sementes constituem os principais problemas entomológicos da cultura, embora ela possa ser atacada por outros artrópodes, em geral menos importantes que os referidos anteriormente (Silva, 1996).

Alguns autores relatam que tanto os percevejos quanto as lagartas desfolhadoras utilizam-se de plantas daninhas como hospedeiros alternativos, na ausência da soja (Herzog \& Todd, 1980 e Kogan \& Turnipseed, 1987).

Corrêa et al. (1977) estudaram a distribuição geográfica e as flutuações estacionais dos principais insetos-praga da soja e seus predadores e verificaram que entre os insetos-praga amostrados, os 
mais importantes foram A. gemmatalis, Pseudoplusia sp., P. guildinii, $N$. viridula, Euschistus heros Fabr., Diabrotica speciosa Germ. e Cerotoma sp. Entre os predadores, Nabis sp. e Geocoris sp. foram os mais importantes.

\subsubsection{Plantas daninhas na cultura}

Diversos autores têm procurado estudar os efeitos deletérios das plantas daninhas sobre a cultura da soja (Pitelli, 1985 e Velini, 1989).

Visando prevenir os efeitos da matointerferência sobre a cultura da soja, são gastos em média de 1,6 a 1,7 1 ou kg de herbicidas (p.c.) por hectare a cada ano, excluindo-se os custos com outros meios de controle. Em conseqüência da grande área plantada de soja no país e a utilização desta quantidade de herbicidas por hectare, a cultura é a maior consumidora nacional de herbicidas. Em função disto, é grande o número de trabalhos feitos no Brasil que estudam o comportamento dos herbicidas recomendados para a cultura, mas poucos são aqueles que têm por objetivo fundamentar programas racionais de controle de plantas daninhas em áreas cultivadas com esta leguminosa (Velini, 1989).

As principais espécies de plantas daninhas nas áreas nacionais da cultura de soja são Brachiaria plantaginea (Link.) Hitch. (capim-marmelada), Digitaria sanguinalis (L.) Scop., Eleusine indica (L.) Gaertn. (capim-pé-de-galinha), Cenchrus echinatus L. (capimcarrapicho), Echinochloa spp., Acanthospermum hispidum DC. (carrapicho-de-carneiro), Acanthospermum australe (Leofl.) O. Kuntz. (carrapicho-rasteiro), Bidens pilosa L. (picão-preto), Portulaca oleracea L. 
(beldroega), Euphorbia heterophyla L. (amendoim-bravo), Sida spp. e Ipomea spp. (Forster \& Alves, 1976).

Sendo a soja uma espécie introduzida, originariamente de clima temperado, não eficiente fotossinteticamente, pode sofrer bastante a interferência de outras plantas que com ela convivem. Estudos tem mostrado que a cultura deve ficar livre da interferência de plantas daninhas nos primeiros 30 dias após a emergência (Deuber, 1997).

Com a utilização intensiva dos herbicidas na cultura da soja, as plantas daninhas, como seres biológicos em evolução, criam mecanismos para suplantar o distúrbio ambiental causado por estes produtos. As duas formas principais de resposta das plantas daninhas causada pela pressão de seleção dos herbicidas é a mudança na flora ou desenvolvimento de biótipos resistentes aos herbicidas (Christoffoleti, 1998).

\subsection{Cultura do milho}

O milho (Zea mays L.), a nivel mundial, ocupa entre os cereais, o terceiro lugar em área semeada e em produção global, sendo apenas precedido pelas culturas do trigo e do arroz.

$\dot{E}$ atualmente um dos mais importantes produtos agricolas brasileiros, constituindo-se num dos principais insumos para $o$ segmento produtivo, sendo utilizado com destaque no arraçoamento de animais e na alimentação humana (Pinazza, 1990). O Brasil ocupa a 3a posição em produção, respondendo por cerca de $5 \%$ do montante produzido e por $10 \%$ da área cultivada (Fornasieri Filho, 1992).

A cultura do milho é a que ocupa a maior extensão entre todas as lavouras no Brasil, com área de plantio oscilando em torno de 12 milhões de hectares. Nessa significativa área incluem-se as áreas de 
milho pipoca, milho verde e milho para silagem. O cultivo do milho após alguma lavoura de verão, chamado de milho "safrinha", ocupa em torno de um milhão de hectares adicionais (Deuber, 1997).

\subsubsection{Artrópodes da cultura}

As principais pragas da cultura do milho segundo Fornasieri Filho (1992) são Scaptocoris castanea Perty e D. speciosa (pragas das raizes); E. lignosellus, A. ipsilon e Diatraea saccharalis (Fabr.) (pragas dos colmos); Spodoptera frugiperda (J.E.Smith); Mocis latipes (Guen.); Rhopalosiphum maidis (Fitch); Deois flavopicta (Stal) e Zulia entreriana (Berg) (pragas das folhas) e Helicoverpa zea (Boddie) (praga da espiga).

De um modo geral, as principais pragas da cultura do milho são a lagarta elasmo e a lagarta do cartucho, sendo que esta pode causar perdas na produção de até 18\% (Fornasieri Filho, 1992).

\subsubsection{Plantas daninhas na cultura}

As plantas daninhas reduzem direta ou indiretamente $o$ rendimento e a qualidade dos produtos na cultura do milho. A redução direta é, basicamente, atribuída à competição exercida por água, luz, nutrientes e gás carbônico disponiveis sob quantidades limitadas, e por ação alelopática (inibição química). A redução indireta é ocasionada por pragas e patógenos que se hospedam intermediariamente nas plantas daninhas antes de passarem para a cultura do milho (Fornasieri Filho, 1992).

O controle das plantas daninhas na cultura do milho se situa dentro de um contexto econômico bastante desfavorável. Assim, evitar a interferência das plantas daninhas sobre a lavoura do milho é 
um dos aspectos mais importantes para a elevação da produtividade. A lavoura do milho deve ficar isenta de plantas daninhas, ou seja, no limpo, no periodo de 20 a 45 dias. A sua presença na fase anterior a 20 dias é tolerável e, após os 45 dias, também (Deuber, 1997).

\subsection{Influência das plantas daninhas sobre as culturas e insetos}

A influência das plantas daninhas sobre a dinâmica populacional dos insetos tem sido amplamente discutida, porém em muitos aspectos o assunto permanece inconclusivo.

A convivência das plantas daninhas com as culturas e suas conseqũências na dinâmica populacional dos artrópodes tem sido estudada por diversos autores. Tais trabalhos buscam estudar os efeitos da diversidade vegetal proporcionada pelo convivio de plantas cultivadas e daninhas numa mesma área, ou por comunidades em que convivem mais de uma cultura, uma vez que é praticamente consensual que a diversidade vegetal pode conduzir à estabilidade da comunidade de artrópodes, com diminuição na possibilidade de ocorrência de surtos populacionais de herbivoros (Levins \& Wilson, 1980).

As plantas daninhas de um ecossistema competem com a cultura por água, luz, nutrientes e espaço. Contudo, outras relações estabelecem-se entre a cultura e as plantas daninhas, relações estas que as incluem como hospedeiras de pragas e vetores de viroses, como fonte de inóculo de inúmeras doenças e como fonte de inimigos naturais. Este conjunto de interações tem sido designado como interferência (Pitelli, 1985).

Para realizar um programa de controle das plantas daninhas é necessário conhecer o período em que esta interferência se estabelece. Pitelli (1985) define três periodos cujo conhecimento é 
fundamental para a elaboração de programas de controle de plantas daninhas. $\mathrm{O}$ periodo que antecede a interferência (PAI) é aquele a partir da semeadura ou da emergência da cultura, em que esta pode conviver com as plantas daninhas sem que ocorram reduções na sua produtividade. $O$ período de prevenção da interferência (PTPI) diz respeito ao periodo a partir da semeadura ou emergência da cultura, em que as plantas daninhas devem ser controladas para que a cultura possa manifestar plenamente seu potencial produtivo. Quando o PTPI é mais longo que o PAI, define-se um intervalo delimitado por ambos e denominado periodo crítico de prevenção da interferência (PCPI), que representa o periodo em que efetivamente a cultura deve ser mantida na ausência das plantas daninhas. Quando ocorre o inverso, ou seja, quando o PAI é mais longo que o PTPI, o intervalo definido e delimitado por ambos não recebe nenhuma denominação especial. Neste caso, apenas uma remoção das plantas daninhas, desde que feita dentro deste intervalo, permite que a cultura apresente produtividade plena (Pitelli, 1985).

O controle das plantas daninhas nas culturas permite um aumento significativo da produção, porém o papel positivo destas plantas nos agroecossistemas não está suficientemente esclarecido, embora um grande número de trabalhos demonstre que as culturas podem conviver com as mesmas, em determinados periodos do seu ciclo, sem decréscimo de produtividade (Zandstra \& Motooka, 1978).

Fontes (1986) conclui em seu trabalho que as vantagens de um sistema de cultura diversificada com plantas daninhas são indiscutiveis. Esta não é uma técnica de controle biológico de apenas uma praga, mas sim uma manipulação do agroecossistema, de forma a permitir um equilibrio no qual as populações de todos os insetos fitófagos são mantidas em niveis economicamente viáveis. 
Observando-se as interações básicas entre as culturas, plantas e insetos, que ocorrem em uma área geográfica, conseguem-se elementos para compreender como os agroecossistemas deveriam ser estruturados para minimizar a incidência de pragas, não só dentro da área cultivada, mas também em nivel regional. Desse modo, a diversificação e a integração dos sistemas de produção possibilitariam ao produtor conviver com agroecossistema sustentável e economicamente viável (Machado, 1988).

O principio da diversidade de espécies, que é um dos aspectos que tem demandado maiores pesquisas dentro da ecologia, pode ser compreendido quando se observa as relações entre plantas daninhas, cultura e insetos, ou mesmo as relações entre mais de uma cultura e sua comunidade de insetos.

\subsection{Plantas daninhas hospedeiras de insetos-praga}

As plantas daninhas são importantes hospedeiras de insetos-praga, e também, hospedeiras intermediárias de doenças transmitidas por insetos vetores. A variação da população de alguns insetos-praga é mais freqüente em culturas agricolas com alguma incidência da vegetação natural do que em sua ausência.

Wallis \& Turner (1969) verificaram os efeitos da eliminação das plantas daninhas através do fogo sobre a população de vetores de virus em beterraba e observaram que nas áreas em que houve a remoção das plantas daninhas a população de afideos foi $51-91 \%$ mais baixa, a incidência de virose foi $77-84 \%$ menor e a produção de beterraba aumentou 1,5-2,3 toneladas nestas mesmas áreas.

Pitre \& Boyd (1970) estudaram o efeito das plantas daninhas em áreas de milho sobre a cigarrinha vetora Graminella 
nigrifrons Forbes e sobre a incidência de "corn stunt" e, observaram que o vetor foi mais abundante em áreas com plantas daninhas e a incidência da doença foi alta na ausência destas plantas, o que sugere que o vetor tem preferência alimentar pela plantas daninhas do que pelo milho. Das espécies encontradas, Brachiaria platyphylla (Griseb.) mostrou-se a mais preferida.

Busching \& Turpin (1976) conduziram, em condições de laboratório, testes para verificar a preferência de oviposição de $A$. ipsilon em várias espécies de plantas daninhas, milho e soja e verificaram que Rumex crispus L. e Barbarea vulgaris são preferidas para a oviposição.

Faifer (1986) estudando a associação de insetos e plantas daninhas em Jaboticabal, observou que das 29 espécies de plantas daninhas estudadas, em apenas duas não se constatou insetos associados. Os insetos demostraram preferência pelo estádio de florescimento das plantas daninhas. A maioria dos insetos associados são considerados insetos-praga de culturas de importância econômica.

Horton \& Capinera (1987) verificaram que altas densidades e diversidade de plantas em 4 combinações (monocultura de batata, bicultura batata/feijão, tricultura batata/feijão/plantas daninhas e batata crescendo sem cultivo), foram responsáveis por plantas de batata de menor porte, ocasionando menor densidade populacional de Leptinotarsa decemlineata (Say).

Oloumi-Sadeghi et al. (1987) desenvolveram um estudo para verificar o impacto das práticas de manejo das plantas daninhas sobre a densidade da população de Empoasca fabae (Harris) na cultura da alfafa. Observaram que a presença de gramineas em campos de alfafa exercem um efeito repelente sobre a populaçāo deste inseto.

No Paraná, a leguminosa Sesbania aculeata Pers. é mencionada como hospedeira preferencial de $P$. guildinii. Assim, Panizzi 
(1987) realizou um estudo para avaliar o efeito de vagens e sementes desta leguminosa na sobrevivência e tempo de desenvolvimento das ninfas de $P$. guildinii. A baixa mortalidade observada para ninfas criadas em vagens desta leguminosa, confirma ser esta um hospedeiro preferencial deste inseto. Estes estudos podem viabilizar o uso dos hospedeiros como plantas atrativas nos programas de manejo de pragas.

Power (1987) estudou o efeito da diversidade e densidade de plantas sobre a cigarrinha-do-milho Dalbulus maidis (DeLong \& Wolcott), observando menor ocorrência do vetor e menor incidência da doença quando o milho esteve associado com plantas daninhas. $O$ autor verificou que estes fatores afetaram significativamente a densidade populacional do inseto, por afetar seu padrão de movimento.

Slansky Júnior (1989) relata que plantas daninhas das espécies Melilotus alba Desrousseaux, Medicago lupulina L. e Vicia angustifolia L. são utilizadas para alimentar lagartas de A. gemmatalis em laboratório e que essas plantas poderiam servir como fonte alimentar alternativa dessa lagarta em condições de campo.

Panizzi \& Rossi (1989) realizaram levantamentos para avaliar as populações dos percevejos $E$. heros e $N$. viridula em carrapicho-de-carneiro no periodo de março a julho no Paraná. Segundo observações dos autores, o número médio foi de 2 percevejos/planta, sendo que, $N$. viridula foi o mais numeroso. Além desses, foram encontrados outros insetos como a cigarrinha Apogonalia grossa (Sign.), o pulgão Uroleucon sp. e a lagarta Chlosyne lacinia Dbl. \& Hew.

Daza \& Pantoja (1992) identificaram 11 espécies de plantas daninhas, dez espécies pertencentes a familia Poaceae e uma a família Cyperaceae, como hospedeiros alternativos de três pentatomideos que atacam arrozais, que são Oebalus ornatus (Sailer), Mormidea pictiventris Stal. e M. maculata Dallas, sendo que, Echinochloa e Paspalum foram os 
hospedeiros preferidos. Assim, a existência dessas plantas daninhas nas proximidades, bem como nos campos de arroz, podem gerar problemas com esses pentatomídeos.

Wardle et al. (1993) avaliaram o efeito de diferentes estratégias de manejo das plantas daninhas sobre os artrópodes do solo em culturas de milho e aspargo. Os autores concluíram que estas estratégias podem exercer efeitos indiretos sobre a artropodofauna do solo, provavelmente por modificar a qualidade do seu habitat, através de mudanças nos niveis de resíduos orgânicos no solo ou por mudança na biomassa das plantas daninhas.

Otero \& Belarmino (1993) observaram que a associação de soja e $B$. pilosa aumenta a população de $N$. viridula, $P$. guildinii, de outros pentatomídeos, além de $D$. speciosa, e reduz a população de $A$. gemmatalis e o somatório total de lagartas filófagas. Essa associação também propiciou um acréscimo na população de Doru lineare Eschs. e de outros inimigos naturais. Já Belarmino \& Gatti (1993) observaram que a associação de soja e Amaranthus spp. propicia o aumento do número de insetos-praga e diminui a população de artrópodes predadores e de parasitóides.

Marucci (1996) avaliou a influência de diferentes manejos da vegetação natural sobre a população de pragas na cultura do algodão e observou que a diversidade da vegetação natural influiu sobre a população de algumas pragas sendo que Alabama argillacea (Hũeb.), Anthonomus grandis Boh., Pectinophora gossypiella Saund e Dysdercus sp. apresentaram populações menores nas áreas mais infestadas pela vegetação natural. A população de $D$. speciosa, Costalimaita ferruginea vulgata (Lefrève), Lagria villosa Fabr. e os insetos da familia Elateridae não se mostraram muito influenciadas pela presença da vegetação natural. Dos métodos de avaliação utilizados, o método da rede 
entomológica foi o que possibilitou a obtenção da maior diversidade $\mathbf{e}$ quantidade de pragas.

Silva (1996) estudou os efeitos da comunidade de plantas daninhas sobre os artrópodes da cultura da soja, através de avaliações no número de artrópodes coletados nos tratamentos com e sem plantas daninhas, observando que não houve efeito da comunidade de plantas daninhas sobre a artropodofauna da cultura da soja embora, a redução na produção foi da ordem de 30 a $40 \%$ quando a cultura foi mantida em associação com as plantas daninhas durante todo o ciclo. As espécies de plantas daninhas que ocorreram em maior porcentagem foram $C$. echinatus, Sida rhombifolia L., Brachiaria decumbens Stapf. e $B$. plantaginea.

\subsection{Plantas daninhas hospedeiras de inimigos naturais}

As plantas daninhas constituem-se em hospedeiros favoráveis aos inimigos naturais, pois servem como fonte de presas $\mathrm{e}$ hospedeiros alternativos, auxiliam na alimentação suplementar pelo fornecimento de pólen e néctar, atuam como repelentes de pragas e reguladoras de populações dos inimigos naturais e, ainda afetam $o$ indice de parasitismo em insetos-praga.

Algumas espécies de plantas daninhas assumem um importante papel como reservatório de insetos benéficos, além de ajudar a regular as populaçōes de pragas e inimigos naturais, uma vez que são componentes do agroecossistema. Entretanto, é necessário estudar como manejar e como distribuir estas plantas daninhas no campo, de forma que não ocorra competição destas com as culturas (Altieri \& Whitcomb, 1979). 
Zandstra \& Motooka (1978) relataram que as plantas daninhas muitas vezes são importantes no Manejo Integrado de Pragas, servindo como hospedeiros alternativos para insetos predadores $\mathrm{e}$ parasitóides de pragas agricolas. Lagartas de Spodoptera eridania (Cr.) e S. exigua (Hūeb.) alimentando-se de caruru-roxo (Amaranthus hybridus L.) na Flórida, EUA, foram hospedeiras dos parasitóides Winthemia rufopicta (Bigot), Eucelatoria rubentis (Coquillett) e Lespesia sp. Estes mesmos parasitóides, e vários outros, atacam também S. frugiperda, importante praga do milho (Tingle et al., 1978).

Experimentos no norte da Flórida, em campos de milho, revelaram que, deixando crescer uma linha de plantas silvestres entre dez linhas de milho, reduzia-se substancialmente a incidência da lagarta-do-cartucho do milho (S. frugiperda) e aumentava-se o número de predadores. No Estado da Georgia, âreas de soja com uma cobertura densa de fedegoso (Cassia obtusifolia L.), mostravam-se menos susceptiveis ao ataque da lagarta-da-soja (A. gemmatalis) e do percevejo verde $(N$. viridula) e tinham mais inimigos naturais da lagarta e do percevejo do que as áreas livres de plantas daninhas (Altieri, 1981). Este autor verificou que o parasitismo natural de vespas (Trichogramma sp.) em ovos da lagarta-da-espiga do milho ( $H$. zea), colocados artificialmente em plantas de soja, depende das espécies de plantas associadas a essa cultura. Foi observado uma maior taxa de parasitismo quando a soja estava associada a Desmodium sp. e Croton sp., quando comparada com aquela ligada a gramineas ou a monocultura de soja. Estudos posteriores indicaram que o comportamento de campo e a eficiência de Trichogramma sp. poderiam ser alterados pulverizando-se as culturas com extratos de várias plantas daninhas.

Altieri \& Todd (1981) estudando a influência da diversidade da vegetação sobre a comunidade de insetos em soja, observaram que os 
predadores foram mais abundantes em campos de soja diversificados com milho nas bordaduras ou em interplantios de milho e soja do que em monoculturas de soja. O mesmo ocorreu para campos de soja com plantas daninhas, seja no centro ou nas bordaduras da cultura. $O$ parasitismo de ovos de $H$. zea por Trichogramma spp. foi maior em plantios de milho $\mathrm{x}$ soja $(48,2 \%)$ que em monoculturas $(22,4 \%)$.

Avaliando os efeitos do manejo das plantas daninhas sobre a abundância de insetos em campos de soja, Altieri et al. (1981) observaram que populações de A. gemmatalis e $N$. viridula foram maiores quando a soja foi mantida livre de plantas daninhas, do que quando essas estavam presentes por 2 a 4 semanas ou durante todo o periodo. Já o predador Geocoris sp. foi mais abundante em campos onde as plantas daninhas estavam presentes.

Altieri \& Letourneau (1982) relataram que o decréscimo da diversidade vegetal pode afetar seriamente a abundância e eficiência dos inimigos naturais, que dependem da complexidade do habitat para obter presas/hospedeiros alternativos, pólen, néctar e abrigo. Relataram ainda que a diversificação da vegetação propicia um aumento da população de predadores pelo aumento da população de presas e, esta diversificação pode resultar também, em aumento de oportunidades para a sobrevivência dos inimigos naturais e consequentemente, melhorar o controle biológico.

Shelton \& Edwards (1983) avaliaram os efeitos das plantas daninhas sobre a diversidade e abundância de insetos em soja em quatro habitats diferentes (soja, soja + plantas daninhas de folhas estreitas, soja + plantas daninhas de folhas largas e soja + plantas daninhas de folhas estreitas e largas). Verificaram que Epilachna varivestis Mulsant, uma das pragas de soja na Índia, foi mais abundante em áreas livres de plantas daninhas que nos demais 
habitats. Os predadores encontrados na soja, Coleomegilla maculata (DeGeer), Orius insidiosus (Say) e Nabis spp., foram mais abundantes em habitats com plantas de folhas largas e estreitas.

Estudos foram desenvolvidos para investigar os efeitos de algumas espécies de plantas daninhas associadas com o milho sobre o parasitóide Meteorus rubens (Nees von Esenbeck). Diversas espécies de plantas daninhas associadas com o milho ou nas bordaduras da área são potencialmente benéficas como fonte de néctar para este parasitóide. Outros importantes parasitóides tais como Bonnetia comta (Fallen) e Microplitis spp. poderiam também se beneficiar com a presença desta fonte de néctar no campo (Foster \& Ruesink, 1984).

Ali \& Reagan (1985) estudaram o impacto da manipulação da vegetação (áreas com gramineas, folhas largas, ambos os grupos de plantas e sem plantas daninhas) sobre a população de predadores e presa associados com cana-de-açúcar. Verificaram que a abundância e diversidade de $D$. saccharalis e de Solenopsis invicta Buren (predador chave) foram maiores em áreas com plantas daninhas.

Algumas plantas silvestres crescem naturalmente ao redor dos cultivos sem competir com a cultura. Este é o caso da erva-lanceta ou arnica-silvestre (Solidago sp.), porém, pode apresentar algumas caracteristicas negativas, como daninha de sementeiras e hospedeira de organismos causadores de doenças. Entretanto, estes efeitos detrimentais podem não ser relevantes nos paises onde essa ocorra naturalmente, quando comparados com seu grande potencial como mantenedora de inimigos naturais, se mantida, ou mesmo introduzida em áreas de cultivo (Fontes, 1986).

Schultz (1988) avaliou o número de ovos de crisopideos na cultura de algodão em interplantio com milho, feijão e plantas daninhas e em monocultura. Um número menor de ovos foi encontrado quando $o$ 
algodão estava associado com milho e plantas daninhas, quando comparado com a monocultura. Esta redução pode estar relacionada com o decréscimo do número de presas (afideos) e a presença de outros predadores como Doru taeniatum (Dorhn).

Frizzas (1996) avaliou a influência de diferentes manejos da vegetação natural sobre a população de inimigos naturais na cultura do algodão e observou que a vegetação natural constituiu-se em hospedeiro favorável aos inimigos naturais, sendo que foram encontradas na área nove familias e duas ordens de inimigos naturais, e destas, as famílias Coccinellidae, Lygaeidae, Nabidae e Forficulidae foram as mais abundantes.

\subsection{Plantas daninhas hospedeiras de insetos na entressafra}

No Brasil, trabalhos sobre a associação de plantas daninhas como hospedeiras de insetos no periodo da entressafra são escassos. As informações bioecológicas sobre insetos-praga após a colheita são raras. A maioria dos estudos diz respeito a sua ocorrência durante a safra das culturas. Assim, existe no Brasil, uma carência de informações sobre a associação insetos-plantas daninhas no periodo da entressafra e sobre o papel que estas plantas assumem neste periodo.

Lewis (1973) mencionou que muitos tripes têm amplo círculo de hospedeiros, incluindo plantas silvestres, e que, na maioria das vezes, sobrevivem em plantas daninhas em crescimento e na entressafra da cultura. Ressaltou ainda, que o controle destas plantas ajudaria a diminuir a infestação deste inseto.

Tamo et al. (1993) conduziram ensaio na África para identificar as principais plantas hospedeiras do tripes Megalurothrips sjostedti (Trybom) e verificaram que na região Sul o tripes foi encontrado 
em plantas anuais e bianuais como Pueraria phaseoloides (Roxb.) Benth, Cajanus cajan (L.) Mills. e plantas do gênero Tephrosia. Já na região Norte foi encontrado exclusivamente em árvores de savanas como Pterocarpus sp. e Milletia thonningii. Os autores concluiram que essas plantas hospedeiras são reservatório para o tripes no período de entressafra da cultura.

Lima (1997) estudando as associaçōes de espécies de tripes com as plantas daninhas durante o periodo da entressafra de amendoim em Jaboticabal, observou que as espécies do gênero Frankliniella foram as mais abundantes, sendo que a incidência de $F$. hemerocallis (Crawford) foi maior em guizo-de-cascavel e de $F$. schultzei (Trybom) nas brássicas (rábano, nabiça e mostarda). Verificou-se a presença de tripes, em 40 das 43 espécies de plantas daninhas amostradas, os quais estavam mais comumente associados com apaga-fogo, caruru-gigante e caruru-rasteiro (amarantáceas); capim-pé-de-galinha, capim-amargoso e capim-carrapicho (poáceas); rábano e nabiça (brássicas); guizo-decascavel (fabácea); losna-branca e macela (asteráceas) e malva-branca e malvastro (malváceas).

Faifer (1986) encontrou insetos-praga de culturas anuais e perenes em plantas daninhas, estando estas culturas ausentes durante o periodo dos levantamentos. Assim, pode-se considerar que as plantas daninhas servem como hospedeiras de alguns insetos durante a entressafra de certas culturas.

Maruyama (1994) avaliou as plantas daninhas em locais adjacentes onde foi instalada a cultura da soja, nas entressafras de $92 \mathrm{e}$ 93, e verificou que posturas do percevejo $P$. guildinii foram facilmente encontradas em anileira e as principais espécies de parasitóides de ovos deste percevejo encontradas em anileira foram Telenomus mormideae Costa Lima e Trissolcus scuticarinatus (Costa Lima). 
Ramiro et al. (1997) avaliaram a população do percevejocastanho (S. castanea) em plantas daninhas no campo de soja e obtiveram o seguinte resultado quanto ao número de ninfas e adultos nas raizes: Amaranthus sp. (58), Alternanthera ficoidea (L.) (39), Commelina sp. (38), B. pilosa (26), A. hispidum (18), C. echinatus (16), Phyllanthus sp. (12), B. plantaginea (11), E. indica (09), Digitaria sp. (09) e $P$. oleracea (08). Esses resultados indicam que as plantas daninhas são importantes hospedeiras do percevejo-castanho, durante e após o ciclo da cultura da soja.

Souza \& Amaral Filho (1998) verificaram que Spathodea campanulata Beauv (Bignoniaceae) pode estar sendo utilizada como planta alternativa, por Leptoglossus zonatus Dallas para sobreviver na entressafra da cultura do milho, na qual é considerado praga.

Determinadas espécies de plantas daninhas podem ser problemáticas ao conviverem com lavouras por serem portadoras ou intermediárias de pragas e doenças. Espécies que ocorrem na entressafra podem ser hospedeiras de insetos-praga e manterem o potencial de ataque na próxima estação (Deuber, 1997). 


\section{MATERIAL E MÉTODOS}

\subsection{Local de instalação}

O experimento foi instalado na Fazenda Experimental de Ensino e Pesquisa da Faculdade de Ciências Agrárias e Veterinárias Câmpus de Jaboticabal, São Paulo. As coordenadas geográficas são: $21^{\circ}$ $15^{\prime} 22^{\prime}$ de latitude Sul, 48 $15^{\prime} 58^{\prime \prime}$ de longitude Oeste e 595 metros de altitude, com uma precipitaçāo média em torno de $1300 \mathrm{~mm}$ e temperatura média de $20^{\circ} \mathrm{C}$. Segundo a classificação de Koppen, o clima da regiāo é do tipo Cwa, caracterizado como subtropical úmido com chuvas de verão e inverno relativamente seco.

Foram consideradas para a condução do experimento quatro áreas, sendo duas áreas de milho e duas áreas de soja. As áreas do milho consistiram de um terraço medindo $18 \mathrm{~m}$ de largura por $500 \mathrm{~m}$ de comprimento, totalizando $9.000 \mathrm{~m}^{2}$ e de um terraço medindo $20 \mathrm{~m}$ largura por $150 \mathrm{~m}$ de comprimento, totalizando $3.000 \mathrm{~m}^{2}$, nos anos de 97 e 98, respectivamente. Já as áreas da soja consistiram de dois terraços com $15 \mathrm{~m}$ de largura cada e $200 \mathrm{~m}$ de comprimento, totalizando $6.000 \mathrm{~m}^{2}$ e de um terraço de $15 \mathrm{~m}$ de largura e $100 \mathrm{~m}$ de comprimento e outro de $15 \mathrm{~m}$ de largura e $40 \mathrm{~m}$ de comprimento, totalizando $2.100 \mathrm{~m}^{2}$, nos anos de 97 e 98, respectivamente.

O experimento foi realizado no periodo da entressafra das culturas de milho e soja nos anos de 1997 e 1998. Nestas áreas, após a 
colheita das culturas, deixou-se ocorrer infestação natural das plantas daninhas para posteriores levantamentos de insetos.

\subsection{Armadilhas}

Foram utilizadas para os levantamentos cinco tipos de armadilhas, a saber: rede entomológica; cone entomológico; armadilha de Malaise; armadilha luminosa e bandeja d'água.

\section{a) rede entomológica}

A rede entomológica consta de um semi-aro de metal de cerca de $30 \mathrm{~cm}$ de diâmetro, fixado a um cabo de madeira, que sustenta uma rede feita de tecido de algodão cru em forma de cone com o fundo arredondado. Em cada ponto de amostragem foram efetuadas duas redadas nas diferentes espécies de plantas daninhas.

\section{b) cone entomológico}

O cone entomológico consta de um cone de metal revestido por um plástico preto. Na lateral existe uma abertura de cerca de $8 \mathrm{~cm}$ de diâmetro, na qual fica acoplada uma "manga" de tecido. Através dessa abertura a planta é sacudida, os insetos tendem a subir pelo cone e ficam aprisionados em um saco plástico transparente, acoplado na abertura superior do cone por um elástico. Em cada ponto de amostragem foi feita uma coleta com o cone nas diferentes espécies de plantas daninhas. 


\section{c) armadilha de Malaise}

A armadilha de Malaise visa estimar a população através da interceptação dos insetos. Esta foi confeccionada com tecido de cor escura tipo "voil", com cerca de $2 \mathrm{~m}$ de comprimento por 1,5 m de altura, a qual foi afixada no solo (Figura 1). Os insetos foram aprisionados no tubo coletor acoplado na parte lateral da armadilha. Em cada área foi colocada uma armadilha.

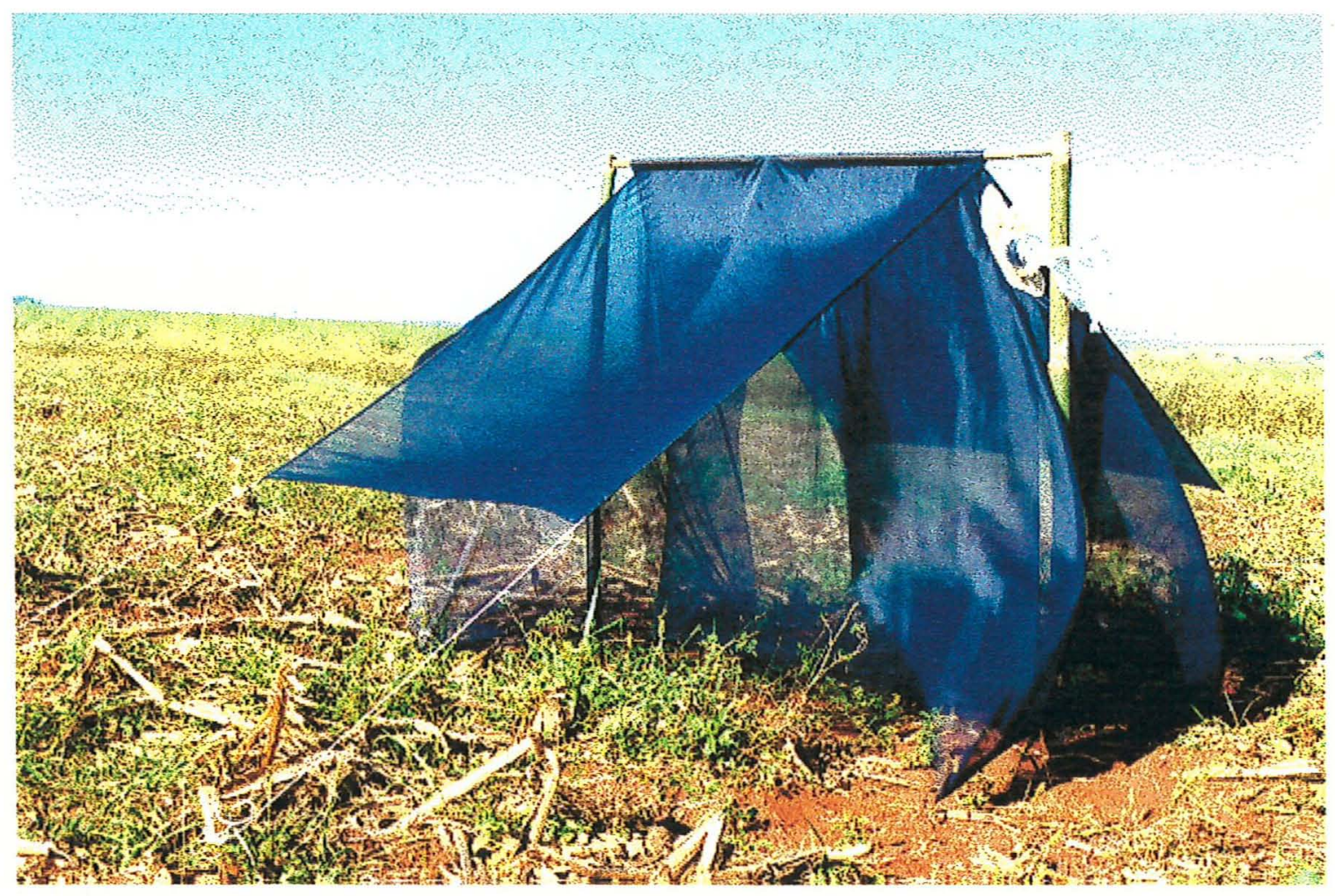

Figura 1 - Armadilha de Malaise. 


\section{d) armadilha luminosa}

A armadilha luminosa visa estimar a população através da interceptação e da atração física dos insetos. Foi utilizada uma armadilha luminosa modelo INTRAL com lâmpada $\mathrm{F}_{15} \mathrm{~T}_{8} \mathrm{BLB}$, alimentada por uma bateria de 12 volts (Figura 2), acoplada a um recipiente de coleta, no qual colocou-se água e detergente. Esta armadilha foi instalada no centro da área experimental, em um mastro de $2 \mathrm{~m}$ de altura.

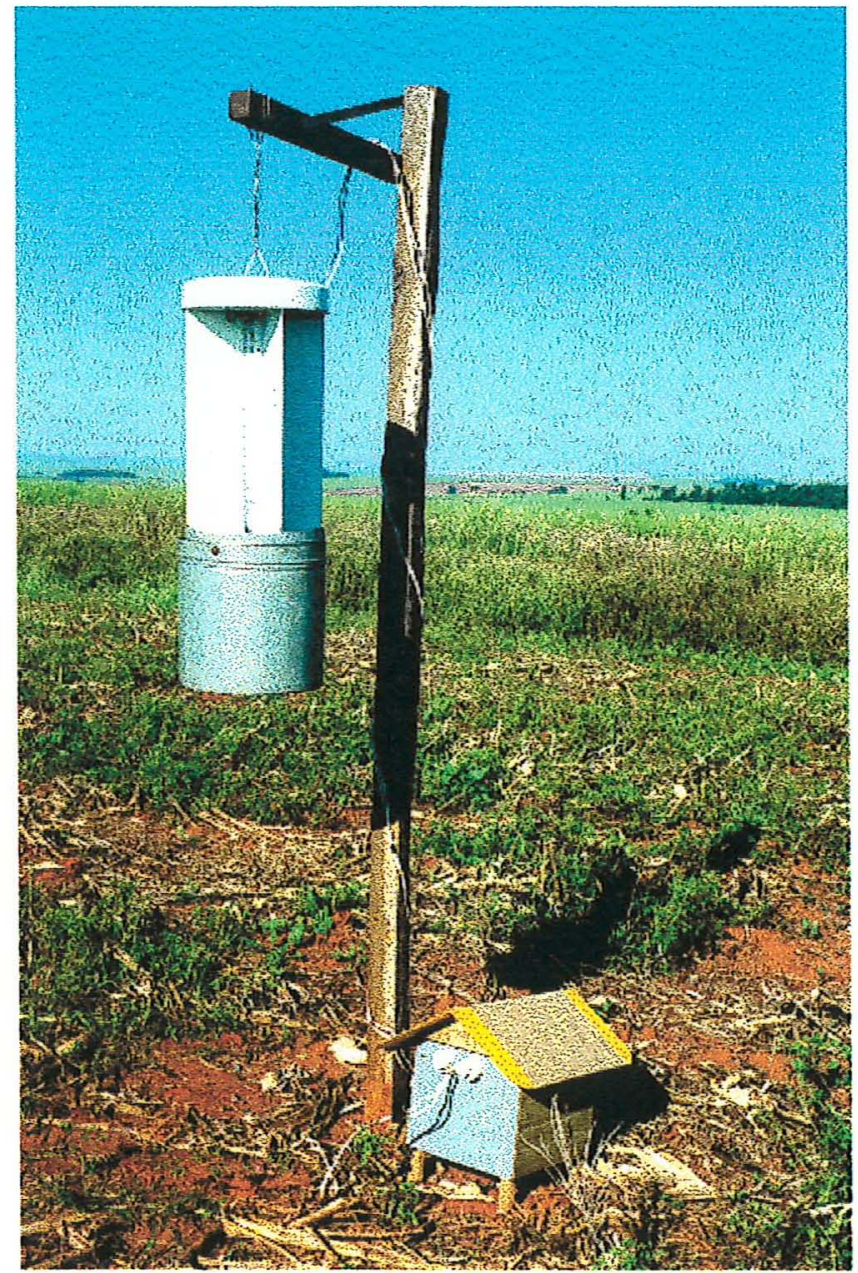

Figura 2 - Armadilha luminosa modelo INTRAL. 


\section{e) bandeja d'água}

Da mesma forma que a armadilha luminosa, a bandeja d'água visa estimar a população através da interceptação e da atração física dos insetos. Esta armadilha consta de uma bandeja quadrada de cerca de $30 \mathrm{~cm}$ de largura e $6 \mathrm{~cm}$ de altura, de coloração amarela, na qual colocou-se água e detergente para a coleta dos insetos (Figura 3). Em cada área experimental foram colocadas duas bandejas.

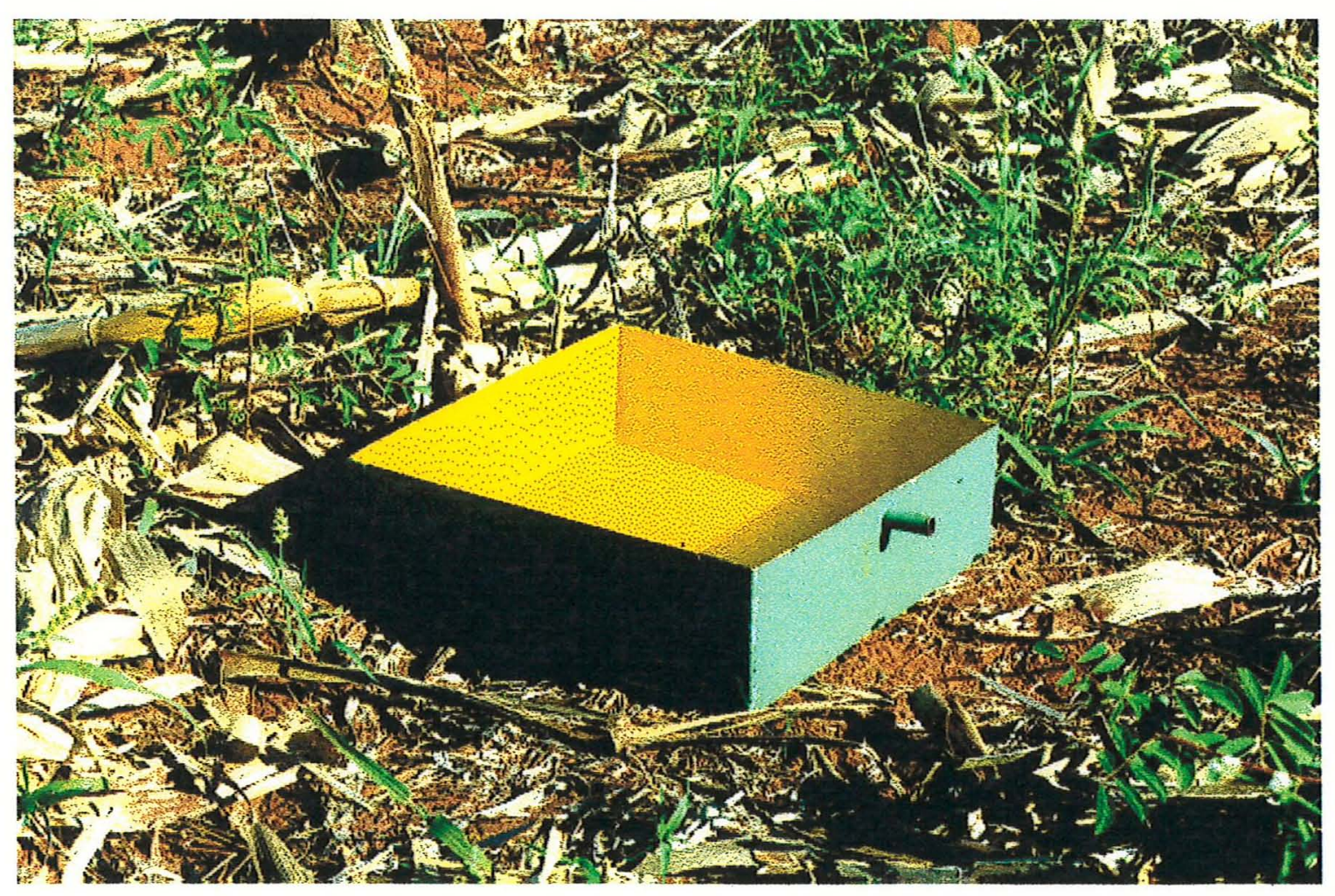

Figura 3 - Bandeja d’água.

A rede $\mathrm{e}$ o cone entomológicos foram utilizados com a finalidade de avaliar a população de insetos presente em cada espécie de 
planta daninha, ou seja, para correlacionar o inseto coletado com a planta avaliada.

Já a armadilha de Malaise, a armadilha luminosa e as bandejas d’água foram utilizadas para avaliar a população de insetos presente na área experimental como um todo, capturando insetos de hábito noturno, diurno e vespertino.

Assim, atravês da utilização dessas armadilhas procurou-se avaliar a população de insetos em toda a área experimental.

\subsection{Avaliaçōes e levantamentos de insetos}

As avaliações foram realizadas atravês da coleta dos insetos nas plantas daninhas, as quais foram efetuadas semanalmente, no periodo da entressafra das culturas de milho e soja. Foram realizadas 15 avaliações, em cada um dos anos de levantamento, entre os meses de maio e setembro.

Para a coleta dos insetos pelos métodos da rede entomológica e cone entomológico, as áreas foram divididas em vários pontos de amostragem. As coletas foram realizadas através de amostragens sistemáticas, onde a linha de corte selecionada foi em forma de II. Considerou-se um ponto de amostragem a cada dez passos (cerca de $8 \mathrm{~m}$ ) e em cada ponto foram amostradas as diferentes espécies de plantas daninhas que ocorreram na área.

Os insetos coletados por estes métodos foram colocados em sacos plásticos devidamente etiquetados e levados para o laboratório, onde foram armazenados em freezer.

Pelo método da bandeja d'água os insetos foram coletados após um periodo de $24 \mathrm{~h}$ e levados para o laboratório, onde foram 
acondicionados em papel toalha para secagem $\mathrm{e}$ posteriormente colocados em sacos plásticos, etiquetados e armazenados em freezer.

$\mathrm{Na}$ armadilha luminosa os insetos foram coletados após um periodo de $12 \mathrm{~h}$ e, submetidos aos mesmos procedimentos citados para a bandeja d'água.

$\mathrm{Na}$ armadilha de Malaise os insetos foram coletados após 24 h, levados para o laboratório em sacos plásticos e armazenados em freezer.

Todos os insetos coletados foram separados, contados, montados, etiquetados e identificados em laboratório. Após a coleta dos dados, foram feitas planilhas para os diferentes métodos de amostragem e diferentes espécies de plantas daninhas.

\subsection{Identificação e coleção dos insetos}

Os insetos foram identificados pelo Prof. Dr. Sinval Silveira Neto. A coleção dos insetos está depositada no Museu do Departamento de Entomologia da Escola Superior de Agricultura “Luiz de Queiroz" ESALQ/USP.

\subsection{Análise faunistica}

Após a confecção das planilhas com os dados coletados, foi feita a análise faunística através do cálculo de vários indices, sendo estes, constância, dominância, abundância e freqüência. Estes índices só foram calculados para os insetos identificados a nivel de gênero ou espécie. 


\section{a) Constância $(C)$}

A constância representa a \% de espécies que estão presentes nos levantamentos. Ela foi calculada atravês do intervalo de confiança (IC) da média aritmética a $5 \%$ de probabilidade.

De acordo com os resultados obtidos as espécies foram dispostas nas seguintes classes:

- Constante $(w)$ - porcentagem de coletas contendo a espécie maior que o limite superior do IC a $5 \%$ de probabilidade;

- Acessória (y) - porcentagem de coletas contendo a espécie situada dentro do IC a $5 \%$ de probabilidade;

- Acidental (z) - porcentagem de coletas contendo a espécie menor que o limite inferior do IC a $5 \%$ de probabilidade.

\section{b) Dominância (D)}

A dominância é definida como a ação exercida pelos organismos dominantes de uma comunidade. Para determinar a dominância utilizou-se o método de Sakagami \& Laroca, conforme trabalho de Fazolin (1991). Este mêtodo considera como espécies dominantes aquelas em que a freqüência exceder o limite de dominância calculado pela fórmula:

$$
L D=1 \times 100
$$

$\mathrm{S}$

Onde: $L D$ = limite de dominância;

$\mathrm{S}=$ número total de espécies por amostra. 


\section{c) Abundância (A)}

A abundância refere-se ao número de individuos por unidade de superficie ou volume e varia no espaço e no tempo. Ela foi calculada através do cálculo do desvio padrão e do intervalo de confiança (IC) da média aritmética para $1 \%$ e $5 \%$ de probabilidade.

Para se estimar a abundância das espécies adotou-se as seguintes classes:

- raro (r) - número de individuos capturados menor que o limite inferior do IC a $1 \%$ de probabilidade;

- disperso (d) - número de individuos capturados situados entre os limites inferiores do IC a $5 \%$ e a $1 \%$ de probabilidade;

- comum (c) - número de indivíduos capturados situados dentro do IC a $5 \%$ de probabilidade;

- abundante (a) - número de indivíduos capturados situados entre os limites superiores do IC a $5 \%$ e a $1 \%$ de probabilidade;

- muito abundante (ma) - número de indivíduos capturados maior que o limite superior do IC a $1 \%$ de probabilidade.

\section{d) Freqüência (F)}

A frequêencia é a porcentagem de individuos de uma espécie em relação ao total de individuos. Sua análise é feita através da distribuição de frequêencias em histogramas. Ela foi calculada segundo a fórmula, citada por Silveira Neto et al. (1976):

$$
F=\underline{n} \times 100
$$

$\mathrm{N}$

Onde: $F$ = freqüência;

$\mathrm{n}$ = número de individuos de cada espécie; 
$\mathrm{N}=$ número total de indivíduos coletados.

De acordo com os resultados obtidos, foi estabelecida uma classe de freqũência para as espécies, através do intervalo de confiança (IC) da média aritmética a $5 \%$ de probabilidade, conforme citado por Fazolin (1991). Foram estabelecidas as seguintes classes:

- pouco freqũentes (pf) - porcentagem de indivíduos menor que o limite inferior do IC a $5 \%$ de probabilidade;

-freqüentes (f) - porcentagem de indivíduos situadas dentro do IC a $5 \%$ de probabilidade;

-muito freqüentes $(\mathrm{mf}$ - porcentagem de individuos maior que o limite superior do IC a $5 \%$ de probabilidade.

Os indices de constância, dominância, abundância $\mathrm{e}$ freqüência foram calculados de acordo com o programa ANAFAU desenvolvido no Departamento de Entomologia da ESALQ/USP.

$\mathrm{Na}$ realização da análise faunistica, os dados discrepantes foram analisados através da análise grăfica de resíduo, conforme Atkinson (1985). Os dados discrepantes foram enquadrados em outra classe, ou seja, foram classificados como super dominantes (sd) com relação a dominância, super abundantes (sa) para a abundância e super freqũentes (sf) para a freqũência.

\section{e) Índice de diversidade $(\alpha)$}

$O$ indice de diversidade é a relação entre o número de espécies e o número de individuos de uma comunidade. É utilizado para representar a riqueza em espécies de uma comunidade.

A diversidade da fauna foi calculada através da aplicação da fórmula proposta por Margalef, citado por Southwood (1971), que é: 


$$
\alpha=\underline{S-1}
$$

LN

Onde: $\alpha=$ indice de diversidade;

$\mathrm{S}=$ número de taxons;

$\mathrm{LN}=$ logaritmo "neperiano" do número de individuos.

\section{f) Indice de similaridade (I)}

$O$ indice de similaridade foi proposto para indicar a semelhança entre duas comunidades, em termos de composição de espécies. Este indice foi calculado através do método proposto por Mountford citado por Silveira Neto et al. (1976), em que:

$$
I=2 j / 2 a b-(a+b) j
$$

Onde: $\mathrm{I}=$ indice de similaridade entre duas áreas;

$\mathrm{a}=$ número de espécies coletadas na área da soja;

$\mathrm{b}=$ número de espécies coletadas na área do milho;

$\mathrm{j}$ = número de espécies coletadas que sejam comuns às duas áreas consideradas (soja e milho).

\section{g) Porcentagem de similaridade (\%S)}

A porcentagem de similaridade entre as duas áreas foi calculada segundo Southwood (1971) de acordo com a seguinte fórmula:

$$
\% \mathrm{~S}=\Sigma \min .(\mathrm{a}+\mathrm{b}+\ldots+\mathrm{n})
$$

Onde: $\% \mathrm{~S}$ = porcentagem de similaridade entre duas áreas;

$a=$ menor \% de ocorrência da espécie “a” observada nas duas áreas de coleta;

$\mathrm{b}=$ menor $\%$ de ocorrência da espécie " $\mathrm{b}$ " observada nas duas áreas de coleta; 
$\mathrm{n}=$ menor \% de ocorrência da espécie " $\mathrm{n}$ " observada nas duas áreas de coleta.

\subsection{Teste do olfatômetro}

O teste do olfatômetro foi conduzido no laboratório do Departamento de Defesa Fitossanitária da Faculdade de Ciências Agrárias e Veterinárias - Câmpus de Jaboticabal. Foi realizado durante o primeiro semestre de 1998.

O olfatômetro consistiu-se de um recipiente plâstico de 16 $\mathrm{cm}$ de diâmetro, no qual foram feitas seis aberturas laterais. Nestas aberturas foram acoplados canos plásticos de $1,5 \mathrm{~cm}$ de diâmetro e 25 $\mathrm{cm}$ de comprimento, os quais ligavam o recipiente às plantas daninhas (Figura 4).

Para a manutenção dos insetos nas plantas daninhas foram confeccionadas armaçōes de ferro de $20 \mathrm{~cm}$ de diâmetro e $40 \mathrm{~cm}$ de altura. Estas armações foram revestidas por um tecido tipo "tule" (Figura 4), e colocadas sobre os vasos contendo as plantas daninhas.

As plantas daninhas utilizadas no teste do olfatômetro foram: apaga-fogo; anileira; crotalária; guanxuma; guizo-de-cascavel e rabo-de-foguete, as quais estavam presentes nas áreas de soja e milho durante a entressafra de 97 . Sementes ou mudas destas plantas foram coletadas no campo e plantadas em vasos plásticos contendo solo devidamente adubado. Estes vasos foram acondicionados em casa-devegetação e irrigados diariamente para o desenvolvimento das plantas. 


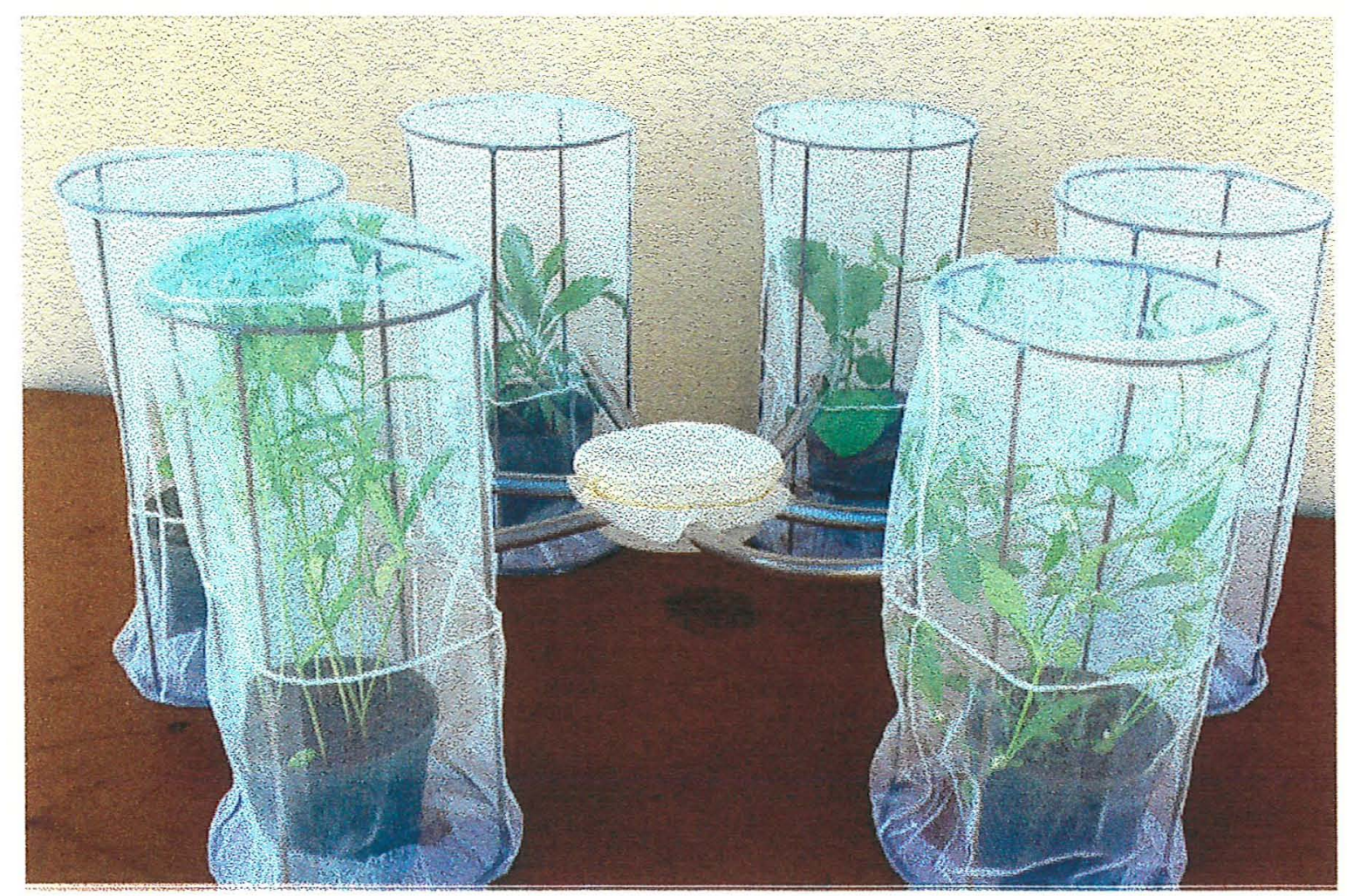

Figura 4 - Olfatômetro.

Após a realização da análise faunística, com os dados coletados durante a entressafra de 97, quatro insetos-praga foram selecionados para a realização do teste por terem se mostrado mais predominantes: Diabrotica speciosa (Coleoptera: Chrysomelidae); Lagria villosa (Coleoptera: Lagriidae); Paranapiacaba significata (Coleoptera: Chrysomelidae) e Piezodorus guildinii (Hemiptera: Pentatomidae). Insetos adultos foram coletados no campo, com o auxílio de rede entomológica, para a realização do teste. Foram utilizados 60 insetos por repetição.

Apôs $24 \mathrm{~h}$ da montagem do teste, foi avaliado o número de insetos em cada planta daninha e o número de insetos no recipiente (vivos e mortos). Foi feita uma análise visual das plantas para verificar 
presença de postura, no caso de percevejos, e ocorrência de alimentação, no caso de coleópteros.

Utilizou-se o delineamento em blocos casualizados com 6 tratamentos (plantas daninhas) e 5 repetições. Os dados foram analisados pelo Teste $\mathrm{F}$ para análise de variância $\mathrm{e}$ as médias comparadas pelo Teste de Tukey ao nivel de $5 \%$ de probabilidade, através do software estatístico SANEST. 


\section{RESULTADOS E DISCUSSÃO}

\subsection{Comunidade de insetos nas áreas de soja e milho}

\subsubsection{Espécies coletadas}

As espécies de insetos coletadas nas 30 avaliações durante a entressafra da cultura da soja e do milho através da armadilha luminosa, armadilha de Malaise e bandejas d'ăgua encontram-se listadas nas Tabelas 1 e 2 .

Tabela 1. Espécies coletadas e resultados da análise faunística dos insetos capturados com armadilha luminosa, armadilha de Malaise e bandeja d'água na entressafra da soja de 1997 e 1998 em Jaboticabal, SP.

\begin{tabular}{llccccc}
\hline Famillia & Espécie & Total & C & D & A & F \\
\hline Coleoptera & & & & & & \\
Carabidae & Callida sp. & 1 & z & nd & r & pf \\
Carabidae & Lebia sp. & 5 & z & nd & r & pf \\
Carabidae & Leptotrachelus sp. & 5 & z & nd & r & pf \\
Chrysomelidae & Diabrotica speciosa Germ. & 62 & w & do & c & f \\
Chrysomelidae & Dysonica sp. & 3 & z & nd & r & pf \\
Chrysomelidae & Paranapiacaba significata (Gahn.) & 32 & w & nd & c & f \\
Coccinellidae & Cycloneda sanguinea (L.) & 17 & w & nd & d & pf \\
Coccinellidae & Delphastus sp. & 14 & w & nd & d & pf \\
Coccinellidae & Eriopis connexa (Germ.) & 8 & z & nd & r & pf \\
Coccinellidae & Hyperaspis sp. & 10 & z & nd & d & pf \\
Coccinellidae & Hyperaspis notata (Muls.) & 16 & y & nd & d & pf \\
Coccinellidae & Olla v-nigrum (Muls.) & 30 & w & nd & c & f
\end{tabular}




\begin{tabular}{|c|c|c|c|c|c|c|}
\hline Familia & Espécie & Total & C & $\mathbf{D}$ & $\mathbf{A}$ & $\mathbf{F}$ \\
\hline Dasytidae & Astylus variegatus Germ. & 1 & $z$ & nd & $r$ & pf \\
\hline Elateridae & Conoderus scalaris (Germ.) & 18 & $\mathbf{w}$ & nd & c & $\mathbf{f}$ \\
\hline Lagriidae & Lagria villosa Fabr. & 27 & $\mathbf{w}$ & nd & c & $\mathbf{f}$ \\
\hline Scarabaeidae & Aphodius sp. & 750 & $\mathbf{w}$ & do & $\mathbf{m a}$ & $\mathbf{m f}$ \\
\hline Scarabaeidae & Euetheola humilis Burm. & 21 & $\mathbf{z}$ & nd & c & $\mathbf{f}$ \\
\hline Staphylinidae & Paederus sp. & 110 & $\mathbf{w}$ & do & $\mathbf{m a}$ & $\mathbf{m f}$ \\
\hline Tenebrionidae & Epitragus similis Steinh. & 47 & $\mathbf{w}$ & do & c & f \\
\hline \multicolumn{7}{|l|}{ Dermaptera } \\
\hline Forficulidae & Doru lineare Eschs. & 1 & $z$ & nd & $\mathbf{r}$ & pf \\
\hline \multicolumn{7}{|l|}{ Diptera } \\
\hline Calliphoridae & Chrysomya sp. & 2 & $\mathbf{z}$ & nd & $\mathrm{r}$ & pf \\
\hline Calliphoridae & Cochliomya sp. & 2 & $z$ & nd & $\mathrm{r}$ & pf \\
\hline Dolichopodidae & Condylostylus sp. & 1061 & $\mathbf{w}$ & do & $\mathbf{m a}$ & $\mathbf{m f}$ \\
\hline Otitidae & Euxesta sp. & 132 & $\mathbf{w}$ & do & $\mathbf{m a}$ & $\mathbf{m f}$ \\
\hline Stratiomyidae & Hermetia illucens (L.) & 14 & $\mathrm{y}$ & nd & $\mathrm{d}$ & pf \\
\hline Tachinidae & Euphasiopteryx sp. & 3 & $\mathbf{z}$ & nd & $\mathbf{r}$ & pf \\
\hline \multicolumn{7}{|c|}{ Hemiptera - Auchenorrhyncha } \\
\hline Cicadellidae & Bucephalogonia xanthophis (Berg) & 8 & $\mathrm{y}$ & nd & $\mathbf{r}$ & pf \\
\hline Cicadellidae & Diedrocephala continua Sak.8Cav. & 1 & $\mathbf{z}$ & nd & $\mathrm{r}$ & pf \\
\hline Cicadellidae & Hortensia simitis (Walk.) & 20 & $\mathrm{y}$ & nd & c & $\mathbf{f}$ \\
\hline Cicadellidae & Macugonalia leucomelas (Walk.) & 1 & $\mathbf{z}$ & nd & $\mathbf{r}$ & pf \\
\hline Cicadellidae & Scaphitopius sp. & 5 & $\mathbf{z}$ & nd & $\mathbf{r}$ & $\mathrm{pf}$ \\
\hline Cicadellidae & Xerophloea sp. & 5 & $\mathbf{z}$ & nd & $\mathbf{r}$ & pf \\
\hline Membracidae & Cyphonia clavata (Fabr.) & 2 & $\mathbf{z}$ & nd & $\mathbf{r}$ & pf \\
\hline \multicolumn{7}{|c|}{ Hemiptera - Heteroptera } \\
\hline Alydidae & Alydus sp. & 245 & $\mathbf{w}$ & do & $\mathbf{m a}$ & $\mathbf{m f}$ \\
\hline Alydidae & Leptocoriza tipuloides (DeGeer) & 1 & $\mathbf{z}$ & nd & $\mathrm{r}$ & pf \\
\hline Corixidae & Sigara sp. & 13 & $z$ & nd & d & pf \\
\hline Cydnidae & Pangaeus sp. & 135 & $\mathbf{w}$ & do & $\mathbf{m a}$ & $\mathbf{m f}$ \\
\hline Lygaeidae & Geocoris sp. & 9 & $\mathrm{y}$ & nd & $\mathbf{d}$ & pf \\
\hline Pentatomidae & Acrosternum hilare (Say) & 1 & $z$ & nd & $\mathbf{r}$ & pf \\
\hline Pentatomidae & Piezodorus guildinii West. & 2 & $z$ & nd & $\mathbf{r}$ & pf \\
\hline Pentatomidae & Thyanta perditor (Fabr.) & 1 & $z$ & nd & $\mathbf{r}$ & pf \\
\hline Pyrrhocoridae & Dysdercus sp. & 6 & $\mathbf{z}$ & nd & $\mathbf{r}$ & pf \\
\hline Reduviidae & Hagahus hamatus (Fabr.) & 2 & $z$ & nd & $\mathbf{r}$ & pf \\
\hline \multicolumn{7}{|l|}{ Hymenoptera } \\
\hline Andrenidae & Exomalopsis sp. & 2 & $\mathbf{z}$ & nd & $\mathbf{r}$ & pf \\
\hline Andrenidae & Oxea sp. & 4 & $z$ & nd & $\mathbf{r}$ & $\mathrm{pf}$ \\
\hline Anthophoridae & Centris sp. & 1 & $\mathbf{z}$ & nd & $\mathbf{r}$ & $\mathrm{pf}$ \\
\hline Anthophoridae & Melissodes sp. & 1 & $\mathbf{z}$ & nd & $\mathbf{r}$ & $\mathrm{pf}$ \\
\hline Apidae & Apis mellifera $\mathrm{L}$ & 24 & $\mathbf{w}$ & nd & $\mathbf{c}$ & f \\
\hline Apidae & Trigona spinipes (Fabr.) & 3 & $\mathrm{z}$ & nd & $\mathbf{r}$ & pf \\
\hline Formicidae & Eciton sp. & 55 & $\mathrm{y}$ & do & c & $\mathbf{f}$ \\
\hline Hallictidae & Augochloropsis sp. & 6 & $z$ & nd & $\mathbf{r}$ & pf \\
\hline Ichneumonidae & Ophion sp. & 42 & $\mathbf{w}$ & nd & $\mathbf{c}$ & $\mathrm{f}$ \\
\hline Sphecidae & Ammophila sp. & 9 & $\mathrm{y}$ & nd & $d$ & pf \\
\hline Vespidae & Polistes vesicolor (Bequaert) & 6 & $\mathbf{y}$ & nd & $\mathbf{r}$ & pf \\
\hline
\end{tabular}




\begin{tabular}{|c|c|c|c|c|c|c|}
\hline Familia & Espécie & Total & $\mathbf{C}$ & $\mathbf{D}$ & $\mathbf{A}$ & $\mathbf{F}$ \\
\hline Vespidae & Polybia sp. & 42 & $\mathbf{w}$ & nd & c & f \\
\hline \multicolumn{7}{|l|}{ Lepidoptera } \\
\hline Amatidae & Aclytia heber $\mathrm{Cr}$. & 2 & $z$ & nd & $r$ & pf \\
\hline Amatidae & Androcharta rubricincta Burm. & 6 & $\mathbf{z}$ & nd & $\mathbf{r}$ & pf \\
\hline Amatidae & Cosmosoma auge (L.) & 3 & $\mathbf{z}$ & nd & $r$ & $\mathrm{pf}$ \\
\hline Amatidae & Cosmosoma remotum Walk. & 9 & $\mathbf{z}$ & nd & d & pf \\
\hline Amatidae & Cosmosoma teuthras Walk. & 2 & $\mathbf{z}$ & nd & $\mathbf{r}$ & $\mathrm{pf}$ \\
\hline Amatidae & Dicladia lucetius (Cr.) & 34 & $w$ & nd & c & $\mathrm{f}$ \\
\hline Amatidae & Philorus rubriceps Walk. & 8 & $\mathrm{y}$ & nd & $\mathbf{r}$ & pf \\
\hline Arctiidae & Antarctia sp. & 3 & $\mathbf{z}$ & nd & $\mathbf{r}$ & pf \\
\hline Arctiidae & Pareuchaetes insulata Walk. & 2 & $\mathbf{z}$ & nd & $\mathbf{r}$ & pf \\
\hline Arctiidae & Ripha superba (Druce) & 1 & $\mathbf{z}$ & nd & $\mathbf{r}$ & pf \\
\hline Arctiidae & Utetheisa ornatrix $\mathrm{L}$. & 345 & $\mathbf{w}$ & do & $\mathbf{m a}$ & $\mathbf{m f}$ \\
\hline Megalopygidae & Norape plumosa (Butler) & 1 & $\mathbf{z}$ & nd & $\mathbf{r}$ & pf \\
\hline Noctuidae & Agrotis subterranea (Fabr.) & 9 & $\mathrm{y}$ & nd & d & $\mathrm{pf}$ \\
\hline Noctuidae & Anomis erosa Hüeb. & 25 & $\mathbf{w}$ & nd & c & $\mathrm{f}$ \\
\hline Noctuidae & Anticarsia gemmatalis Hūeb. & 45 & $\mathbf{w}$ & nd & c & f \\
\hline Noctuidae & Bagisara subusta Hüeb. & 89 & $\mathbf{w}$ & do & $\mathbf{m a}$ & $\mathbf{m f}$ \\
\hline Noctuidae & Blosyres sp. & 2 & $z$ & nd & $\mathrm{r}$ & pf \\
\hline Noctuidae & Cirphis latiuscula (Herr. - Sch.) & 84 & $\mathbf{w}$ & do & $\mathbf{a}$ & $\mathbf{m f}$ \\
\hline Noctuidae & Leucania humidicola (Guen.) & 52 & $\mathrm{y}$ & do & c & $\mathbf{f}$ \\
\hline Noctuidae & Mocis latipes (Guen.) & 2 & $\mathbf{z}$ & nd & $\mathbf{r}$ & $\mathrm{pf}$ \\
\hline Noctuidae & Monodes sp. & 62 & $\mathbf{w}$ & do & c & $\mathrm{f}$ \\
\hline Noctuidae & Helicoverpa zea (Boddie) & 18 & $\mathbf{w}$ & nd & c & $\mathbf{f}$ \\
\hline Noctuidae & Heliothis virescens (Fabr.) & 23 & $\mathbf{y}$ & nd & c & f \\
\hline Noctuidae & Perigea sutor Guen. & 13 & $\mathbf{z}$ & nd & $\mathrm{d}$ & $\mathrm{pf}$ \\
\hline Noctuidae & Pseudoplusia includens Walk. & 1 & $\mathbf{z}$ & nd & $r$ & $\mathrm{pf}$ \\
\hline Noctuidae & Spodoptera frugiperda (J.E.Smith) & 60 & $\mathbf{w}$ & do & c & f \\
\hline Noctuidae & Spodoptera latifascia Walk. & 9 & $\mathbf{z}$ & nd & $\mathrm{d}$ & pf \\
\hline Noctuidae & Tarache sp. & 1 & $\mathbf{z}$ & nd & $\mathbf{r}$ & $\mathrm{pf}$ \\
\hline Pyralidae & Diatraea saccharalis (Fabr.) & 6 & $\mathbf{z}$ & nd & $\mathbf{r}$ & $\mathrm{pf}$ \\
\hline Pyralidae & Diatraea sp. & 68 & $\mathbf{y}$ & do & c & $\mathbf{f}$ \\
\hline Pyralidae & Elasmopalpus lignosellus (Zeller) & 147 & $\mathbf{w}$ & do & $\mathbf{m a}$ & $\mathbf{m f}$ \\
\hline Sphingidae & Pachilisides sp. & 3 & $\mathbf{z}$ & nd & $\mathrm{r}$ & $\mathrm{pf}$ \\
\hline \multicolumn{7}{|l|}{ Mantodea } \\
\hline Mantidae & Thesprotia macilenta Sauss. & 1 & $\mathbf{z}$ & nd & $\mathrm{r}$ & $\mathrm{pf}$ \\
\hline \multicolumn{7}{|l|}{ Neuroptera } \\
\hline Chrysopidae & Chrysoperla externa (Hagen) & 28 & $\mathbf{w}$ & nd & c & $\mathrm{f}$ \\
\hline Hemerobiidae & Hemerobius sp. & 10 & $z$ & nd & d & $\mathrm{pf}$ \\
\hline \multicolumn{7}{|l|}{ Orthoptera } \\
\hline Acrididae & Orphulella sp. & 12 & $\mathbf{w}$ & nd & $\mathrm{d}$ & $\mathrm{pf}$ \\
\hline
\end{tabular}


Tabela 2. Espécies coletadas e resultados da análise faunistica dos insetos capturados com armadilha luminosa, armadilha de Malaise e bandeja d'água na entressafra do milho de 1997 e 1998 em Jaboticabal, SP.

\begin{tabular}{|c|c|c|c|c|c|c|}
\hline Familia & Espécie & Total & $\mathbf{C}$ & $\mathbf{D}$ & $\mathbf{A}$ & $\mathbf{F}$ \\
\hline \multicolumn{7}{|l|}{ Coleoptera } \\
\hline Carabidae & Callida scutellaris Chaud. & 3 & $z$ & nd & $\mathrm{r}$ & pf \\
\hline Carabidae & Callida sp. & 1 & $z$ & nd & $\mathbf{r}$ & $\mathrm{pf}$ \\
\hline Carabidae & Lebia sp. & 8 & $\mathbf{z}$ & nd & $\mathbf{r}$ & pi \\
\hline Carabidae & Leptotrachelus sp. & 3 & $\mathbf{z}$ & nd & $\mathbf{r}$ & pf \\
\hline Chrysomelidae & Diabrotica speciosa Germ. & 85 & $\mathbf{w}$ & do & $\mathbf{m a}$ & $\mathbf{m f}$ \\
\hline Chrysomelidae & Dysonica sp. & 1 & $\mathbf{z}$ & nd & $\mathrm{r}$ & $\mathrm{pf}$ \\
\hline Chrysomelidae & Paranapiacaba significata (Gahn.) & 46 & $\mathbf{w}$ & do & c & $\mathrm{f}$ \\
\hline Chrysomelidae & Poecilaspis nervosa (Fabr.) & 2 & $z$ & nd & $\mathrm{r}$ & $\mathrm{pf}$ \\
\hline Coccinellidae & Cycloneda sanguinea (L.) & 23 & $\mathbf{w}$ & nd & c & f \\
\hline Coccinellidae & Delphastus sp. & 25 & w & nd & c & f \\
\hline Coccinellidae & Eriopis connexa Germ. & 1 & $z$ & nd & $\mathbf{r}$ & pf \\
\hline Coccinellidae & Hyperaspis sp. & 4 & $\mathbf{z}$ & nd & $\mathbf{r}$ & pf \\
\hline Coccinellidae & Hyperaspis notata (Muls.) & 4 & $\mathbf{z}$ & nd & $\mathbf{r}$ & $\mathrm{pf}$ \\
\hline Coccinellidae & Olla v-nigrum (Muls.) & 8 & $z$ & nd & $\mathbf{r}$ & $\mathbf{p i}$ \\
\hline Curculionidae & Pantomorus sp. & 1 & $\mathbf{z}$ & nd & $\mathbf{r}$ & pi \\
\hline Dasytidae & Astylus variegatus Germ. & 15 & $\mathrm{y}$ & nd & $\mathbf{r}$ & $\mathrm{pf}$ \\
\hline Elateridae & Conoderus scalaris (Germ.) & 25 & w & nd & c & 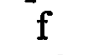 \\
\hline Lagriidae & Lagria villosa Fabr. & 5 & $z$ & nd & $\mathrm{r}$ & $\mathrm{pf}$ \\
\hline Scarabaeidae & Aphodius sp. & 403 & $\mathbf{w}$ & do & $\mathbf{m a}$ & \\
\hline Scarabaeidae & Euetheola humilis Burm. & 6 & $z$ & nd & $\mathrm{r}$ & 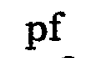 \\
\hline Staphylinidae & Paederus sp. & 89 & $\mathbf{w}$ & do & $\mathbf{m a}$ & \\
\hline Tenebrionidae & Epitragus similis Steinh. & 235 & $\mathbf{w}$ & do & $\mathbf{m a}$ & $\mathbf{m f}$ \\
\hline \multicolumn{7}{|l|}{ Dermaptera } \\
\hline Forficulidae & Doru lineare Eschs. & 3 & $\mathbf{z}$ & nd & $\mathbf{r}$ & $\mathrm{p}$ \\
\hline \multicolumn{7}{|l|}{ Diptera } \\
\hline Calliphoridae & Chrysomya sp. & 1 & $\mathbf{z}$ & nd & $\mathbf{r}$ & $\mathrm{p}$ \\
\hline Dolichopodidae & Condylostylus sp. & 396 & $\mathbf{w}$ & do & $\mathbf{m a}$ & $\mathbf{m f}$ \\
\hline Otitidae & Euxesta sp. & 49 & $\mathbf{w}$ & do & c & \\
\hline Stratiomyidae & Hermetia illucens (L.) & 3 & $z$ & nd & $\mathbf{r}$ & pf \\
\hline Tachinidae & Euphasiopteryx sp. & 6 & $\mathbf{z}$ & nd & $\mathbf{r}$ & \\
\hline \multicolumn{7}{|c|}{ Hemiptera - Auchenorrhyncha } \\
\hline Cicadellidae & Bucephalogonia xanthophis (Berg) & 32 & $\mathbf{w}$ & nd & c & $f$ \\
\hline Cicadellidae & Diedrocephala continua Sak.8Cav. & 44 & $\mathbf{w}$ & do & c & $\mathbf{f}$ \\
\hline Cicadellidae & Hortensia similis (Walk.) & 17 & $\mathrm{y}$ & nd & $\mathbf{r}$ & $\mathrm{pf}$ \\
\hline Cicadellidae & Macugonalia leucomelas (Walk.) & 17 & $\mathbf{w}$ & nd & $\mathbf{r}$ & $\mathrm{p}$ \\
\hline Cicadellidae & Scaphitopius sp. & 1 & $\mathbf{z}$ & nd & $\mathbf{r}$ & 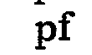 \\
\hline Cicadellidae & Xerophloea sp. & 19 & w & nd & $\mathrm{d}$ & pt \\
\hline
\end{tabular}




\begin{tabular}{|c|c|c|c|c|c|c|}
\hline Familia & Espécie & Total & C & $\mathbf{D}$ & $\mathbf{A}$ & $\mathbf{F}$ \\
\hline Membracidae & Cyphonia clavata (Fabr.) & 4 & $z$ & nd & $\mathbf{r}$ & pf \\
\hline \multicolumn{7}{|c|}{ Hemiptera - Heteroptera } \\
\hline Alydidae & Alydus sp. & 84 & $\mathbf{w}$ & do & $\mathbf{m a}$ & $\mathbf{m f}$ \\
\hline Alydidae & Leptocoriza tipuloides (DeGeer) & 1 & $\mathbf{z}$ & nd & $\mathbf{r}$ & pf \\
\hline Cydnidae & Pangaeus sp. & 177 & $\mathbf{w}$ & do & $\mathbf{m a}$ & $\mathbf{m f}$ \\
\hline Coreidae & Leptoglossus zonatus (Dallas) & 1 & $\mathbf{z}$ & nd & $\mathbf{r}$ & pf \\
\hline Coreidae & Zica sp. & 1 & $\mathbf{z}$ & nd & $\mathbf{r}$ & pf \\
\hline Corixidae & Sigara sp. & 84 & $\boldsymbol{y}$ & do & $\mathbf{m a}$ & $\mathbf{m f}$ \\
\hline Largidae & Lygaeus alboornatus (Blanch.) & 1 & $z$ & nd & $\mathbf{r}$ & pf \\
\hline Lygaeidae & Geocoris sp. & 2 & $\mathbf{z}$ & nd & $r$ & pf \\
\hline Pentatomidae & Piezodorus guildinii West. & 5 & $z$ & nd & $\mathrm{r}$ & $\mathrm{pf}$ \\
\hline Pentatomidae & Thyanta perditor (Fabr.) & 1 & $\mathbf{z}$ & nd & $\mathbf{r}$ & pf \\
\hline Pyrrhocoridae & Dysdercus sp. & 6 & $\mathbf{y}$ & nd & $\mathbf{r}$ & pf \\
\hline Reduviidae & Hagahus hamatus (Fabr.) & 8 & $\mathrm{y}$ & nd & $\mathrm{r}$ & $\mathrm{pf}$ \\
\hline \multicolumn{7}{|l|}{ Hymenoptera } \\
\hline Andrenidae & Oxea sp. & 2 & $\mathbf{z}$ & nd & $\mathbf{r}$ & pf \\
\hline Anthophoridae & Melissodes sp. & 2 & $\mathbf{z}$ & nd & $\mathbf{r}$ & $\mathrm{pf}$ \\
\hline Apidae & Apis mellifera $\mathrm{L}$. & 25 & $\mathbf{w}$ & nd & c & $\mathrm{f}$ \\
\hline Apidae & Trigona spinipes (Fabr.) & 2 & $\mathbf{z}$ & nd & $\mathrm{r}$ & pf \\
\hline Formicidae & Eciton sp. & 70 & $\boldsymbol{g}$ & do & $\mathbf{m a}$ & $\mathbf{m f}$ \\
\hline Hallictidae & Augochloropsis sp. & 2 & $\mathbf{z}$ & nd & $\mathbf{r}$ & pf \\
\hline Ichneumonidae & Mallochia sp. & 1 & $\mathbf{z}$ & nd & $\mathrm{r}$ & $\mathrm{pf}$ \\
\hline Ichneumonidae & Ophion sp. & 87 & $\mathbf{w}$ & do & $\mathbf{m a}$ & $\mathbf{m f}$ \\
\hline Sphecidae & Ammophila sp. & 1 & $\mathbf{z}$ & nd & $r$ & pf \\
\hline Vespidae & Apoica pallens (Oliv.) & 1 & $\mathbf{z}$ & nd & $\mathbf{r}$ & pf \\
\hline Vespidae & Polistes vesicolor (Bequaert) & 1 & $\mathbf{Z}$ & nd & $\mathbf{r}$ & pf \\
\hline Vespidae & Polybia sp. & 11 & $\mathbf{y}$ & nd & $\mathbf{r}$ & pf \\
\hline \multicolumn{7}{|l|}{ Lepidoptera } \\
\hline Amatidae & Androcharta rubricincta Burm. & 4 & $\mathbf{z}$ & nd & $\mathbf{r}$ & pf \\
\hline Amatidae & Cosmosoma auge (L.) & 4 & $\mathbf{z}$ & nd & $\mathbf{r}$ & $\mathrm{pf}$ \\
\hline Amatidae & Cosmosoma remotum Walk. & 3 & $\mathbf{z}$ & nd & $\mathbf{r}$ & $\mathrm{pf}$ \\
\hline Amatidae & Cosmosoma teuthras Walk. & 3 & $\mathbf{z}$ & nd & $\mathbf{r}$ & $\mathrm{pf}$ \\
\hline Amatidae & Dicladia lucetius (Cr.) & 23 & $\mathbf{w}$ & nd & c & f \\
\hline Amatidae & Eucereon marcata Schs. & 2 & $\mathbf{z}$ & nd & $\mathrm{r}$ & pf \\
\hline Amatidae & Hyaleucerea vulnerata Butler & 1 & $z$ & nd & $\mathbf{r}$ & $\mathrm{pf}$ \\
\hline Amatidae & Philorus rubriceps Walk. & 20 & $\mathbf{w}$ & nd & d & pf \\
\hline Arctiidae & Antarctia sp. & 7 & $\mathbf{z}$ & nd & $\mathbf{r}$ & $\mathrm{pf}$ \\
\hline Arctiidae & Pareuchaetes insulata Walk. & 2 & $\mathbf{z}$ & nd & $\mathbf{r}$ & $\mathrm{pf}$ \\
\hline Arctiidae & Ripha superba (Druce) & 1 & $\mathbf{z}$ & nd & $\mathrm{r}$ & pf \\
\hline Arctiidae & Utetheisa ornatrix L. & 14 & $\mathbf{w}$ & nd & $\mathbf{r}$ & $\mathrm{pf}$ \\
\hline Noctuidae & Agrotis subterranea (Fabr.) & 21 & $\mathbf{y}$ & nd & d & pf \\
\hline Noctuidae & Anomis erosa Hüeb. & 45 & $\mathrm{w}$ & do & c & f \\
\hline Noctuidae & Anticarsia gemmatalis Hüeb. & 104 & $\mathbf{w}$ & do & $\mathbf{m a}$ & $\mathbf{m f}$ \\
\hline Noctuidae & Bagisara subusta Hüeb. & 111 & $\boldsymbol{y}$ & do & $\mathbf{m a}$ & $\mathbf{m f}$ \\
\hline Noctuidae & Blosyres sp. & 1 & $\mathbf{z}$ & nd & $\mathbf{r}$ & pf \\
\hline Noctuidae & Cirphis latiuscula (Herr. - Sch.) & 163 & $\mathbf{w}$ & do & $\mathbf{m a}$ & $\mathbf{m f}$ \\
\hline Noctuidae & Helicoverpa zea (Boddie) & 22 & $\mathbf{y}$ & nd & d & $\mathrm{pf}$ \\
\hline
\end{tabular}




\begin{tabular}{|c|c|c|c|c|c|c|}
\hline Familia & Espécie & Total & $\mathbf{C}$ & $\mathbf{D}$ & $\mathbf{A}$ & $\mathbf{F}$ \\
\hline Noctuidae & Heliothis virescens (Fabr.) & 15 & $z$ & nd & $\mathrm{r}$ & $\mathrm{pf}$ \\
\hline Noctuidae & Leucania humidicola (Guen.) & 229 & $\mathbf{w}$ & do & $\mathbf{m a}$ & $\mathbf{m f}$ \\
\hline Noctuidae & Monodes sp. & 37 & $\mathbf{w}$ & nd & c & f \\
\hline Noctuidae & Perigea sutor Guen. & 23 & $\mathbf{z}$ & nd & c & f \\
\hline Noctuidae & Pseudaletia sequax Francl. & 23 & $\mathbf{z}$ & nd & c & f \\
\hline Noctuidae & Pseudoplusia includens Walk. & 5 & $\mathbf{z}$ & nd & $\mathbf{r}$ & pf \\
\hline Noctuidae & Spodoptera frugiperda (J.E.Smith) & 156 & $\mathbf{w}$ & do & $\mathbf{m a}$ & $\mathbf{m f}$ \\
\hline Noctuidae & Spodoptera latifascia Walk. & 5 & $\mathbf{z}$ & nd & $\mathbf{r}$ & pf \\
\hline Noctuidae & Tarache sp. & 2 & $z$ & nd & $r$ & $\mathrm{pf}$ \\
\hline Nymphalidae & Anartia sp. & 1 & $\mathbf{z}$ & nd & $\mathbf{r}$ & pf \\
\hline Pyralidae & Desmia melanopalis Hamps. & 8 & $\mathbf{z}$ & nd & $\mathbf{r}$ & $\mathrm{pf}$ \\
\hline Pyralidae & Diatraea saccharalis (Fabr.) & 3 & $\mathbf{z}$ & nd & $r$ & $\mathrm{pf}$ \\
\hline Pyralidae & Diatraea sp. & 13 & $\mathbf{z}$ & nd & $\mathbf{r}$ & pf \\
\hline Pyralidae & Elasmopalpus lignosellus (Zeller) & 477 & $\mathbf{w}$ & do & $\mathbf{m a}$ & mf \\
\hline Saturniidae & Automeris complicata (Walk.) & 3 & $\mathbf{z}$ & nd & $\mathbf{r}$ & $\mathrm{pf}$ \\
\hline Sphingidae & Pachilisides sp. & 6 & $z$ & nd & $\mathbf{r}$ & pf \\
\hline Sphingidae & Pholus labruscae (L.) & 1 & $\mathbf{z}$ & nd & $\mathrm{r}$ & pf \\
\hline \multicolumn{7}{|l|}{ Mantodea } \\
\hline Mantidae & Thesprotia macilenta Sauss. & 1 & $\mathbf{z}$ & nd & $\mathbf{r}$ & pf \\
\hline \multicolumn{7}{|l|}{ Neuroptera } \\
\hline Chrysopidae & Chrysoperla externa (Hagen) & 103 & $\mathbf{w}$ & do & $\mathbf{m a}$ & $\mathbf{m f}$ \\
\hline Hemerobiidae & Hemerobius sp. & 6 & $\mathrm{y}$ & nd & $\mathbf{r}$ & $\mathrm{pf}$ \\
\hline \multicolumn{7}{|l|}{ Orthoptera } \\
\hline Acrididae & Orphulella sp. & 12 & $\mathbf{w}$ & nd & $\mathbf{r}$ & pf \\
\hline
\end{tabular}

Nos dois anos foram coletadas 91 espécies e 4.230 individuos durante a entressafra da cultura da soja e, 99 espécies e 3.841 individuos na entressafra do milho. Das espécies coletadas, 84 foram comuns as duas áreas estudadas. Comparando-se as áreas, observou-se que na área da soja coletou-se um maior número de individuos, no entanto a área do milho apresentou maior número de espécies coletadas (Tabelas 1 e 2).

\subsubsection{Caracterizaçāo das comunidades}

A caracterização das comunidades nas áreas de soja e milho, através da análise faunistica, acham-se nas Tabelas 1 e 2 . 
$\mathrm{Na}$ área da soja foram encontradas 29 espécies constantes, 13 acessórias e 49 acidentais. Com relação a abundância, 9 foram muito abundantes, 1 abundante, 22 comuns, 14 dispersas e 45 raras. Para a freqüência, 10 muito freqüentes, 22 freqũentes e 45 pouco freqüentes. Destas, 17 espécies foram dominantes e 74 não dominantes.

$\mathrm{Na}$ área da soja 10 espécies foram consideradas predominantes, as quais foram classificadas como constantes, dominantes, muito abundantes e muito freqüentes. Estas espécies foram: Aphodius sp.; Paederus sp.; Condylostylus sp.; Euxesta sp.; Alydus sp; Pangaeus sp.; B. subusta; C. latiuscula; E. lignosellus e $U$. ornatrix.

Foram considerados mais dois grupos de insetos na área de soja. Um classificado como espécies constantes, comuns e freqüentes, onde foram encontradas 16 espécies: C. scalaris; $D$. speciosa; E. similis; L. villosa; O. v-nigrum; P. significata; A. mellifera; Ophion sp.; Polybia sp.; A. erosa; A. gemmatalis; D. lucetius; H. zea; Monodes sp.; S. frugiperda e C. externa;. E outro classificado como espécies acessórias, comuns e freqũentes que foram: $H$. similis; Eciton sp.; Diatraea sp.; $H$. virescens e L. humidicola.

Silva (1977) realizando um levantamento para as principais pragas da soja, observou que $A$. gemmatalis e $E$. lignosellus ocorreram praticamente o ano todo. Isto condiz com o que foi observado, ou seja, $A$. gemmatalis e E. lignosellus foram duas pragas predominantes e que ocorreram na entressafra da soja.

Das espécies coletadas na área da soja, as mais freqüentes foram Condylostylus sp. (25,1\%); Aphodius sp. $(17,7 \%) ;$ U. ornatrix $(8,2 \%)$; Alydus sp. $(5,8 \%)$ e E. lignosellus (3,5\%).

$\mathrm{Na}$ área do milho 30 espécies foram constantes, 12 acessórias e 57 acidentais. Com relação a abundância e freqūência, 17 
espécies foram muito abundantes e muito freqüentes, 13 comuns e freqüentes e 69 pouco freqüentes, sendo 4 dispersas e 65 raras. Destas, 21 foram dominantes e 78 não dominantes.

Encontraram-se 14 espécies predominantes, as quais foram: Aphodius sp; D. speciosa; E. similis; Paederus sp.; Condylostylus sp.; Alydus sp.; Pangaeus sp.; Ophion sp.; A. gemmatalis; C. latiuscula; E. lignosellus; L. humidicola; $S$. frugiperda e C. externa. Alêm destas, mais 3 espécies podem ser consideradas predominantes, as quais foram dominantes, muito abundantes e muito freqũentes, mas acessórias, sendo estas: Sigara sp.; Eciton sp. e $B$. subusta.

Outro grupo a ser considerado foi o das espécies constantes, comuns e freqüentes onde encontrou-se 11 espécies, que foram: $C$. sanguinea; C. scalaris; Delphastus sp.; P. significata; Euxesta sp.; B. xanthophis; D. continua; A. mellifera; A. erosa; D. lucetius e Monodes sp.

Das espécies coletadas na área do milho as mais freqüentes foram E. lignosellus (12,4\%); Aphodius sp. (10,5\%); Condylostylus sp. (10,3\%); E. similis $(6,1 \%)$; L. humidicola $(6,0 \%)$; Pangaeus sp. $(4,6 \%)$; . latiuscula $(4,2 \%)$ e $S$. frugiperda $(4,1 \%)$.

Comparando as espécies predominantes nas duas áreas, observou-se que a área do milho apresentou maior número de espécies predominantes e vários insetos foram comuns as duas áreas, entre eles: Aphodius sp.; Paederus sp.; Condylostylus sp.; Alydus sp.; Pangaeus sp.; B. subusta ; C. latiuscula e E. lignosellus.

Fazolin (1991) também encontrou as espécies Aphodius sp.; Paederus sp. e Pangaeus sp. como sendo predominantes em coletas feitas com armadilha luminosa em seringueira, mostrando que para este método de coleta esses insetos ocorrem com muita freqūência.

$\mathrm{Na}$ área da soja foram encontradas importantes pragas, entre elas pode-se citar E. lignosellus; A. gemmatalis; Alydus sp.; $D$. 
speciosa; L. villosa; U. ornatrix e P. guildinii, conforme citado por Kogan \& Turnipseed (1987) e Corrêa et al. (1977). O mesmo foi observado para a área do milho, onde ocorreram pragas como D. speciosa; E. lignosellus; S. frugiperda; D. saccharalis; $M$. latipes e $H$. zea, conforme Fornasieri Filho (1992).

Dentre os insetos coletados durante a entressafra da soja e do milho, a maioria são insetos-praga e alguns de grande importância para as culturas em questão, embora diversos inimigos naturais ocorreram nas áreas durante os levantamentos (Figura 5).

Observou-se que as porcentagens de pragas e inimigos naturais foram praticamente iguais nas duas áreas, sendo que as espécies de insetos considerados pragas representaram quase a metade dos insetos coletados. Isto indica que em termos de espécies as duas áreas estudadas mostraram-se semelhantes.

Pragas $\square$ Inimigos naturais $\square$ Outros

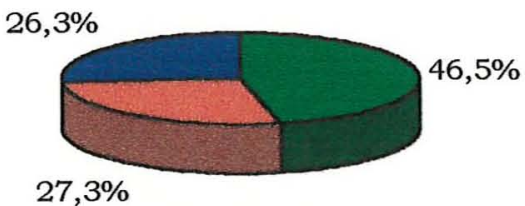

口Pragas GInimigos naturais $\square$ Outros

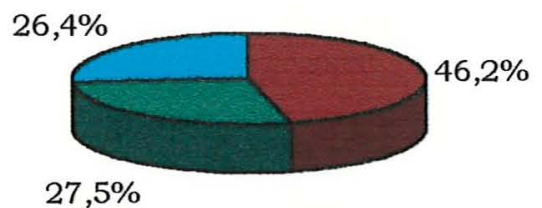

Figura 5 - Porcentagem de insetos coletados durante a entressafra nas áreas de soja e milho. Jaboticabal, SP, 1997 e 1998. 


\subsubsection{Delimitação das comunidades}

Para a delimitação das comunidades e comparação das áreas de soja e milho, realizou-se o cálculo dos indices de diversidade, similaridade e da porcentagem de similaridade.

Com relação ao indice de diversidade, o qual representa a riqueza em espécies de uma comunidade, obteve-se o valor de 10,8 para a área da soja e de 11,9 para a área do milho. Pode-se observar que, embora a área do milho tenha apresentado maior valor para o indice de diversidade, esta diferença é muito pequena quando compara-se as duas áreas. Esses valores indicam uma diversidade média de gêneros e espécies nas duas áreas.

Conforme citado por Silveira Neto et al. (1976) o indice de diversidade tende a aumentar em regiōes tropicais, que abrigam numerosos nichos, isto é, há maior quantidade de espécies, embora com menos indivíduos. Já em locais onde os fatores limitantes atuam intensamente, o indice de diversidade tende a diminuir, pois aumenta o número de espécies comuns e diminui as espécies mais raras.

Comunidades com maiores indices de diversidade tendem a ser mais estáveis, pois as espécies raras podem garantir a sobrevivência de comunidades. Assim espécies, raras e aparentemente sem importância podem ser fundamentais para a manutenção da biodiversidade e do equilibrio em um ambiente em que os fatores ecológicos limitantes foram mudados (Santos \& Marques, 1996).

Observou-se que a ărea do milho foi mais rica em termos de espécies, embora tenha apresentado um menor número de individuos quando comparada com a área da soja. Isto está de acordo com o que foi mencionado por Silveira Neto et al. (1976), em que uma comunidade pode ser mais rica em espécies do que a outra, mas não 
necessariamente em indivíduos por unidade de área, quando utiliza-se o indice de diversidade para comparar comunidades.

$O$ indice de similaridade obtido para as duas áreas foi de 0,082 e a porcentagem de similaridade foi de 58,43\%. Verificou-se através destes valores que as áreas mostraram-se diferentes em termos de composição de espécies. Santos \& Marques (1996) comparando a comunidade de formigas epigéias em uma pastagem e em um bananal também concluíram que apesar das áreas possuírem o mesmo número de espécies, apresentaram baixa similaridade, sendo que a porcentagem de similaridade foi de $36,39 \%$.

Diante dos resultados obtidos, comparando-se as áreas de soja e milho durante a entressafra destas culturas, pode-se dizer que as áreas apresentaram indices de diversidade semelhantes, mostrando pouca diferença em riqueza de espécies. Das espécies coletadas a grande maioria são insetos-praga, sendo encontradas 10 espécies predominantes na área da soja e 17 na área do milho. $O$ indice de similaridade e a porcentagem de similaridade mostraram a diferença entre as duas áreas em relação a essas espécies.

Assim, pode-se dizer que em termos de comunidade de insetos, as duas áreas foram semelhantes, embora as espécies de insetos tenham variado de uma cultura para a outra.

\subsection{Levantamento de insetos em plantas daninhas na área de soja}

\subsubsection{Espécies de plantas daninhas}

As espécies de plantas daninhas que ocorreram durante a entressafra da cultura da soja estão listadas na Tabela 3. 
Tabela 3. Relação das espécies de plantas daninhas encontradas na entressafra da cultura da soja de 1997 e 1998 em Jaboticabal, SP.

\begin{tabular}{lcc}
\hline Espécie & Nome comum & Familia \\
\hline Alternanthera tenella Colla & apaga-fogo & Amaranthaceae \\
Crotalaria incana L. & guizo-de-cascavel & Fabaceae \\
Crotalaria juncea L. & crotaläria & Fabaceae \\
Digitaria insularis (L.) Mea ex Ekman & capim-amargoso & Poaceae \\
Indigofera hirsuta L. & anileira & Fabaceae \\
Parthenium hysterophorus L. & losna-branca & Asteraceae \\
Sida sp. & guanxuma & Malvaceae \\
\hline
\end{tabular}

Dentre as espécies de plantas daninhas encontradas na entressafra da soja, verificou-se que anileira, guanxuma e crotalária estiveram presentes nas áreas durante os dois anos de levantamento. Embora presentes nas duas áreas, a intensidade de ocorrência destas plantas foi muito diferente, principalmente para anileira. Já guizo-decascavel só ocorreu na entressafra de 97 e, apaga-fogo, losna-branca e capim-amargoso na entressafra de 98.

Das plantas daninhas encontradas na entressafra de 97, guizo-de-cascavel foi a espécie que apresentou maior incidência, mas não foi uma diferença muito acentuada quando comparada com as outras espécies presentes na área. Já na entressafra de 98 , crotalária e guanxuma foram as espécies mais abundantes, sendo que crotalária apresentou maior incidência.

Maruyama (1994) observou que as espécies de plantas daninhas predominantes na entressafra da soja foram anileira, apagafogo, capim-carrapicho, picão-preto, mamona, guanxuma, malva-preta, entre outras. 
Um aspecto que deve ser ressaltado é que as plantas daninhas tiveram diferentes porcentagens de cobertura nas áreas experimentais durante a entressafra de 97 e 98.

\subsubsection{Análise faunistica}

Os insetos foram coletados nas diferentes espécies de plantas daninhas presentes na entressafra da soja, através de rede e cone entomológicos. Os resultados da análise faunistica encontram-se nas Tabelas 4 a 10.

\section{Guizo-de-cascavel}

As espécies de insetos coletadas em guizo-de-cascavel na entressafra da soja e a análise faunistica encontram-se na Tabela 4.

Como esta planta ocorreu só na entressafra de 97, foram realizadas 15 avaliações, nas quais coletou-se 32 espécies de insetos e 1.343 individuos.

Das espécies coletadas, 12 foram consideradas constantes, 5 acessórias e 15 acidentais. Com relação a abundância , 8 espécies foram muito abundantes, 2 abundantes, 2 comuns, 2 dispersas e 18 raras. Já para o indice de freqūência, 10 espécies foram muito freqüentes, 2 freqũentes e 20 pouco freqũentes. Destas, 11 foram dominantes e 21 não dominantes.

Foram encontradas 10 espécies predominantes, as quais foram: $C$. sanguinea; Delphastus sp., $D$. speciosa; $H$. notata; $L$. villosa; $P$. significata; P. guildinii; T. perditor, Polybia sp. e C. externa. Além destas, 
Tabela 4. Espécies coletadas e resultados da análise faunística dos insetos coletados em guizo-de-cascavel com rede e cone entomológicos na entressafra da soja de 1997 em Jaboticabal, SP.

\begin{tabular}{|c|c|c|c|c|c|c|}
\hline Familia & Espécie & Total & $\mathbf{C}$ & $\mathbf{D}$ & $\mathbf{A}$ & $\mathbf{F}$ \\
\hline \multicolumn{7}{|l|}{ Coleoptera } \\
\hline Carabidae & Lebia sp. & 4 & $z$ & nd & $\mathbf{r}$ & pf \\
\hline Chrysomelidae & Diabrotica sp. & 1 & $\mathbf{z}$ & nd & $\mathrm{r}$ & pf \\
\hline Chrysomelidae & Diabrotica speciosa Germ. & 208 & $\mathbf{w}$ & do & $\mathbf{m a}$ & $\mathbf{m f}$ \\
\hline Chrysomelidae & Paranapiacaba significata (Gahn.) & 65 & $\mathbf{w}$ & do & $\mathbf{a}$ & $\mathbf{m f}$ \\
\hline Coccinellidae & Cycloneda sanguinea (L.) & 173 & $\mathbf{w}$ & do & $\mathbf{m a}$ & $\mathbf{m f}$ \\
\hline Coccinellidae & Delphastus sp. & 93 & $\mathbf{w}$ & do & $\mathbf{m a}$ & $\mathbf{m f}$ \\
\hline Coccinellidae & Eriopis connexa (Germ.) & 12 & $\mathrm{y}$ & nd & $r$ & pf \\
\hline Coccinellidae & Hyperaspis sp. & 19 & $\mathrm{y}$ & nd & d & pf \\
\hline Coccinellidae & Hyperaspis notata (Muls.) & 155 & $\mathbf{w}$ & do & $\mathbf{m a}$ & $\mathbf{m f}$ \\
\hline Coccinellidae & Olla v-nigrum (Muls.) & 1 & $\mathbf{z}$ & nd & $\mathbf{r}$ & pf \\
\hline Dasytidae & Astylus variegatus Germ. & 1 & $\mathbf{z}$ & nd & $\mathbf{r}$ & pf \\
\hline Elateridae & Loboederus luderwalti Cam & 1 & $\mathbf{z}$ & nd & $\mathbf{r}$ & pf \\
\hline Lagriidae & Lagria villosa Fabr. & 96 & $\mathbf{w}$ & do & $\mathbf{m a}$ & $\mathbf{m f}$ \\
\hline Tenebrionidae & Epitragus simitis Steinh. & 4 & $\mathbf{z}$ & nd & $\mathbf{r}$ & pf \\
\hline \multicolumn{7}{|l|}{ Diptera } \\
\hline Calliphoridae & Chrysomya sp. & 1 & $\mathbf{z}$ & nd & $\mathbf{r}$ & pf \\
\hline Dolichopodidae & Condylostylus sp. & 7 & $\mathrm{y}$ & nd & $\mathrm{r}$ & pf \\
\hline Otitidae & Euxesta sp. & 14 & $\mathrm{y}$ & nd & $\mathrm{r}$ & $\mathrm{pf}$ \\
\hline \multicolumn{7}{|c|}{ Hemiptera - Heteroptera } \\
\hline Alydidae & Alydus sp. & 35 & w & nd & c & f \\
\hline Alydidae & Leptocoriza tipuloides (DeGeer) & 3 & $z$ & nd & $\mathbf{r}$ & pf \\
\hline Lygaeidae & Geocoris sp. & 16 & $\mathrm{y}$ & nd & d & $\mathrm{pf}$ \\
\hline Pentatomidae & Acrosternum hilare (Say) & 6 & $\mathbf{z}$ & nd & $\mathbf{r}$ & pf \\
\hline Pentatomidae & Piezodorus guildinii West. & 62 & $\mathbf{w}$ & do & $\mathbf{a}$ & $\mathbf{m f}$ \\
\hline Pentatomidae & Thyanta perditor (Fabr.) & 69 & $\mathbf{w}$ & do & $\mathbf{m a}$ & $\operatorname{mf}$ \\
\hline Pyrrhocoridae & Dysdercus sp. & 2 & $\mathbf{z}$ & nd & $\mathbf{r}$ & pf \\
\hline \multicolumn{7}{|l|}{ Hymenoptera } \\
\hline Apidae & Apis mellifera $\mathrm{L}$. & 9 & $\mathbf{z}$ & nd & $\mathrm{r}$ & pf \\
\hline Apidae & Trigona spinipes (Fabr.) & 48 & $\mathbf{w}$ & do & c & f \\
\hline Hallictidae & Augochloropsis sp. & 1 & $\mathbf{z}$ & nd & $\mathbf{r}$ & pf \\
\hline Vespidae & Polistes vesicolor (Bequaert) & 1 & $\mathbf{Z}$ & nd & $\mathrm{r}$ & pf \\
\hline Vespidae & Polybia sp. & 121 & $\mathbf{w}$ & do & $\mathbf{m a}$ & $\mathbf{m} \mathbf{f}$ \\
\hline \multicolumn{7}{|l|}{ Lepidoptera } \\
\hline Pyralidae & Desmia melanopalis Hamps. & 9 & $\mathbf{z}$ & nd & $\mathbf{r}$ & pf \\
\hline Pyralidae & Diatraea saccharalis (Fabr.) & 1 & $\mathbf{z}$ & nd & $r$ & pf \\
\hline \multicolumn{7}{|l|}{ Neuroptera } \\
\hline Chrysopidae & Chrysoperla externa (Hagen) & 105 & $\mathbf{w}$ & do & $\mathbf{m a}$ & $\mathbf{m f}$ \\
\hline
\end{tabular}


Alydus sp. e T. spinipes foram consideradas constantes, embora tenham sido comuns e freqūentes.

Outras 5 espécies foram classificadas como acessórias, $E$. connexa; Hyperaspis sp.; Condylostylus sp.; Euxesta sp. e Geocoris sp. As espécies mais freqüentes foram $D$. speciosa (15,5\%); C. sanguinea (12,9\%); H. notata $(11,5 \%)$ e Polybia sp. $(9,0 \%)$.

Esta planta foi uma importante hospedeira de insetos durante a entressafra da soja e, embora tenha ocorrido só durante a entressafra de 97, ela hospedou um grande número de indivíduos. Podese considerar que guizo-de-cascavel foi um reservatório para os inimigos naturais, principalmente quando esta planta atingiu o estádio de florescimento, servindo como fonte de néctar, pólen e presas alternativas, fato observado também por Fontes (1986) para plantas do gênero Solidago.

Os crisopideos são atraidos pelas cores de algumas flores e por compostos voláteis emanados das plantas (Silva, 1996), o que pode explicar a grande quantidade de $C$. externa em plantas de guizo-decascavel.

Observou-se que embora guizo-de-cascavel tenha hospedado muitos inimigos naturais, ela hospedou também importantes pragas da soja, podendo ser considerada uma planta daninha de grande importância no manejo integrado de pragas.

\section{Anileira}

As espécies de insetos coletadas em anileira na entressafra da soja e a análise faunistica encontram-se na Tabela 5. 
Tabela 5. Espécies coletadas e resultados da análise faunistica dos insetos coletados em anileira com rede e cone entomológicos na entressafra da soja de 1997 e 1998 em Jaboticabal, SP.

\begin{tabular}{|c|c|c|c|c|c|c|}
\hline Familia & Espécie & Total & $\mathbf{C}$ & $\mathbf{D}$ & $\mathbf{A}$ & $\mathbf{F}$ \\
\hline \multicolumn{7}{|l|}{ Coleoptera } \\
\hline Carabidae & Lebia sp. & 2 & $\mathbf{z}$ & nd & $\mathbf{r}$ & pf \\
\hline Chrysomelidae & Diabrotica rufolimbata (Baly) & 1 & $z$ & nd & $\mathbf{r}$ & pf \\
\hline Chrysomelidae & Diabrotica speciosa Germ. & 125 & $\mathbf{w}$ & do & $\mathbf{m a}$ & $\mathbf{m f}$ \\
\hline Chrysomelidae & Paranapiacaba significata (Gahn.) & 17 & $\mathbf{w}$ & nd & c & $\mathbf{f}$ \\
\hline Coccinellidae & Cycloneda sanguinea (L.) & 46 & $\mathbf{w}$ & do & $\mathbf{m a}$ & $\mathbf{m f}$ \\
\hline Coccinellidae & Delphastus sp. & 46 & $\mathbf{w}$ & do & $\mathbf{m a}$ & $\mathbf{m f}$ \\
\hline Coccinellidae & Eriopis connexa (Germ.) & 6 & $\mathrm{y}$ & nd & d & $\mathrm{pf}$ \\
\hline Coccinellidae & Hyperaspis sp. & 2 & $z$ & nd & $\mathrm{r}$ & pf \\
\hline Coccinellidae & Hyperaspis notata (Muls.) & 6 & $z$ & nd & $\mathrm{d}$ & pf \\
\hline Coccinellidae & Olla v-nigrum (Muls.) & 1 & z & nd & $\mathbf{r}$ & pf \\
\hline Curculionidae & Pantomorus sp. & 2 & $\mathbf{z}$ & nd & $\mathbf{r}$ & $\mathrm{pf}$ \\
\hline Lagriidae & Lagria villosa Fabr. & 46 & $\mathbf{w}$ & do & $\mathbf{m a}$ & $\mathbf{m f}$ \\
\hline Scarabaeidae & Aphodius sp. & 1 & $\mathbf{z}$ & nd & $\mathbf{r}$ & $\mathrm{pf}$ \\
\hline \multicolumn{7}{|l|}{ Diptera } \\
\hline Dolichopodidae & Condylostylus sp. & 23 & $\mathrm{y}$ & nd & c & $\mathbf{f}$ \\
\hline Otitidae & Euxesta sp. & 4 & $\mathbf{z}$ & nd & $\mathbf{r}$ & pf \\
\hline \multicolumn{7}{|c|}{ Hemiptera - Auchenorrhyncha } \\
\hline Cicadellidae & Bucephalogonia xanthophis (Berg) & 2 & $\mathbf{z}$ & nd & $\mathbf{r}$ & pf \\
\hline Cicadellidae & Diedrocephala continua Sak. \& Cav. & $\overline{2}$ & $\mathbf{z}$ & nd & $\mathbf{r}$ & pf \\
\hline Cicadellidae & Hortensia similis (Walk.) & 1 & $\mathbf{z}$ & nd & $\mathbf{r}$ & $\mathrm{pf}$ \\
\hline Cicadellidae & Scaphitopius sp. & 2 & $\mathbf{z}$ & nd & $\mathbf{r}$ & $\mathrm{pf}$ \\
\hline Cicadellidae & Xerophloea sp. & 4 & $\mathbf{z}$ & nd & $\mathbf{r}$ & pf \\
\hline Membracidae & Cyphonia clavata (Fabr.) & 3 & $\mathbf{z}$ & nd & $\mathbf{r}$ & pf \\
\hline \multicolumn{7}{|c|}{ Hemiptera - Heteroptera } \\
\hline Alydidae & Alydus sp. & 42 & $\mathbf{w}$ & do & $\mathbf{a}$ & $\mathbf{m f}$ \\
\hline Largidae & Lygaeus alboornatus (Blanch.) & 1 & $z$ & nd & $\mathbf{r}$ & $\mathrm{pf}$ \\
\hline Lygaeidae & Geocoris sp. & 227 & $\mathbf{w}$ & do & $\mathbf{m a}$ & $\mathbf{m f}$ \\
\hline Pentatomidae & Acrosternum hilare (Say) & 1 & $\mathbf{z}$ & nd & $\mathbf{r}$ & pf \\
\hline Pentatomidae & Piezodorus guildinii West. & 152 & $\mathbf{w}$ & do & $\mathbf{m a}$ & $\mathbf{m r}$ \\
\hline Pentatomidae & Thyanta perditor (Fabr.) & 28 & $\mathbf{w}$ & do & c & $\mathbf{f}$ \\
\hline Pyrrhocoridae & Dysdercus sp. & 4 & $\mathbf{z}$ & nd & $\mathbf{r}$ & $\mathrm{pf}$ \\
\hline \multicolumn{7}{|l|}{ Hymenoptera } \\
\hline Andrenidae & Exomalopsis sp. & 2 & $z$ & nd & $\mathbf{r}$ & $\mathrm{pf}$ \\
\hline Apidae & Trigona spinipes (Fabr.) & 10 & $\mathbf{z}$ & nd & c & f \\
\hline Hallictidae & Augochloropsis sp. & 1 & $\mathbf{z}$ & nd & $\mathbf{r}$ & pf \\
\hline \multicolumn{7}{|l|}{ Lepidoptera } \\
\hline Arctiidae & Utetheisa ornatrix L. & 2 & $z$ & nd & $\mathbf{r}$ & pf \\
\hline
\end{tabular}




\begin{tabular}{|c|c|c|c|c|c|c|}
\hline Familia & Espécie & Total & $\mathbf{c}$ & $\mathbf{D}$ & $\mathbf{A}$ & $\mathbf{F}$ \\
\hline \multicolumn{7}{|l|}{ Mantodea } \\
\hline Mantidae & Thesprotia macilenta Sauss. & 1 & $\mathbf{z}$ & nd & $\mathbf{r}$ & pf \\
\hline \multicolumn{7}{|l|}{ Neuroptera } \\
\hline Chrysopidae & Chrysoperla externa (Hagen) & 47 & $\mathbf{w}$ & do & $\mathbf{m a}$ & $\mathbf{m f}$ \\
\hline \multicolumn{7}{|l|}{ Orthoptera } \\
\hline Acrididae & Orphulella sp. & 26 & $\mathbf{w}$ & do & c & f \\
\hline
\end{tabular}

Foram realizadas 30 avaliações com esta planta daninha e coletou-se 36 espécies e 907 indivíduos.

Com relação a constância, 11 espécies foram constantes, 3 acessórias e 22 acidentais. Já para abundância observou-se que 7 foram muito abundantes, 1 abundante, 6 comuns, 2 dispersas e 20 raras e para freqüência, 8 muito freqüentes, 6 freqüentes e 22 pouco freqüentes. Destas, 10 foram dominantes e 26 não dominantes.

Foram encontradas 8 espécies predominantes entre as quais tem-se C. sanguinea; Delphastus sp.; D. speciosa; L. villosa; Alydus sp.; Geocoris sp.; $P$. guildinii e $C$. externa. Além destas, 3 espécies foram constantes e 3 acessórias que foram respectivamente $P$. significata; $T$. perditor, Orphulella sp.; E. connexa; Condylostylus sp. e Polybia sp.

As espécies mais freqüentes foram Geocoris sp. (25,03\%); $P$. guildinii $(16,8 \%)$ e $D$. speciosa $(13,8 \%)$.

Observou-se que esta planta hospedou diversas espécies de insetos-praga de grande importância para a cultura da soja durante a entressafra, entre estas destaca-se $D$. speciosa; Alydus sp., P. guildinii e $T$. perditor. Esta planta daninha foi hospedeira de adultos e ninfas de $P$. guildinii e $T$. perditor, principalmente de $P$. guildinii. Dentre as leguminosas não cultivadas, a anileira é mencionada como importante planta hospedeira de $P$. guildinii na Colômbia, aparentemente servindo 
de fonte de infestação deste inseto para a cultura da soja (Hallman ${ }^{1}$, citado por Panizzi, 1987).

Hospedou também vários inimigos naturais, sendo que, o predador Geocoris sp. foi a espécie mais freqüente. A predominância deste importante predador para a cultura da soja também foi observada por Côrrea et al. (1977).

\section{Guanxuma}

As espécies de insetos coletadas em guanxuma na entressafra da soja e a análise faunística encontram-se na Tabela 6.

Tabela 6. Espécies coletadas e resultados da análise faunistica dos insetos coletados em guanxuma com rede e cone entomológicos na entressafra da soja de 1997 e 1998 em Jaboticabal, SP.

\begin{tabular}{|c|c|c|c|c|c|c|}
\hline Familla & Espécie & Total & $\mathbf{C}$ & $\mathbf{D}$ & $\mathbf{A}$ & $\mathbf{F}$ \\
\hline \multicolumn{7}{|l|}{ Coleoptera } \\
\hline Carabidae & Callida sp. & 1 & $z$ & nd & $\mathbf{r}$ & pf \\
\hline Carabidae & Lebia sp. & 2 & $z$ & nd & $\mathbf{r}$ & $\mathrm{pf}$ \\
\hline Chrysomelidae & Diabrotica sp. & 1 & $z$ & nd & $\mathbf{r}$ & pf \\
\hline Chrysomelidae & Diabrotica speciosa Germ. & 216 & $\mathbf{w}$ & do & $\mathbf{m a}$ & $\mathbf{m f}$ \\
\hline Chrysomelidae & Dysonica sp. & 1 & $\mathbf{z}$ & nd & $\mathbf{r}$ & pf \\
\hline Chrysomelidae & Paranapiacaba significata (Gahn.) & 51 & $\mathbf{w}$ & do & $\mathbf{m a}$ & $\mathbf{m f}$ \\
\hline Coccinellidae & Cycloneda sanguinea (L.) & 72 & $\mathbf{w}$ & do & $\mathbf{m a}$ & $\mathbf{m f}$ \\
\hline Coccinellidae & Delphastus sp. & 62 & $\mathbf{w}$ & do & $\mathbf{m a}$ & $\mathbf{m f}$ \\
\hline Coccinellidae & Eriopis connexa (Germ.) & 11 & w & nd & d & $\mathrm{pf}$ \\
\hline Coccinellidae & Hyperaspis notata (Muls.) & 19 & $y$ & nd & c & f \\
\hline Coccinellidae & Hyperaspis sp. & 5 & $z$ & nd & $\mathbf{r}$ & $\mathrm{pf}$ \\
\hline Coccinellidae & Olla v-nigrum (Muls.) & 2 & $z$ & nd & $\mathbf{r}$ & pf \\
\hline Curculionidae & Pantomorus sp. & 2 & $z$ & nd & $r$ & pf \\
\hline Lagriidae & Lagria villosa Fabr. & 74 & $\mathbf{w}$ & do & $\mathbf{m a}$ & $\mathbf{m f}$ \\
\hline Scarabaeidae & Aphodius sp. & 1 & $z$ & nd & $\mathrm{r}$ & pf \\
\hline
\end{tabular}

${ }^{1}$ HALLMAN, G. Importancia de algunas relaciones naturales plantas-artropodos en la agriculturade la zona calida del Tolima central. Revista Colombiana de Entomologia, v.5, p.19-26, 1979. 


\begin{tabular}{|c|c|c|c|c|c|c|}
\hline Familia & Espécie & Total & c & $\mathbf{D}$ & $\mathbf{A}$ & $\mathbf{F}$ \\
\hline \multicolumn{7}{|l|}{ Diptera } \\
\hline Dolichopodidae & Condylostylus sp. & 5 & $\mathbf{z}$ & nd & $\mathrm{r}$ & pf \\
\hline Otitidae & Euxesta sp. & 3 & $z$ & nd & $r$ & pf \\
\hline \multicolumn{7}{|c|}{ Hemiptera - Auchenorrhyncha } \\
\hline Cicadellidae & Bucephalogonia xanthophis (Berg) & 3 & $z$ & nd & $r$ & pf \\
\hline Cicadellidae & Diedrocephala continua Sak.\&Cav. & 1 & $\mathbf{z}$ & nd & $r$ & pf \\
\hline Cicadellidae & Hortensia similis (Walk.) & 1 & $\mathbf{z}$ & nd & $\mathbf{r}$ & pf \\
\hline Cicadellidae & Scaphitopius sp. & 90 & $\mathbf{w}$ & do & $\mathbf{m a}$ & $\mathbf{m f}$ \\
\hline Cicadellidae & Xerophloea sp. & 9 & $\mathbf{z}$ & nd & $\mathrm{d}$ & pf \\
\hline Membracidae & Cyphonia clavata (Fabr.) & 1 & $\mathbf{z}$ & nd & $r$ & pf \\
\hline \multicolumn{7}{|c|}{ Hemiptera - Heteroptera } \\
\hline Alydidae & Alydus sp. & 37 & w & do & c & f \\
\hline Lygaeidae & Geocoris sp. & 70 & $\mathbf{w}$ & do & $\mathbf{m a}$ & $\mathbf{m f}$ \\
\hline Pentatomidae & Piezodorus guildinii West. & 73 & $\mathbf{w}$ & do & $\mathbf{m a}$ & $\mathbf{m f}$ \\
\hline Pentatomidae & Thyanta perditor (Fabr.) & 22 & $\mathbf{w}$ & nd & $\mathrm{c}$ & $\mathrm{f}$ \\
\hline Pyrrhocoridae & Dysdercus sp. & 36 & $\mathbf{w}$ & do & c & $\mathbf{f}$ \\
\hline \multicolumn{7}{|l|}{ Hymenoptera } \\
\hline Apidae & Apis mellifera $\mathrm{L}$. & 2 & $\mathbf{z}$ & nd & $\mathbf{r}$ & $\mathrm{pf}$ \\
\hline Hallictidae & Augochloropsis sp. & 1 & $\mathbf{z}$ & nd & $\mathbf{r}$ & pf \\
\hline Ichneumonidae & Ophion sp. & 2 & $\mathbf{z}$ & nd & $r$ & $\mathrm{pf}$ \\
\hline Vespidae & Polybia sp. & 20 & $\mathrm{y}$ & nd & c & f \\
\hline \multicolumn{7}{|l|}{ Lepidoptera } \\
\hline Arctiidae & Utetheisa ornatrix $\mathrm{L}$. & 5 & $\mathbf{z}$ & nd & $\mathbf{r}$ & pf \\
\hline Megalopygidae & Norape plumosa (Butler) & 2 & $\mathbf{z}$ & nd & $\mathbf{r}$ & pf \\
\hline Noctuidae & Leucania humidicola (Guen.) & 1 & $\mathbf{z}$ & nd & $\mathrm{r}$ & $\mathrm{pf}$ \\
\hline Pieridae & Eurema sp. & 1 & $\mathbf{z}$ & nd & $r$ & pf \\
\hline \multicolumn{7}{|l|}{ Neuroptera } \\
\hline Chrysopidae & Chrysoperla externa (Hagen) & 89 & $\mathbf{w}$ & do & $\mathbf{m a}$ & $\mathbf{m f}$ \\
\hline \multicolumn{7}{|l|}{ Orthoptera } \\
\hline Acrididae & Orphulella sp. & 7 & 2 & nd & $r$ & pf \\
\hline
\end{tabular}

Em guanxuma foram realizadas 30 avaliaçōes, nas quais coletou-se 39 espécies e 1.003 individuos.

Com relação a constância, 13 espécies foram constantes, 2 acessórias e 24 acidentais. Já para abundância, 9 foram muito abundantes, 5 comuns, 2 dispersas e 23 raras e para freqüência, encontraram-se 9 muito freqüentes, 5 freqüentes e 25 pouco freqüentes. Destas, 11 espécies foram dominantes e 28 não dominantes.

Das espécies coletadas, 9 foram consideradas predominantes, sendo estas C. sanguinea; Delphastus sp.; D. speciosa; 
L. villosa; P. significata; Scaphitopius sp.; Geocoris sp.; P. guildinii e C. externa. Além destas, 4 espécies foram classificadas como constantes e 2 como acessórias, as quais foram respectivamente $E$. connexa; Alydus sp.; Dysdercus sp.; $T$. perditor, $H$. notata e Polybia sp.

As espécies mais freqüentes foram $D$. speciosa $(21,5 \%)$, Scaphitopius sp. $(9,0 \%)$ e C. externa $(8,9 \%)$.

Observou-se que esta planta hospedou diversas pragas, principalmente D. speciosa, L. villosa; P. guildinii e Scaphitopius sp., sendo esta última citada como um inseto vetor de doenças. Nielson (1985) registrou espécies pertencentes ao gênero Scaphitopius como transmissoras de fitoviroses em soja e citros. Silveira Neto et al. (1983) relataram que Scaphitopius lineatus (Stal) foi uma das espécies predominantes em levantamentos feitos em citros.

Dentre os inimigos naturais, os principais foram C. externa, que foi o mais freqüente, $C$. sanguinea; Hyperaspis sp. e Geocoris sp. Um aspecto importante é que boa parte dos crisopídeos coletados em guanxuma encontravam-se no estágio larval.

\section{Crotalária}

As espécies de insetos coletadas em crotalária na entressafra da soja e a análise faunística encontram-se na Tabela 7.

Foram realizadas 24 avaliaçōes em crotalária nos dois anos de levantamento. $O$ menor número de avaliações para esta planta daninha foi devido a não ocorrência desta espécie durante todo o periodo de levantamento na entressafra de 97 . Nesta planta coletou-se 37 espécies e 1.385 individuos.

Com relação a constância, 10 espécies foram constantes, 7 acessórias e 20 acidentais. Para a abundância e freqüência 
encontraram-se 8 espécies muito freqüentes, sendo 7 muito abundantes e 1 abundante, 8 comuns e freqüentes e 20 raras e pouco freqüentes. Tabela 7. Espécies coletadas e resultados da análise faunistica dos insetos coletados em crotalária com rede $\mathrm{e}$ cone entomológicos na entressafra da soja de 1997 e 1998 em Jaboticabal, SP.

\begin{tabular}{|c|c|c|c|c|c|c|}
\hline Familia & Espécie & Total & $\mathbf{C}$ & $\mathbf{D}$ & $\mathbf{A}$ & $\mathbf{F}$ \\
\hline \multicolumn{7}{|l|}{ Coleoptera } \\
\hline Carabidae & Lebia sp. & 1 & $\mathbf{z}$ & nd & $\mathbf{r}$ & pf \\
\hline Chrysomelidae & Diabrotica sp. & 3 & $\mathbf{z}$ & nd & $\mathrm{r}$ & pf \\
\hline Chrysomelidae & Diabrotica speciosa Germ. & 642 & $\mathbf{w}$ & $\mathbf{s d}$ & $\mathbf{s a}$ & sf \\
\hline Chrysomelidae & Paranapiacaba significata (Gahn.) & 170 & $\mathbf{w}$ & do & $\mathbf{m a}$ & $\mathbf{m f}$ \\
\hline Coccinellidae & Cycloneda sanguinea (L.) & 47 & $\mathbf{w}$ & do & $\mathbf{m a}$ & $\mathbf{m f}$ \\
\hline Coccinellidae & Delphastus sp. & 57 & $\mathbf{w}$ & do & $\mathbf{m a}$ & $\mathbf{m f}$ \\
\hline Coccinellidae & Eriopis connexa (Germ.) & 19 & $\mathbf{y}$ & nd & $\mathrm{c}$ & $\mathbf{f}$ \\
\hline Coccinellidae & Hyperaspis notata (Muls.) & 33 & $\mathrm{z}$ & do & a & $\mathrm{mf}$ \\
\hline Coccinellidae & Hyperaspis sp. & 5 & $\mathrm{z}$ & nd & $\mathbf{r}$ & pf \\
\hline Coccinellidae & Olla v-nigrum (Muls.) & 4 & $\mathbf{z}$ & nd & $\mathbf{r}$ & pf \\
\hline Curculionidae & Pantomorus sp. & 1 & $z$ & nd & $\mathbf{r}$ & pf \\
\hline Lagriidae & Lagria villosa Fabr. & 38 & $\mathbf{W}$ & do & $\mathbf{m a}$ & $\mathbf{m f}$ \\
\hline Tenebrionidae & Epitragus similis Steinh. & 2 & $z$ & nd & $\mathbf{r}$ & $\mathrm{pf}$ \\
\hline \multicolumn{7}{|l|}{ Diptera } \\
\hline Dolichopodidae & Condylostylus sp. & 4 & $\mathrm{Z}$ & nd & $\mathbf{r}$ & pf \\
\hline Otitidae & Euxesta sp. & 3 & $z$ & nd & $\mathbf{r}$ & pf \\
\hline \multicolumn{7}{|c|}{ Hemiptera - Auchenorrhyncha } \\
\hline Cicadellidae & Bucephalogonia xanthophis (Berg) & 15 & $\mathrm{y}$ & nd & c & $\mathbf{f}$ \\
\hline Cicadellidae & Macugonalia leucomelas (Walk.) & 1 & $\mathbf{z}$ & nd & $\mathbf{r}$ & pf \\
\hline Cicadellidae & Scaphitopius sp. & 62 & $\mathbf{w}$ & do & $\mathbf{m a}$ & $\mathbf{m f}$ \\
\hline Cicadellidae & Xerophloea sp. & 4 & $z$ & nd & $\mathrm{r}$ & $\mathrm{pf}$ \\
\hline Membracidae & Cyphonia clavata (Fabr.) & 4 & $\mathbf{z}$ & nd & $\mathbf{r}$ & pf \\
\hline \multicolumn{7}{|c|}{ Hemiptera - Heteroptera } \\
\hline Alydidae & Alydus sp. & 29 & w & do & $\mathbf{c}$ & $\mathbf{f}$ \\
\hline Alydidae & Leptocoriza tipuloides (DeGeer) & 2 & $z$ & nd & $\mathbf{r}$ & pf \\
\hline Lygaeidae & Geocoris sp. & 22 & $\mathbf{w}$ & do & c & f \\
\hline Pentatomidae & Acrosternum hilare (Say) & 6 & $\mathrm{y}$ & nd & $\mathbf{r}$ & pf \\
\hline Pentatomidae & Piezodorus guildinii West. & 13 & $\mathrm{y}$ & nd & c & $\mathrm{f}$ \\
\hline Pentatomidae & Podisus sp. & 2 & $\mathrm{z}$ & nd & $\mathbf{r}$ & $\mathrm{pf}$ \\
\hline Pentatomidae & Thyanta perditor (Fabr.) & 88 & $\mathbf{w}$ & do & $\mathbf{m a}$ & $\mathbf{m f}$ \\
\hline Pyrrhocoridae & Dysdercus sp. & 5 & $z$ & nd & $\mathrm{r}$ & $\mathrm{pf}$ \\
\hline \multicolumn{7}{|l|}{ Hymenoptera } \\
\hline Anthophoridae & Centris sp. & 1 & $z$ & nd & $\mathbf{r}$ & pf \\
\hline Apidae & Apis mellifera $\mathrm{L}$. & 1 & $\mathbf{z}$ & nd & $r$ & pf \\
\hline
\end{tabular}




\begin{tabular}{|c|c|c|c|c|c|c|}
\hline Familia & Espécie & Total & $\mathbf{C}$ & $\mathbf{D}$ & $\mathbf{A}$ & $\mathbf{F}$ \\
\hline Apidae & Trigona spinipes (Fabr.) & 10 & $\mathrm{y}$ & nd & c & $\bar{f}$ \\
\hline Vespidae & Polybia sp. & 24 & $\mathbf{y}$ & do & c & f \\
\hline \multicolumn{7}{|l|}{ Lepidoptera } \\
\hline Arctiidae & Utetheisa ornatrix L. & 1 & $\mathbf{z}$ & nd & $\mathbf{r}$ & pf \\
\hline Pyralidae & Elasmopalpus lignosellus (Zeller) & 1 & $\mathbf{z}$ & nd & $r$ & pf \\
\hline \multicolumn{7}{|l|}{ Mantodea } \\
\hline $\begin{array}{l}\text { Mantidae } \\
\text { Neuroptera }\end{array}$ & Thesprotia macilenta Sauss. & 2 & $z$ & nd & $\mathbf{r}$ & pf \\
\hline Chrysopidae & Chrysoperla externa (Hagen) & 48 & $\mathbf{w}$ & do & $\mathbf{m a}$ & $\mathbf{m f}$ \\
\hline Orthoptera & & & & & & \\
\hline Acrididae & Orphulella sp. & 15 & $\mathrm{y}$ & nd & c & $\mathbf{f}$ \\
\hline
\end{tabular}

Destas, 11 foram dominantes e 25 não dominantes e uma espécie foi classificada como super dominante, super abundante e super freqüente.

Das espécies coletadas, 7 foram consideradas predominantes, as quais foram C. sanguinea; Delphastus sp.; L. villosa; P. significata; Scaphitopius sp.; T. perditor e C. externa. Além destas, D. speciosa foi considerada uma espécie super predominante, em virtude de ter ocorrido em quantidade muito maior que as demais espécies coletadas.

Foram encontradas ainda 2 espécies constantes e 7 acessórias, sendo Alydus sp. e Geocoris sp. constantes e E. connexa; $B$. xanthophis; A. hilare; P. guildinii; Polybia sp.; T. spinipes e Orphulella sp. acessórias. Deve ser salientada também a espécie $H$. notata, a qual foi considerada uma espécie acidental mas, dominante, abundante e muito freqüente, ou seja, foi coletada em poucas avaliações, mas em grande quantidade.

As espécies mais freqüentes foram $D$. speciosa $(46,4 \%), P$. significata $(12,3 \%)$ e $T$. perditor $(6,4 \%)$. Observa-se que $D$. speciosa representou quase metade do total de insetos coletados nesta planta daninha. 
Crotalária foi uma importante hospedeira dos percevejos da soja, principalmente de $T$. perditor, sendo hospedeira tanto dos adultos quanto das ninfas desses percevejos.

\section{Losna-branca}

As espécies de insetos coletadas em losna-branca na entressafra da soja e a análise faunistica encontram-se na Tabela 8.

Foram realizadas 15 avaliações em losna-branca, sendo que esta planta só ocorreu na entressafra de 98, e coletou-se 31 espécies e 506 indivíduos.

Quanto a constância, 8 espécies foram constantes, 8 acessórias e 15 acidentais. Com relação a abundância e freqüência, 3 espécies foram muito abundantes e muito freqüentes, 12 comuns $\mathrm{e}$ freqüentes e 16 dispersas e pouco freqüentes. Destas, 5 espécies foram dominantes e 26 não dominantes.

Das espécies coletadas, apenas 3 foram consideradas predominantes, que foram $D$. speciosa; $P$. significata e Xerophloea sp. No entanto, 5 espécies foram constantes e 8 acessórias, as quais foram respectivamente $C$. sanguinea; Delphastus sp.; $E$. connexa; $B$. xanthophis; Scaphitopius sp.; L. villosa; D. continua; C. clavata; Alydus sp.; Geocoris sp.; Polybia sp.; C. externa e Orphulella sp. Faifer (1986) também encontrou $L$. villosa; $X$. viridis; $C$. sanguinea e Geocoris sp. associados com losna-branca.

As espécies mais freqũentes foram as 3 predominantes, sendo $P$. significata $(26,3 \%), D$. speciosa $(25,7 \%)$ e Xerophloea sp. $(17,0 \%)$. 
Tabela 8. Espécies coletadas e resultados da análise faunistica dos insetos coletados em losna-branca com rede e cone entomológicos na entressafra da soja de 1998 em Jaboticabal, SP.

\begin{tabular}{|c|c|c|c|c|c|c|}
\hline Familia & Espécie & Total & $\mathbf{C}$ & $\mathbf{D}$ & $\mathbf{A}$ & $\mathbf{F}$ \\
\hline \multicolumn{7}{|l|}{ Coleoptera } \\
\hline Chrysomelidae & Diabrotica sp. & 3 & $\mathbf{z}$ & nd & d & pf \\
\hline Chrysomelidae & Diabrotica speciosa Germ. & 130 & $\mathbf{w}$ & do & $\mathbf{m a}$ & $\mathbf{m f}$ \\
\hline Chrysomelidae & Paranapiacaba significata (Gahn.) & 133 & $\mathbf{w}$ & do & $\mathbf{m a}$ & $\mathbf{m f}$ \\
\hline Coccinellidae & Cycloneda sanguinea (L.) & 13 & $w$ & nd & c & $\mathbf{f}$ \\
\hline Coccinellidae & Delphastus sp. & 20 & $\mathbf{w}$ & do & c & $\mathbf{f}$ \\
\hline Coccinellidae & Eriopis connexa (Germ.) & 17 & $\mathbf{w}$ & do & c & f \\
\hline Coccinellidae & Hyperaspis notata (Muls.) & 1 & $z$ & nd & d & pf \\
\hline Coccinellidae & Hyperaspis sp. & 1 & $\mathbf{z}$ & nd & d & $\mathrm{pf}$ \\
\hline Lagriidae & Lagria villosa Fabr. & 8 & $\mathrm{y}$ & nd & c & f \\
\hline \multicolumn{7}{|l|}{ Diptera } \\
\hline Otitidae & Euxesta sp. & 2 & $\mathbf{z}$ & nd & d & pf \\
\hline \multicolumn{7}{|c|}{ Hemiptera - Auchenorrhyncha } \\
\hline Cicadellidae & Bucephalogonia xanthophis (Berg) & 14 & $\mathbf{w}$ & nd & c & f \\
\hline Cicadellidae & Diedrocephala continua Sak. \& Cav. & 9 & $\mathbf{y}$ & nd & c & $\mathbf{f}$ \\
\hline Cicadellidae & Hortensia similis (Walk.) & 3 & $\mathbf{z}$ & nd & d & pf \\
\hline Cicadellidae & Scaphitopius sp. & 11 & $\mathbf{w}$ & nd & c & $\mathbf{f}$ \\
\hline Cicadellidae & Xerophloea sp. & 86 & $\mathbf{w}$ & do & $\mathbf{m a}$ & $\mathbf{m f}$ \\
\hline Membracidae & Cyphonia clavata (Fabr.) & 6 & $\mathrm{y}$ & nd & c & $\mathbf{f}$ \\
\hline \multicolumn{7}{|c|}{ Hemiptera - Heteroptera } \\
\hline Alydidae & Alydus sp. & 5 & $\mathbf{y}$ & nd & c & $\mathbf{f}$ \\
\hline Alydidae & Leptocoriza tipuloides (DeGeer) & 1 & $\mathbf{z}$ & nd & d & pf \\
\hline Lygaeidae & Geocoris sp. & 5 & $\mathrm{y}$ & nd & $\mathbf{c}$ & $\mathbf{f}$ \\
\hline Pentatomidae & Piezodorus guildinii West. & 2 & $\mathbf{z}$ & nd & $\mathrm{d}$ & $\mathrm{pf}$ \\
\hline Pentatomidae & Thyanta perditor (Fabr.) & 2 & $\mathbf{z}$ & nd & $\mathrm{d}$ & pf \\
\hline Pyrrhocoridae & Dysdercus sp. & 1 & $\mathbf{z}$ & nd & $\mathrm{d}$ & pf \\
\hline \multicolumn{7}{|l|}{ Hymenoptera } \\
\hline Apidae & Apis mellifera $\mathrm{L}$. & 1 & $\mathbf{z}$ & nd & $d$ & pf \\
\hline Apidae & Trigona spinipes (Fabr.) & 2 & $\mathbf{z}$ & nd & d & $\mathrm{pf}$ \\
\hline Hallictidae & Augochloropsis sp. & 1 & $\mathbf{z}$ & nd & $\mathrm{d}$ & $\mathrm{pf}$ \\
\hline $\begin{array}{l}\text { Vespidae } \\
\text { Lepidoptera }\end{array}$ & \multicolumn{5}{|c|}{ Lepidoptera } & f \\
\hline $\begin{array}{l}\text { Pyralidae } \\
\text { Neuroptera }\end{array}$ & Elasmopalpus lignosellus (Zeller) & 1 & $z$ & nd & d & pf \\
\hline Chrysopidae & Chrysoperla externa (Hagen) & 10 & $\mathrm{y}$ & nd & c & $\mathbf{f}$ \\
\hline Hemerobiidae & Hemerobius sp. & 1 & $z$ & nd & d & pf \\
\hline \multicolumn{7}{|l|}{ Mantodea } \\
\hline $\begin{array}{l}\text { Mantidae } \\
\text { Orthoptera }\end{array}$ & Thesprotia macilenta Sauss. & 3 & $z$ & nd & d & $\mathrm{pf}$ \\
\hline Acrididae & Orphulella sp. & 4 & $\mathrm{y}$ & nd & $\mathrm{d}$ & pf \\
\hline
\end{tabular}


A predominância de $D$. speciosa também foi observada por Otero \& Belarmino (1993) quando avaliaram a entomofauna da soja em coexistência com $B$. pilosa, planta daninha pertencente a mesma família que losna-branca.

Pragas da cultura da soja e inimigos naturais estiveram associados com esta planta durante a entressafra da soja e principalmente durante o estâdio de florescimento desta planta. Losnabranca foi uma importante hospedeira de diversos cicadelideos, entre estes o gênero Xerophloea foi considerado predominante. Nielson (1962) relata que espécies deste gênero assumem considerável importância econômica e algumas espécies são consideradas vetores de viroses de plantas.

\section{Apaga-fogo}

As espécies de insetos coletadas em apaga-fogo na entressafra da soja e a análise faunística encontram-se na Tabela 9.

Foram realizadas 15 avaliações em apaga-fogo e coletou-se 27 espécies e 361 indivíduos.

Com relação a constância, 7 espécies foram constantes, 6 acessórias e 14 acidentais. Quanto a abundância e freqüência, 12 espécies foram dispersas e pouco freqüentes, 10 comuns e freqüentes e 5 muito freqūentes, sendo 4 muito abundantes e 1 abundante. Para a dominância coletou-se 5 espécies dominantes e 22 não dominantes.

Das espécies coletadas 5 foram predominantes, sendo estas D. speciosa; L. villosa; P. significata; Geocoris sp. e Xerophloea sp. Dentre as demais espécies, Alydus sp. e Orphulella sp. foram constantes e, E. connexa; Euxesta sp.; D. continua; Scaphitopius sp.; T. perditor e C. externa; foram acessórias. 
Tabela 9. Espécies coletadas e resultados da análise faunistica dos insetos coletados em apaga-fogo com rede $e$ cone entomológicos na entressafra da soja de 1998 em Jaboticabal, SP.

\begin{tabular}{|c|c|c|c|c|c|c|}
\hline Familia & Espécie & Total & $\mathbf{C}$ & $\mathbf{D}$ & $\mathbf{A}$ & $\mathbf{F}$ \\
\hline \multicolumn{7}{|l|}{ Coleoptera } \\
\hline Chrysomelidae & Diabrotica speciosa Germ. & 127 & $\mathbf{w}$ & do & $\mathbf{m a}$ & $\mathbf{m f}$ \\
\hline Chrysomelidae & Dysonica sp. & 1 & $\mathbf{z}$ & nd & d & pf \\
\hline Chrysomelidae & Paranapiacaba significata (Gahn.) & 51 & $\mathbf{w}$ & do & $\mathbf{m a}$ & $\mathbf{m f}$ \\
\hline Coccinellidae & Delphastus sp. & 3 & $\mathbf{z}$ & nd & $\mathrm{d}$ & $\mathrm{pf}$ \\
\hline Coccinellidae & Eriopis connexa (Germ.) & 4 & $\mathrm{y}$ & nd & c & f \\
\hline Coccinellidae & Hyperaspis sp. & 1 & $\mathbf{z}$ & nd & d & pf \\
\hline Dasytidae & Astylus variegatus Germ. & 2 & $\mathbf{z}$ & nd & d & pf \\
\hline Lagriidae & Lagria villosa Fabr. & 25 & $\mathbf{w}$ & do & $\mathbf{a}$ & $\mathbf{m f}$ \\
\hline \multicolumn{7}{|l|}{ Diptera } \\
\hline Otitidae & Euxesta sp. & 7 & $\mathrm{y}$ & nd & c & $\mathbf{f}$ \\
\hline \multicolumn{7}{|c|}{ Hemiptera - Auchenorrhyncha } \\
\hline Cicadellidae & Bucephalogonia xanthophis (Berg) & 2 & $z$ & nd & $\mathrm{d}$ & pf \\
\hline Cicadellidae & Diedrocephala continua Sak. \& Cav. & 4 & $\mathrm{y}$ & nd & c & $\mathbf{f}$ \\
\hline Cicadellidae & Hortensia similis (Walk.) & 4 & $\mathbf{z}$ & nd & c & $\mathbf{f}$ \\
\hline Cicadellidae & Macugonalia leucomelas (Walk.) & 1 & $z$ & nd & $\mathrm{d}$ & pf \\
\hline Cicadellidae & Scaphitopius sp. & 8 & $\mathrm{y}$ & nd & c & $\mathbf{f}$ \\
\hline Cicadellidae & Xerophloea sp. & 49 & $\mathbf{w}$ & do & $\mathbf{m a}$ & $\mathbf{m f}$ \\
\hline Membracidae & Cyphonia clavata (Fabr.) & 2 & $z$ & nd & d & pf \\
\hline \multicolumn{7}{|c|}{ Hemiptera - Heteroptera } \\
\hline Alydidae & Alydus sp. & 8 & $\mathbf{w}$ & nd & c & $\mathbf{f}$ \\
\hline Coreidae & Zica sp. & 1 & $\mathbf{z}$ & nd & d & pf \\
\hline Lygaeidae & Geocoris sp. & 29 & $\mathbf{w}$ & do & $\mathbf{m a}$ & $\mathbf{m f}$ \\
\hline Pentatomidae & Piezodorus guildinii West. & 2 & $\mathbf{z}$ & nd & $\mathrm{d}$ & pf \\
\hline Pentatomidae & Thyanta perditor (Fabr.) & 5 & $\mathrm{y}$ & nd & c & $\mathbf{f}$ \\
\hline \multicolumn{7}{|l|}{ Hymenoptera } \\
\hline Apidae & Trigona spinipes (Fabr.) & 4 & $\mathbf{z}$ & nd & c & $\mathbf{f}$ \\
\hline Hallictidae & Augochloropsis sp. & 1 & $\mathbf{z}$ & nd & $\mathrm{d}$ & $\mathrm{pf}$ \\
\hline Vespidae & Polybia sp. & 1 & $z$ & nd & $d$ & pf \\
\hline \multicolumn{7}{|l|}{ Mantodea } \\
\hline $\begin{array}{l}\text { Mantidae } \\
\text { Neuroptera }\end{array}$ & Thesprotia macilenta Sauss. & 1 & $z$ & nd & d & pf \\
\hline Chrysopidae & Chrysoperla externa (Hagen) & 8 & $\mathrm{y}$ & nd & c & $\mathbf{f}$ \\
\hline \multicolumn{7}{|l|}{ Orthoptera } \\
\hline Acrididae & Orphulella sp. & 10 & $\mathrm{w}$ & nd & c & $\mathbf{f}$ \\
\hline
\end{tabular}


As espécies mais freqũentes foram $D$. speciosa $(35,2 \%), P$. significata $(14,1 \%)$ e Xerophloea $(13,6 \%)$.

No geral, apaga-fogo hospedou muito mais insetos-praga do que inimigos naturais. Entre as pragas, as mais importantes foram os crisomelídeos $D$. speciosa e $P$. significata e os cicadelídeos Xeroplhoea $\mathbf{s p}$. e Scaphitopius sp., os quais além de causarem danos diretos às culturas são vetores de vírus.

\section{Capim-amargoso}

As espécies de insetos coletadas em capim-amargoso na entressafra da soja e a análise faunística encontram-se na Tabela 10.

Foram realizadas 8 avaliações com esta planta daninha durante a entressafra da soja de 98 e coletou-se 12 espécies e 60 indivíduos.

Com relação a constância foram coletadas 1 espécie constante, 5 acessórias e 5 acidentais. Das espécies coletadas, uma foi classificada como constante, super dominante, super abundante e super freqüente. Quanto a abundância e freqüência coletou-se 3 espécies muito abundantes e muito freqüentes, 3 comuns e freqüentes e 5 raras e pouco freqũentes. Destas, 4 espécies foram dominantes e 7 não dominantes.

Das espécies coletadas, $D$. speciosa foi considerada uma espécie super predominante e $H$. similis uma espécie predominante. Além destas, E. connexa e $L$. villosa foram classificadas como dominantes, muito abundantes e muito freqüentes, mas foram espécies acessórias. 
Tabela 10. Espécies coletadas e resultados da análise faunística dos insetos coletados em capim-amargoso com rede e cone entomológicos na entressafra da soja de 1998 em Jaboticabal, SP.

\begin{tabular}{|c|c|c|c|c|c|c|}
\hline Familia & Espécie & Total & $\mathbf{C}$ & $\mathbf{D}$ & $\mathbf{A}$ & $\mathbf{F}$ \\
\hline \multicolumn{7}{|l|}{ Coleoptera } \\
\hline Chrysomelidae & Diabrotica speciosa Germ. & 25 & $\mathbf{w}$ & sd & $\mathbf{s a}$ & sf \\
\hline Chrysomelidae & Paranapiacaba significata (Gahn.) & 4 & $\mathbf{y}$ & do & c & $\mathbf{f}$ \\
\hline Coccinellidae & Eriopis connexa (Germ.) & 7 & $\mathbf{y}$ & do & ma & $\mathrm{mf}$ \\
\hline Lagriidae & Lagria villosa Fabr. & 7 & $\mathrm{y}$ & do & ma & $\mathrm{mf}$ \\
\hline \multicolumn{7}{|l|}{ Diptera } \\
\hline Otitidae & Euxesta sp. & 1 & $\mathbf{z}$ & nd & $\mathbf{r}$ & pf \\
\hline \multicolumn{7}{|c|}{ Hemiptera - Auchenorrhyncha } \\
\hline Cicadellidae & Hortensia similis (Walk.) & 7 & $\mathbf{w}$ & do & $\mathbf{m a}$ & $\mathbf{m f}$ \\
\hline Cicadellidae & Scaphitopius sp. & 1 & $z$ & nd & $\mathbf{r}$ & pf \\
\hline Cicadellidae & Xerophloea sp. & 2 & $\mathrm{y}$ & nd & c & $\mathbf{f}$ \\
\hline \multicolumn{7}{|c|}{ Hemiptera - Heteroptera } \\
\hline Alydidae & Alydus sp. & 1 & $z$ & nd & $\mathbf{r}$ & pf \\
\hline $\begin{array}{l}\text { Pentatomidae } \\
\text { Lepidoptera }\end{array}$ & Thyanta perditor (Fabr.) & 1 & $\mathbf{z}$ & nd & $\mathbf{r}$ & $\mathrm{pf}$ \\
\hline $\begin{array}{l}\text { Pyralidae } \\
\text { Neuroptera }\end{array}$ & Elasmopalpus lignosellus (Zeller) & 1 & $\mathbf{z}$ & nd & $\mathbf{r}$ & pf \\
\hline Chrysopidae & Chrysoperla externa(Hagen) & 3 & $\mathrm{y}$ & nd & $\mathbf{c}$ & f \\
\hline
\end{tabular}

P. significata, Xerophloea sp. e C. externa foram consideradas espécies acessórias. A espécie mais freqũente foi $D$. speciosa $(41,7 \%)$.

Esta planta daninha hospedou um menor número de indivíduos quando comparada com as outras plantas avaliadas. Foi hospedeira de insetos-praga, principalmente $D$. speciosa e $H$. similis, espécie citada como importante vetora de virus.

Analisando-se os insetos coletados em plantas daninhas durante a entressafra da soja, observou-se que as plantas que hospedaram maior número de insetos foram crotalária e guizo-decascavel e a que hospedou o menor número foi capim-amargoso. No entanto, considerando a área da soja como um todo, as plantas 
daninhas hospedaram um grande número de insetos. Guanxuma foi a planta na qual coletou-se o maior número de espécies.

Com relação aos insetos coletados, as pragas predominantes na área foram D. speciosa; L. villosa; P. significata; Xerophloea sp.; Scaphitopius sp.; Alydus sp.; P. guildinii e T. perditor. Quanto aos inimigos naturais, predominaram C. sanguinea; Delphastus sp.; $E$. connexa; H. notata; Geocoris sp.; Polybia sp. e C. externa.

Observou-se que $D$. speciosa; $P$. significata; $P$. guildinii e $T$. perditor foram pragas muito abundantes nas plantas daninhas durante a entressafra, sendo que o número de coleópteros foi bem maior que o de hemipteros, fato este observado também por Rodini \& Grazia (1979).

Entre os Pentatomidae, $P$. guildinii foi a espécie mais abundante na entressafra da soja, e anileira foi a planta daninha em que este inseto mais ocorreu, conforme citado também por Maruyama (1994). Panizzi \& Slansky Jr. (1985) observaram que ovos, ninfas e adultos de $P$. guildinii foram muito abundantes em plantas de $I$. hirsuta e C. lanceolata, as quais crescem próximo de campos de soja, sugerindo que essas duas plantas servem como importantes hospedeiros, mantendo a população deste inseto quando a soja não se encontra no campo. As estruturas de frutificação dessas plantas são um dos principais sitios de alimentação dos percevejos. Observou-se que em anileira $P$. guildinii, foi o percevejo mais abundante, mas em crotalária foi $T$. perditor.

Quanto as espécies predominantes encontradas nas diferentes plantas daninhas, guizo-de-cascavel foi a que apresentou o maior número, com 10 espécies predominantes, seguida por guanxuma com 9, crotalária e anileira, ambas com 8 espécies. Já capim-amargoso e losna-branca apresentaram os menores números com 2 e 3 espécies predominantes, respectivamente. 
Dentre estas espécies, $D$. speciosa foi a única predominante em todas as plantas daninhas avaliadas, sendo classificada como super predominante em duas. Já $L$. villosa foi predominante na maioria, exceto em losna-branca.

Oliveira \& Panizzi (1998) relataram que C. juncea e as indigóferas, entre outras leguminosas, são hospedeiros alternativos à soja que servem de alimento para $A$. gemmatalis, na ausência do hospedeiro principal contribuindo para aumentar a população dessa praga em soja.

De um modo geral, as plantas daninhas hospedaram diversos insetos na entressafra da cultura da soja, tanto pragas como inimigos naturais. Diversas pragas de importância econômica para a soja encontraram nas plantas daninhas abrigo durante a entressafra.

\subsection{Levantamento de insetos em plantas daninhas na área de milho}

\subsubsection{Espécies de plantas daninhas}

As espécies de plantas daninhas que ocorreram durante a entressafra da cultura do milho estão listadas na Tabela 11.

Das espécies de plantas daninhas encontradas na entressafra do milho, apaga-fogo e guanxuma estiveram presentes durante os dois anos de levantamento. No entanto, rabo-de-foguete esteve presente só na entressafra de 97 e anileira, carrapicho-decarneiro, falsa-serralha e nabiça na entressafra de 98. 
Tabela 11. Relação das espécies de plantas daninhas encontradas na entressafra da cultura do milho de 1997 e 1998 em Jaboticabal, SP.

\begin{tabular}{lcc}
\hline Espécie & Nome comum & Familia \\
\hline Alternanthera tenella Colla & apaga-fogo & Amaranthaceae \\
Acanthospermum hispidum DC. & carrapicho-de-carneiro & Asteraceae \\
Conyza bonariensis (L.) Cronq. & rabo-de-foguete & Asteraceae \\
Emilia sonchifolia DC. & falsa-serralha & Asteraceae \\
Indigofera hirsuta L. & anileira & Fabaceae \\
Raphanus raphanistrum L. & nabiça & Brassicaceae \\
Sida sp. & guanxuma & Malvaceae \\
\hline
\end{tabular}

$\mathrm{Na}$ entressafra de 97 observou-se que apaga-fogo foi a espécie de maior incidência, cobrindo grande parte da área experimental quando comparada com as outras duas espécies. Das espécies de plantas daninhas encontradas na área durante a entressafra de 98, anileira e nabiça foram as mais abundantes, sendo que nabiça foi a espécie de maior incidência.

As porcentagens de cobertura das áreas experimentais pela comunidade infestante foram diferentes, além disso, algumas espécies não estiveram presentes durante todo o periodo em que foram realizadas as avaliações.

\subsubsection{Análise faunistica}

Os insetos foram coletados nas diferentes espécies de plantas daninhas presentes na entressafra do milho, através de rede e cone entomológicos. Os resultados da análise faunística encontram-se nas Tabelas 12 a 18. 


\section{Rabo-de-foguete}

As espécies de insetos coletadas em rabo-de-foguete na entressafra do milho e a análise faunistica encontram-se na Tabela 12.

Tabela 12. Espécies coletadas e resultados da análise faunística dos insetos coletados em rabo-de-foguete com rede e cone entomológicos na entressafra do milho de $1997 \mathrm{em}$ Jaboticabal, SP.

\begin{tabular}{|c|c|c|c|c|c|c|}
\hline Familia & Espécie & Total & $\mathbf{C}$ & $\mathbf{D}$ & $\mathbf{A}$ & $\mathbf{F}$ \\
\hline \multicolumn{7}{|l|}{ Coleoptera } \\
\hline Chrysomelidae & Diabrotica speciosa Germ. & 26 & $\mathbf{w}$ & do & $\mathbf{m a}$ & $\mathbf{m f}$ \\
\hline Chrysomelidae & Dysonica sp. & 2 & $\mathbf{z}$ & nd & c & $\mathbf{f}$ \\
\hline Chrysomelidae & Paranapiacaba significata (Gahn.) & 10 & $\mathbf{w}$ & do & $\mathbf{a}$ & $\mathbf{m f}$ \\
\hline Coccinellidae & Cycloneda sanguinea (L.) & 1 & $z$ & nd & $\mathrm{d}$ & pf \\
\hline Coccinellidae & Delphastus sp. & 2 & $\mathbf{z}$ & nd & c & $\mathbf{f}$ \\
\hline Coccinellidae & Eriopis connexa (Germ.) & 1 & $\mathbf{z}$ & nd & d & pf \\
\hline \multicolumn{7}{|l|}{ Diptera } \\
\hline Otitidae & Euxesta sp. & 1 & $\mathbf{z}$ & nd & $\mathrm{d}$ & pf \\
\hline \multicolumn{7}{|c|}{ Hemiptera - Auchenorrhyncha } \\
\hline Membracidae & Cyphonia clavata (Fabr.) & 6 & $\mathbf{w}$ & do & c & $\mathbf{f}$ \\
\hline \multicolumn{7}{|c|}{ Hemiptera - Heteroptera } \\
\hline Alydidae & Alydus sp. & 1 & $z$ & nd & $d$ & $\mathrm{pf}$ \\
\hline Lygaeidae & Geocoris sp. & 12 & $\mathbf{w}$ & do & $\mathbf{m a}$ & $\mathbf{m f}$ \\
\hline Pentatomidae & Acrosternum hilare (Say) & 1 & $\mathbf{z}$ & nd & $\mathrm{d}$ & $\mathrm{pf}$ \\
\hline Pentatomidae & Piezodorus guildinii West. & 6 & $\mathbf{w}$ & do & c & $\mathrm{f}$ \\
\hline \multicolumn{7}{|l|}{ Hymenoptera } \\
\hline Vespidae & Polybia sp. & 1 & $\mathbf{z}$ & nd & d & pf \\
\hline \multicolumn{7}{|l|}{ Neuroptera } \\
\hline Chrysopidae & Chrysoperla externa (Hagen) & 3 & $\mathrm{y}$ & nd & c & $\mathrm{f}$ \\
\hline
\end{tabular}

Foram realizadas 5 avaliações nesta planta daninha na entressafra da cultura do milho de 97 e coletou-se 14 espécies e 73 indivíduos.

Com relação a constância foram coletadas 5 espécies constantes, 1 acessória e 8 acidentais. Quanto a abundância e 
freqūência encontraram-se 5 espécies comuns e freqũentes, 6 dispersas e pouco freqüentes e 3 muito freqüentes, sendo 2 muito abundantes e 1 abundante. Destas, 5 foram dominantes e 9 não dominantes.

Destas espécies, 3 foram consideradas predominantes que foram $D$. speciosa; $P$. significata e Geocoris sp. C. clavata e $P$. guildinii foram consideradas espécies constantes e C. externa acessória.

As espécies mais freqüentes foram D. speciosa $(35,6 \%)$, Geocoris sp. $(16,4 \%)$ e $P$. significata $(13,7 \%)$.

Esta planta daninha abrigou um menor número de individuos quanto comparada com as demais plantas avaliadas. Dentre os insetos coletados, hospedou alguns insetos-praga, principalmente os crisomelideos e entre os inimigos naturais Geocoris sp. foi o que mais se destacou.

\section{Guanxuma}

As espécies de insetos coletadas em guanxuma na entressafra do milho e a análise faunística encontram-se na Tabela 13.

Foram realizadas 12 avaliações com esta planta daninha nas entressafras de 97 e 98 . Esta planta não esteve presente nas áreas durante todo o periodo em que foram realizados os levantamentos, sendo coletadas 25 espécies e 298 individuos.

Com relação a constância encontrou-se 8 espécies constantes, 3 acessórias e 14 acidentais. Quanto a abundância e frequêencia, 4 espécies foram muito abundantes e muito freqũentes, 7 comuns e freqüentes e 14 pouco freqüentes, sendo 6 dispersas e 8 raras. Destas, 6 foram dominantes e 19 não dominantes. 
Tabela 13. Espécies coletadas e resultados da análise faunística dos insetos coletados em guanxuma com rede $\mathrm{e}$ cone entomológicos na entressafra do milho de 1997 e 1998 em Jaboticabal, SP.

\begin{tabular}{|c|c|c|c|c|c|c|}
\hline Família & Espécie & Total & $\mathbf{C}$ & $\mathbf{D}$ & $\mathbf{A}$ & $\mathbf{F}$ \\
\hline \multicolumn{7}{|l|}{ Coleoptera } \\
\hline Chrysomelidae & Diabrotica sp. & 2 & $\mathbf{z}$ & nd & $\mathrm{d}$ & $\mathrm{pf}$ \\
\hline Chrysomelidae & Diabrotica speciosa Germ. & 86 & $\mathbf{w}$ & do & $\mathbf{m a}$ & mf \\
\hline Chrysomelidae & Paranapiacaba significata (Gahn.) & 42 & $\mathbf{w}$ & do & $\mathbf{m a}$ & $\mathbf{m f}$ \\
\hline Coccinellidae & Cycloneda sanguinea (L.) & 8 & $\mathbf{w}$ & nd & c & f \\
\hline Coccinellidae & Delphastus sp. & 5 & $\mathbf{w}$ & nd & c & $\mathbf{f}$ \\
\hline Coccinellidae & Eriopis connexa (Germ.) & 1 & $z$ & nd & $\mathbf{r}$ & pf \\
\hline Coccinellidae & Hyperaspis notata & 1 & 2 & nd & $\mathbf{r}$ & pf \\
\hline Coccinellidae & Hyperaspis sp. & 1 & $z$ & nd & $\mathbf{r}$ & pf \\
\hline Lagriidae & Lagria villosa Fabr. & 7 & $\mathbf{w}$ & nd & $\mathbf{c}$ & f \\
\hline \multicolumn{7}{|l|}{ Diptera } \\
\hline Dolichopodidae & Condylostylus sp. & 1 & $z$ & nd & $\mathbf{r}$ & pf \\
\hline Otitidae & Euxesta sp. & 1 & $\mathbf{z}$ & nd & $\mathbf{r}$ & $\mathrm{pf}$ \\
\hline \multicolumn{7}{|c|}{ Hemiptera - Auchenorrhyncha } \\
\hline Cicadellidae & Bucephalogonia xanthophis (Berg) & 45 & $\mathbf{y}$ & do & $\mathbf{m a}$ & $\mathbf{m f}$ \\
\hline Cicadellidae & Macugonalia leucomelas (Walk.) & 1 & $\mathbf{z}$ & nd & $r$ & pf \\
\hline Cicadellidae & Scaphitopius sp. & 13 & $\mathbf{y}$ & do & c & $\mathbf{f}$ \\
\hline Cicadellidae & Xerophloea sp. & 2 & $\mathbf{z}$ & nd & d & $\mathrm{pf}$ \\
\hline \multicolumn{7}{|c|}{ Hemiptera - Heteroptera } \\
\hline Alydidae & Alydus sp. & 1 & $\mathbf{z}$ & nd & $\mathbf{r}$ & pf \\
\hline Lygaeidae & Geocoris sp. & 35 & $\mathbf{w}$ & do & $\mathbf{m a}$ & $\mathbf{m f}$ \\
\hline Pentatomidae & Piezodorus guildinii West. & 8 & $\mathrm{y}$ & nd & c & f \\
\hline Pentatomidae & Thyanta perditor (Fabr.) & 3 & $z$ & nd & $\mathrm{d}$ & $\mathrm{pf}$ \\
\hline \multicolumn{7}{|l|}{ Hymenoptera } \\
\hline Apidae & Apis mellifera $\mathrm{L}$. & 2 & $\mathbf{z}$ & nd & d & pf \\
\hline $\begin{array}{l}\text { Hallictidae } \\
\text { Lepidoptera }\end{array}$ & Augochloropsis sp. & 2 & $z$ & nd & $\mathrm{d}$ & pf \\
\hline \multicolumn{6}{|l|}{ Mantodea } & pf \\
\hline $\begin{array}{l}\text { Mantidae } \\
\text { Neuroptera }\end{array}$ & Thesprotia macilenta Sauss. & 10 & $\mathbf{w}$ & nd & c & $\mathbf{f}$ \\
\hline Chrysopidae & Chrysoperla externa (Hagen) & 17 & $\mathbf{w}$ & do & $\mathbf{c}$ & f \\
\hline \multicolumn{7}{|l|}{ Orthoptera } \\
\hline Acrididae & Orphulella sp. & 3 & $z$ & nd & $\mathrm{d}$ & pf \\
\hline
\end{tabular}

Das espécies coletadas, 4 foram consideradas predominantes, sendo que $D$. speciosa; $P$. significata e Geocoris sp. 
foram classificadas como constantes, dominantes, muito abundantes e muito freqüentes, enquanto, $B$. xanthophis foi classificada como uma espécie dominante, muito abundante, muito freqüente mas, acessória.

Outras 5 espécies foram consideradas constantes, as quais foram C. sanguinea; Delphastus sp.; L. villosa; T. macilenta e C. externa enquanto, Scaphitopius sp. foi considerada uma espécie acessória.

As espécies mais freqüentes foram $D$. speciosa $(28,9 \%), B$. xanthophis $(15,1 \%)$ e $P$. significata $(14,1 \%)$.

\section{Apaga-fogo}

As espécies de insetos coletadas em apaga-fogo na entressafra do milho e a análise faunistica encontram-se na Tabela 14.

Foram realizadas 30 avaliaçōes em apaga-fogo na entressafra do milho e coletou-se 37 espécies e 523 individuos.

Com relação a constância encontrou-se 10 espécies constantes, 7 acessórias e 20 acidentais. Quanto a abundância e freqūência foram coletadas 6 espécies muito abundantes e muito freqüentes, 10 comuns e freqüentes e 21 raras e pouco freqüentes. Para a dominância, 10 espécies foram dominantes e 27 não dominantes.

Foram consideradas predominantes 6 espécies que foram $D$. speciosa; L. villosa; P. significata; Alydus sp.; T. perditor e Geocoris sp. Além destas, Delphastus sp.; B. xanthophis; $P$. guildinii e C. externa foram consideradas espécies constantes. Já Condylostylus sp.; $D$. continua; H. similis; Xerophloea sp.; A. mellifera; E. lignosellus e Orphulella sp. foram acessórias.

As espécies mais freqüentes foram $D$. speciosa $(20,3 \%)$, Geocoris sp. $(15,9 \%)$ e $L$. villosa $(12,8 \%)$. 
Tabela 14. Espécies coletadas e resultados da análise faunística dos insetos coletados em apaga-fogo com rede $\mathrm{e}$ cone entomológicos na entressafra do milho de 1997 e 1998 em Jaboticabal, SP.

\begin{tabular}{|c|c|c|c|c|c|c|}
\hline Familia & Espécie & Total & $\mathbf{C}$ & $\mathbf{D}$ & $\mathbf{A}$ & $\mathbf{F}$ \\
\hline \multicolumn{7}{|l|}{ Coleoptera } \\
\hline Chrysomelidae & Diabrotica sp. & 2 & $\mathbf{z}$ & nd & $\mathbf{r}$ & pf \\
\hline Chrysomelidae & Diabrotica speciosa Germ. & 106 & $\mathbf{w}$ & do & $\mathbf{m a}$ & $\mathbf{m f}$ \\
\hline Chrysomelidae & Dysonica sp. & 1 & $\mathbf{z}$ & nd & $\mathbf{r}$ & pf \\
\hline Chrysomelidae & Paranapiacaba significata (Gahn.) & 43 & $\mathbf{w}$ & do & $\mathbf{m a}$ & $\mathbf{m f}$ \\
\hline Coccinellidae & Cycloneda sanguinea (L.) & 4 & $z$ & nd & $\mathbf{r}$ & $\mathrm{pf}$ \\
\hline Coccinellidae & Delphastus sp. & 12 & $\mathbf{w}$ & nd & c & f \\
\hline Coccinellidae & Eriopis connexa (Germ.) & 1 & $z$ & nd & $\mathrm{r}$ & pf \\
\hline Coccinellidae & Hyperaspis notata (Muls.) & 1 & $\mathbf{z}$ & nd & $r$ & pf \\
\hline Dasytidae & Astylus variegatus Germ. & 1 & $z$ & nd & r) & pf \\
\hline Lagriidae & Lagria villosa Fabr. & 67 & $\mathbf{w}$ & do & $\mathbf{m a}$ & $\mathbf{m f}$ \\
\hline \multicolumn{7}{|l|}{ Diptera } \\
\hline Dolichopodidae & Condylostylus sp. & 10 & $\mathrm{y}$ & nd & c & f \\
\hline \multicolumn{7}{|c|}{ Hemiptera - Auchenorrhyncha } \\
\hline Cicadellidae & Bucephalogonia xanthophis (Berg) & 15 & $\mathbf{w}$ & do & c & $\mathbf{f}$ \\
\hline Cicadellidae & Diedrocephala continua Sak.8Cav. & 9 & $\mathrm{y}$ & nd & c & $\mathbf{f}$ \\
\hline Cicadellidae & Hortensia similis (Walk.) & 14 & $\mathrm{y}$ & nd & c & $\mathbf{f}$ \\
\hline Cicadellidae & Macugonalia leucomelas (Walk.) & 2 & $\mathbf{z}$ & nd & $\mathbf{r}$ & pf \\
\hline Cicadellidae & Scaphitopius sp. & 3 & $z$ & nd & $\mathbf{r}$ & pf \\
\hline Cicadellidae & Xerophloea sp. & 10 & $\mathrm{y}$ & nd & $\mathbf{c}$ & $\mathbf{f}$ \\
\hline Membracidae & Cyphonia clavata (Fabr.) & 2 & $z$ & nd & $\mathrm{r}$ & pf \\
\hline \multicolumn{7}{|c|}{ Hemiptera - Heteroptera } \\
\hline Alydidae & Alydus sp. & 25 & $\mathbf{w}$ & do & $\mathbf{m a}$ & $\mathbf{m f}$ \\
\hline Alydidae & Leptocoriza tipuloides (DeGeer) & 1 & $\mathbf{z}$ & nd & $\mathrm{r}$ & pf \\
\hline Coreidae & Zica sp. & 1 & $\mathbf{z}$ & nd & $\mathbf{r}$ & $\mathrm{pf}$ \\
\hline Largidae & Lygaeus alboornatus (Blanch.) & 1 & $\mathrm{z}$ & nd & $r$ & $\mathrm{pf}$ \\
\hline Lygaeidae & Geocoris sp. & 83 & $\mathbf{w}$ & do & $\mathbf{m a}$ & $\mathbf{m f}$ \\
\hline Pentatomidae & Acrosternum hilare (Say) & 2 & $\mathbf{z}$ & nd & $\mathbf{r}$ & pf \\
\hline Pentatomidae & Piezodorus guildinii West. & 15 & $\mathbf{w}$ & do & c & $\mathbf{f}$ \\
\hline Pentatomidae & Podisus sp. & 1 & $z$ & nd & $\mathrm{r}$ & pf \\
\hline Pentatomidae & Thyanta perditor (Fabr.) & 29 & $\mathbf{w}$ & do & $\mathbf{m a}$ & $\mathbf{m f}$ \\
\hline Pyrrhocoridae & Dysdercus sp. & 1 & $z$ & nd & $\mathrm{r}$ & pf \\
\hline \multicolumn{7}{|l|}{ Hymenoptera } \\
\hline Apidae & Apis mellifera $\mathrm{L}$ & 18 & $\mathrm{y}$ & do & c & $\mathbf{f}$ \\
\hline Apidae & Trigona spinipes (Fabr.) & 2 & $\mathrm{z}$ & nd & $r$ & pf \\
\hline Vespidae & Polybia sp. & 2 & $z$ & nd & $\mathbf{r}$ & pf \\
\hline \multicolumn{7}{|l|}{ Lepidoptera } \\
\hline Pyralidae & Diatraea sp. & 2 & 2 & nd & $\mathbf{r}$ & pf \\
\hline
\end{tabular}




\begin{tabular}{llccccc} 
Familia & Espécie & Total & C & D & A & F \\
\hline $\begin{array}{l}\text { Pyralidae } \\
\begin{array}{l}\text { Pyralidae } \\
\text { Mantodea }\end{array}\end{array}$ & $\begin{array}{l}\text { Desmia melanopalis Hamps. } \\
\text { Elasmopalpus lignosellus (Zeller) }\end{array}$ & 4 & y & nd & r & pf \\
$\begin{array}{l}\text { Mantidae } \\
\text { Neuroptera }\end{array}$ & Thesprotia macilenta Sauss. & 1 & z & nd & r & pf \\
$\begin{array}{l}\text { Chrysopidae } \\
\text { Orthoptera }\end{array}$ & Chrysoperla externa (Hagen) & 19 & w & do & c & f \\
Acrididae & Orphulella sp. & 12 & y & nd & c & f \\
\hline
\end{tabular}

\section{Carrapicho-de-carneiro}

As espécies de insetos coletadas em carrapicho-de-carneiro na entressafra do milho e a análise faunistica encontram-se na Tabela 15.

Foram realizadas 11 avaliações em carrapicho-de-carneiro na entressafra do milho de 98 e coletou-se 23 espécies e 88 individuos.

Com relação a constância coletou-se 6 espécies constantes, 8 acessórias e 9 acidentais. Quanto a abundância e freqüência, 6 espécies foram muito abundantes e muito freqũentes, 6 comuns e freqüentes e 11 raras e pouco freqüentes. Para o indice de dominância encontrou-se 12 espécies dominantes e 11 não dominantes.

Destas espécies, 6 foram consideradas predominantes, sendo que Delphastus sp.; D. speciosa; D. continua; Xerophloea sp. e Alydus sp. foram classificadas como constantes, dominantes, muito abundantes e muito freqüentes, enquanto $H$. similis foi dominante, muito abundante, muito freqüente mas, acessória.

P. guildinii foi classificado como uma espécie constante e, Aphodius sp.; C. sanguinea; B. xanthophis; M. leucomelas; Scaphitopius sp.; T. macilenta e Orphulella sp. como espécies acessórias. A espécie mais freqüente foi $D$. continua $(15,9 \%)$. 
Tabela 15. Espécies coletadas e resultados da análise faunística dos insetos coletados em carrapicho-de-carneiro com rede e cone entomológicos na entressafra do milho de 1998 em Jaboticabal, SP.

\begin{tabular}{|c|c|c|c|c|c|c|}
\hline Família & Espécie & Total & $\mathbf{C}$ & $\mathbf{D}$ & $\mathbf{A}$ & $\mathbf{F}$ \\
\hline \multicolumn{7}{|l|}{ Coleoptera } \\
\hline Chrysomelidae & Diabrotica speciosa Germ. & 7 & $\mathbf{w}$ & do & $\mathbf{m a}$ & $\mathbf{m f}$ \\
\hline Coccinellidae & Cycloneda sanguinea (L.) & 5 & $\mathrm{y}$ & do & c & f \\
\hline Coccinellidae & Delphastus sp. & 6 & $\mathbf{w}$ & do & $\mathbf{m a}$ & $\mathbf{m f}$ \\
\hline Coccinellidae & Hyperaspis sp. & 1 & $\mathbf{z}$ & nd & $\mathrm{r}$ & pf \\
\hline Lagriidae & Lagria villosa Fabr. & 1 & $z$ & nd & $\mathbf{r}$ & pf \\
\hline Scarabaeidae & Aphodius sp. & 2 & $\mathrm{y}$ & nd & $\mathbf{r}$ & pf \\
\hline \multicolumn{7}{|l|}{ Diptera } \\
\hline Dolichopodidae & Condylostylus sp. & 1 & $z$ & nd & $\mathbf{r}$ & pf \\
\hline \multicolumn{7}{|c|}{ Hemiptera - Auchenorrhyncha } \\
\hline Cicadellidae & Bucephalogonia xanthophis (Berg) & 4 & $\mathrm{y}$ & do & c & f \\
\hline Cicadellidae & Diedrocephala continua Sak.84Cav. & 14 & $\mathbf{w}$ & do & $\mathbf{m a}$ & mf \\
\hline Cicadellidae & Hortensia similis(Walk.) & 7 & $\mathbf{y}$ & do & $\mathbf{m a}$ & $\mathbf{m f}$ \\
\hline Cicadellidae & Macugonalia leucomelas (Walh.) & 2 & $\mathrm{y}$ & nd & $r$ & $\mathrm{pf}$ \\
\hline Cicadellidae & Scaphitopius sp. & 5 & $\mathrm{y}$ & do & c & f \\
\hline Cicadellidae & Xerophloea sp. & 7 & $\mathbf{w}$ & do & $\mathbf{m a}$ & $\mathbf{m f}$ \\
\hline Membracidae & Cyphonia clavata (Fabr.) & 1 & $\mathbf{z}$ & nd & $\mathbf{r}$ & pf \\
\hline \multicolumn{7}{|c|}{ Hemiptera - Heteroptera } \\
\hline Alydidae & Alydus sp. & 7 & $\mathbf{w}$ & do & $\mathbf{m a}$ & $\mathbf{m f}$ \\
\hline Coreidae & Zica sp. & 1 & $\mathbf{z}$ & nd & $\mathbf{r}$ & pf \\
\hline Lygaeidae & Geocoris sp. & 1 & $\mathbf{z}$ & nd & $\mathbf{r}$ & $\mathrm{pf}$ \\
\hline Pentatomidae & Piezodorus guildinii West. & 4 & w & do & c & f \\
\hline \multicolumn{7}{|l|}{ Hymenoptera } \\
\hline Apidae & Apis mellifera $\mathrm{L}$. & 1 & $z$ & nd & $\mathbf{r}$ & pf \\
\hline Hallictidae & Augochloropsis sp. & 1 & $z$ & nd & $\mathbf{r}$ & $\mathrm{pf}$ \\
\hline \multicolumn{7}{|l|}{ Mantodea } \\
\hline \multicolumn{6}{|l|}{ Neuroptera } & f \\
\hline Chrysopidae & Chrysoperla externa (Hagen) & 2 & $z$ & nd & $\mathbf{r}$ & pf \\
\hline \multicolumn{7}{|l|}{ Orthoptera } \\
\hline Acrididae & Orphulella sp. & 4 & $\mathrm{y}$ & do & c & f \\
\hline
\end{tabular}

Esta planta daninha foi uma importante hospedeira de cigarrinhas. Carrapicho-de-carneiro não esteve presente durante todo o periodo em que ocorreram os levantamentos e foi uma planta que 
abrigou menor número de insetos, no entanto, a maioria dos insetos que ocorreram foram pragas.

\section{Falsa-serralha}

As espécies de insetos coletadas em falsa-serralha na entressafra do milho e a análise faunística encontram-se na Tabela 16.

Foram realizadas 12 avaliações em falsa-serralha na entressafra do milho de 98 e coletou-se 29 espécies e 144 indivíduos.

Para a constância foram coletadas 8 espécies constantes, 6 acessórias e 15 acidentais. Com relação a abundância e freqüência encontrou-se 4 espécies muito abundantes e muito freqüentes, 12 comuns e freqüentes e 13 raras e pouco freqüentes. Quanto a dominância, 11 espécies foram dominantes e 18 não dominantes.

Destas, foram predominantes C. sanguinea; $D$. speciosa; $B$. xanthophis e T. perditor. Outras 4 espécies foram consideradas constantes e 6 foram acessórias, as quais foram respectivamente Delphastus sp.; D. continua; A. mellifera; Orphulella sp. e L. villosa; $P$. significata; $H$. similis; $M$. leucomelas; Alydus sp. e C. externa.

As espécies mais freqūentes foram $B$. xanthophis $(20,8 \%), D$. speciosa $(11,8 \%)$ e C. sanguinea $(9,03 \%)$.

Observou-se que esta planta daninha hospedou diversas pragas, entre elas merece destaque as cigarrinhas $B$. xanthophis; $D$. continua; $H$. similis e $M$. leucomelas. Estes insetos são citados como importantes vetores da bactéria Xylella fastidiosa, que causa a clorose variegada do citros (CVC). Yamamoto \& Gravena (1998) relataram que muitas dessas espécies foram coletadas tanto na vegetação invasora quanto em laranjeira, sendo que algumas predominam na vegetação invasora. 
Tabela 16. Espécies coletadas e resultados da análise faunistica dos insetos coletados em falsa-serralha com rede $\mathrm{e}$ cone entomológicos na entressafra do milho de $1998 \mathrm{em}$ Jaboticabal, SP.

\begin{tabular}{|c|c|c|c|c|c|c|}
\hline Familia & Espécie & Total & $\mathbf{C}$ & $\mathbf{D}$ & $\mathbf{A}$ & $\mathbf{F}$ \\
\hline \multicolumn{7}{|l|}{ Coleoptera } \\
\hline Chrysomelidae & Diabrotica speciosa Germ. & 17 & $\mathbf{w}$ & do & $\mathbf{m a}$ & $\mathbf{m f}$ \\
\hline Chrysomelidae & Paranapiacaba significata (Gahn.) & 5 & $\mathrm{y}$ & do & c & $\mathbf{f}$ \\
\hline Coccinellidae & Cycloneda sanguinea (L.) & 13 & $\mathbf{w}$ & do & $\mathbf{m a}$ & $\mathbf{m f}$ \\
\hline Coccinellidae & Delphastus sp. & 5 & $\mathbf{w}$ & do & c & $\mathbf{f}$ \\
\hline Coccinellidae & Eriopis connexa (Germ.) & 2 & $\mathbf{z}$ & nd & $\mathbf{r}$ & $\mathrm{pf}$ \\
\hline Lagriidae & Lagria villosa Fabr. & 6 & $\mathrm{y}$ & do & c & f \\
\hline \multicolumn{7}{|l|}{ Diptera } \\
\hline Dolichopodidae & Condylostylus sp. & 1 & $z$ & nd & $\mathrm{r}$ & $\mathrm{pf}$ \\
\hline Otitidae & Euxesta sp. & 1 & $z$ & nd & $r$ & pf \\
\hline \multicolumn{7}{|c|}{ Hemiptera - Auchenorrhyncha } \\
\hline Cicadellidae & Bucephalogonia xanthophis (Berg) & 30 & $\mathbf{w}$ & do & $\mathbf{m a}$ & $\mathbf{m f}$ \\
\hline Cicadellidae & Diedrocephala continua Sak.8Cav. & 5. & $\mathbf{w}$ & do & c & f \\
\hline Cicadellidae & Hortensia similis (Walk.) & 5 & $\mathbf{y}$ & do & c & $\mathbf{f}$ \\
\hline Cicadellidae & Macugonalia leucomelas (Walk.) & 4 & $\mathrm{y}$ & nd & c & $\mathbf{f}$ \\
\hline Cicadellidae & Scaphitopius sp. & 2 & $\mathbf{z}$ & nd & $\mathbf{r}$ & pf \\
\hline Cicadellidae & Xerophloea sp. & 2 & $z$ & nd & $\mathbf{r}$ & $\mathrm{pf}$ \\
\hline \multicolumn{7}{|c|}{ Hemiptera - Heteroptera } \\
\hline Alydidae & Alydus sp. & 5 & $\mathrm{y}$ & do & c & $\mathbf{f}$ \\
\hline Alydidae & Leptocoriza tipuloides (DeGeer) & 1 & $\mathbf{z}$ & nd & $r$ & $\mathrm{pf}$ \\
\hline Largidae & Lygaeus alboornatus (Blanch.) & 5 & $z$ & do & c & f \\
\hline Lygaeidae & Geocoris sp. & 1 & $z$ & nd & $\mathbf{r}$ & pf \\
\hline Pentatomidae & Piezodorus guildinii West. & 2 & $\mathbf{z}$ & nd & $\mathbf{r}$ & $\mathrm{pf}$ \\
\hline Pentatomidae & Thyanta perditor (Fabr.) & 9 & $\mathbf{w}$ & do & $\mathbf{m a}$ & $\mathbf{m f}$ \\
\hline $\begin{array}{l}\text { Pyrrhocoridae } \\
\text { Hymenoptera }\end{array}$ & Dysdercus sp. & 1 & $\mathbf{z}$ & nd & $\mathbf{r}$ & $\mathrm{pf}$ \\
\hline Andrenidae & Exomalopsis sp. & 1 & $\mathbf{z}$ & nd & $\mathbf{r}$ & pf \\
\hline Apidae & Apis mellifera $\mathrm{L}$. & 4 & $\mathbf{w}$ & nd & c & f \\
\hline Apidae & Trigona spinipes (Fabr.) & 2 & $\mathbf{z}$ & nd & $\mathbf{r}$ & pf \\
\hline Vespidae & Polybia sp. & 2 & $\mathbf{z}$ & nd & $\mathrm{r}$ & pi \\
\hline \multicolumn{7}{|l|}{ Lepidoptera } \\
\hline Pyralidae & Diatraea sp. & 3 & $\mathbf{z}$ & nd & c & $\mathbf{f}$ \\
\hline \multicolumn{7}{|l|}{ Mantodea } \\
\hline Mantidae & Thesprotia macilenta Sauss. & 2 & $\mathbf{z}$ & nd & $\mathbf{r}$ & pf \\
\hline \multicolumn{7}{|l|}{ Neuroptera } \\
\hline Chrysopidae & Chrysoperla externa (Hagen) & 4 & $\mathrm{y}$ & nd & c & $\mathbf{f}$ \\
\hline \multicolumn{7}{|l|}{ Orthoptera } \\
\hline Acrididae & Orphulella sp. & 4 & $\mathbf{w}$ & nd & c & $\mathbf{f}$ \\
\hline
\end{tabular}




\section{Nabiça}

As espécies de insetos coletadas em nabiça na entressafra do milho e a análise faunistica encontram-se na Tabela 17.

Foram realizadas 15 avaliações em nabiça na entressafra do milho de 98 e coletou-se 28 espécies e 372 individuos.

Com relação a constância, 5 espécies foram constantes, 13 acessórias e 10 acidentais. Para a abundância e freqūência, 5 espécies foram muito abundantes e muito freqūentes, 13 comuns e freqüentes e 10 pouco freqüentes, sendo 3 dispersas e 7 raras. Quanto a dominância, 5 espécies foram dominantes e 23 não dominantes.

Destas espécies, 5 foram consideradas predominantes: $C$. sanguinea; $D$. speciosa; $P$. significata; $B$. xanthophis e A. mellifera. Outras 13 espécies foram classificadas como acessórias, as quais foram Delphastus sp.; E. connexa; L. villosa; D. continua; M. leucomelas; Xerophloea sp.; Scaphitopius sp.; Alydus sp.; Polybia sp.; T. spinipes; T. macilenta; C. externa e Orphulella sp.

As espécies mais freqüentes foram $A$. mellifera $(28,0 \%), D$. speciosa $(14,25 \%)$ e $P$. significata $(11,3 \%)$.

Observou-se que nabiça hospedou um grande número de insetos, principalmente quando atingiu o estádio de florescimento. Esta planta foi muito visitada por A. mellifera, provavelmente porque serve como fonte de néctar e pólen para este inseto. 
Tabela 17. Espécies coletadas e resultados da análise faunistica dos insetos coletados em nabiça com rede e cone entomológicos na entressafra do milho de 1998 em Jaboticabal, SP.

\begin{tabular}{|c|c|c|c|c|c|c|}
\hline Familia & Espécie & Total & $\mathbf{C}$ & $\mathbf{D}$ & $\mathbf{A}$ & $\mathbf{F}$ \\
\hline \multicolumn{7}{|l|}{ Coleoptera } \\
\hline Chrysomelidae & Diabrotica speciosa Germ. & 53 & $\mathbf{w}$ & do & $\mathbf{m a}$ & $\mathbf{m f}$ \\
\hline Chrysomelidae & Paranapiacaba significata (Gahn.) & 42 & $\mathbf{w}$ & do & $\mathbf{m a}$ & $\mathbf{m f}$ \\
\hline Coccinellidae & Cycloneda sanguinea (L.) & 33 & $\mathbf{w}$ & do & $\mathbf{m a}$ & $\mathbf{m f}$ \\
\hline Coccinellidae & Delphastus sp. & 7 & $\mathrm{y}$ & nd & c & $\mathbf{f}$ \\
\hline Coccinellidae & Eriopis connexa (Germ.) & 7 & $\mathrm{y}$ & nd & c & $\mathbf{f}$ \\
\hline Coccinellidae & Olla v-nigrum (Muls.) & 1 & $z$ & nd & $\mathrm{r}$ & $\mathrm{pf}$ \\
\hline Dasytidae & Astylus variegatus Germ. & 1 & $z$ & nd & $\mathrm{r}$ & $\mathrm{pf}$ \\
\hline Lagriidae & Lagria villosa Fabr. & 12 & $\mathrm{y}$ & nd & c & f \\
\hline \multicolumn{7}{|l|}{ Diptera } \\
\hline Dolichopodidae & Condylostylus sp. & 1 & $z$ & nd & $\mathbf{r}$ & pf \\
\hline \multicolumn{7}{|c|}{ Hemiptera - Auchenorrhyncha } \\
\hline Cicadellidae & Bucephalogonia xanthophis (Berg) & 39 & $\mathbf{w}$ & do & $\mathbf{m a}$ & $\mathbf{m f}$ \\
\hline Cicadellidae & Diedrocephala continua Sak.8Cav. & 5 & $\mathbf{y}$ & nd & $\mathrm{c}$ & f \\
\hline Cicadellidae & Hortensia similis (Walk.) & 3 & $\boldsymbol{Z}$ & nd & $\mathrm{d}$ & pf \\
\hline Cicadellidae & Macugonalia leucomelas (Walk.) & 5 & $\mathrm{y}$ & nd & c & f \\
\hline Cicadellidae & Scaphitopius sp. & 6 & $\mathrm{y}$ & nd & c & $\mathbf{f}$ \\
\hline Cicadellidae & Xerophloea sp. & 5 & $\mathrm{y}$ & nd & c & $\mathbf{f}$ \\
\hline Membracidae & Cyphonia clavata (Fabr.) & 1 & 2 & nd & $\mathrm{r}$ & pf \\
\hline \multicolumn{7}{|c|}{ Hemiptera - Heteroptera } \\
\hline Alydidae & Alydus sp. & 6 & $\mathrm{y}$ & nd & c & $\mathbf{f}$ \\
\hline Pentatomidae & Acrosternum hilare (Say) & 3 & $\mathbf{z}$ & nd & $\mathrm{d}$ & $\mathrm{pf}$ \\
\hline Pentatomidae & Podisus sp. & 1 & $z$ & nd & $\mathrm{r}$ & pf \\
\hline Pentatomidae & Thyanta perditor (Fabr.) & 4 & $z$ & nd & $\mathrm{d}$ & $\mathrm{pf}$ \\
\hline \multicolumn{7}{|l|}{ Hymenoptera } \\
\hline Andrenidae & Exomalopsis sp. & 2 & $z$ & nd & $\mathrm{r}$ & pf \\
\hline Apidae & Apis mellifera $\mathrm{L}$ & 104 & $\mathbf{w}$ & do & $\mathbf{m a}$ & $\mathbf{m f}$ \\
\hline Apidae & Trigona spinipes (Fabr.) & 5 & $\mathrm{y}$ & nd & $\mathrm{c}$ & $\mathbf{f}$ \\
\hline Vespidae & Polybia sp. & 6 & $\mathrm{y}$ & nd & c & $\mathrm{f}$ \\
\hline \multicolumn{7}{|l|}{ Lepidoptera } \\
\hline Pyralidae & Diatraea sp. & 1 & $z$ & nd & $\mathbf{r}$ & pf \\
\hline \multicolumn{7}{|l|}{ Mantodea } \\
\hline Mantidae & Thesprotia macilenta Sauss. & 5 & $\mathrm{y}$ & nd & c & f \\
\hline \multicolumn{7}{|l|}{ Neuroptera } \\
\hline Chrysopidae & Chrysoperla externa (Hagen) & 9 & $\mathrm{y}$ & nd & c & $\mathbf{f}$ \\
\hline \multicolumn{7}{|l|}{ Orthoptera } \\
\hline Acrididae & Orphulella sp. & 5 & $\mathrm{y}$ & nd & c & f \\
\hline
\end{tabular}


Além dos insetos listados, foram coletados também nesta planta daninha diversos pulgões e alguns tripes. Estes insetos não foram identificados, mas assumem um importante papel visto que causam danos as culturas, além de serem vetores de virus. Lima (1997) relatou que espécies de tripes estão comumente associadas com nabiça e outras plantas daninhas. Relatou ainda que na entressafra do amendoim diversos tripes utilizam as plantas daninhas como hospedeiras. De modo geral, esses tripes foram encontrados no estádio vegetativo da planta daninha, fato também observado por Faifer (1986) em apaga-fogo.

\section{Anileira}

As espécies de insetos coletadas em anileira na entressafra do milho e a análise faunística encontram-se na Tabela 18.

Foram realizadas 15 avaliaçōes em anileira na entressafra do milho de 98 e coletou-se 29 espécies e 277 indivíduos.

Encontrou-se 10 espécies constantes, 8 acessórias e 11 acidentais. Com relação a abundância e freqüência, 6 foram muito freqüentes, sendo 5 muito abundantes e 1 abundante; 9 comuns e freqüentes e 14 pouco freqüentes, sendo 4 dispersas e 10 raras. Para a dominância, 11 espécies foram dominantes e 18 não dominantes.

Destas, 6 foram consideradas predominantes que foram $C$. sanguinea; Delphastus sp.; D. speciosa; B. xanthophis; Alydus sp. e P. guildinii. No entanto, D. continua; $H$. similis; Scaphitopius sp. e $C$. externa foram classificadas como espécies constantes. Já $P$. significata; M. leucomelas; Xerophloea sp.; Geocoris sp.; T. perditor, A. mellifera; T. macilenta e Orphulella sp. foram classificadas como espécies acessórias. 
Tabela 18. Espécies coletadas e resultados da análise faunistica dos insetos coletados em anileira com rede e cone entomológicos na entressafra do milho de 1998 em Jaboticabal, SP.

\begin{tabular}{|c|c|c|c|c|c|c|}
\hline Família & Espécie & Total & $\mathbf{C}$ & $\mathbf{D}$ & $\mathbf{A}$ & $\mathbf{F}$ \\
\hline \multicolumn{7}{|l|}{ Coleoptera } \\
\hline Chrysomelidae & Diabrotica speciosa Germ. & 20 & $\mathbf{w}$ & do & $\mathbf{m a}$ & $\mathbf{m f}$ \\
\hline Chrysomelidae & Paranapiacaba significata (Gahn.) & 4 & $\mathbf{y}$ & nd & $\mathrm{d}$ & $\mathrm{pf}$ \\
\hline Coccinellidae & Cycloneda sanguinea (L.) & 20 & $\mathbf{w}$ & do & $\mathbf{m a}$ & $\mathbf{m f}$ \\
\hline Coccinellidae & Delphastus sp. & 15 & $\mathbf{w}$ & do & $\mathbf{a}$ & $\mathbf{m f}$ \\
\hline Coccinellidae & Hyperaspis sp. & 1 & $\mathbf{z}$ & nd & $\mathrm{r}$ & $\mathrm{pf}$ \\
\hline Dasytidae & Astylus variegatus Germ. & 1 & $\mathbf{z}$ & nd & $\mathrm{r}$ & pf \\
\hline Lagriidae & Lagria villosa Fabr. & 4 & $z$ & nd & $\mathrm{d}$ & $\mathrm{pf}$ \\
\hline \multicolumn{7}{|c|}{ Hemiptera - Auchenorrhyncha } \\
\hline Cicadellidae & Bucephalogonia xanthophis (Berg) & 58 & $\mathbf{w}$ & do & $\mathbf{m a}$ & $\mathbf{m f}$ \\
\hline Cicadellidae & Diedrocephala continua Sak. ${ }^{8} \mathrm{Cav}$. & 13 & $\mathbf{w}$ & do & $\mathrm{c}$ & f \\
\hline Cicadellidae & Hortensia similis (Walk.) & 9 & w & nd & c & f \\
\hline Cicadellidae & Macugonalia leucomelas (Walk.) & 6 & $\mathrm{y}$ & nd & c & $\mathbf{f}$ \\
\hline Cicadellidae & Scaphitopius sp. & 8 & $\mathrm{w}$ & nd & c & $\mathbf{f}$ \\
\hline Cicadellidae & Xerophloea sp. & 5 & $\mathbf{y}$ & nd & $\mathrm{d}$ & $\mathrm{pf}$ \\
\hline Membracidae & Cyphonia clavata (Fabr.) & 1 & $z$ & nd & $r$ & $\mathrm{pf}$ \\
\hline \multicolumn{7}{|c|}{ Hemiptera - Heteroptera } \\
\hline Alydidae & Alydus sp. & 21 & $\mathbf{w}$ & do & $\mathbf{m a}$ & $\mathbf{m f}$ \\
\hline Largidae & Lygaeus alboornatus (Blanch.) & 1 & $z$ & nd & $\mathrm{r}$ & $\mathrm{pf}$ \\
\hline Lygaeidae & Geocoris sp. & 11 & $\mathbf{y}$ & do & c & f \\
\hline Pentatomidae & Acrosternum hilare (Say) & 1 & $z$ & nd & $\mathrm{r}$ & pf \\
\hline Pentatomidae & Piezodorus guildinii West. & 24 & $\mathbf{w}$ & do & $\mathbf{m a}$ & $\mathbf{m f}$ \\
\hline Pentatomidae & Podisus sp. & 1 & $z$ & nd & $r$ & pf \\
\hline Pentatomidae & Thyanta perditor (Fabr.) & 10 & $\mathbf{y}$ & do & c & f \\
\hline \multicolumn{7}{|l|}{ Hymenoptera } \\
\hline Apidae & Apis mellifera L. & 8 & $\mathrm{y}$ & nd & c & $\mathbf{f}$ \\
\hline Vespidae & Polybia sp. & 1 & $\mathbf{z}$ & nd & $\mathrm{r}$ & pf \\
\hline \multicolumn{7}{|l|}{ Lepidoptera } \\
\hline Noctuidae & Bagisara subusta Hüeb. & 1 & $z$ & nd & $\mathbf{r}$ & pf \\
\hline Pyralidae & Diatraea sp. & 2 & $z$ & nd & $\mathrm{r}$ & pf \\
\hline $\begin{array}{l}\text { Pyralidae } \\
\text { Mantodea }\end{array}$ & Elasmopalpus lignosellus (Zeller) & 2 & $z$ & nd & $\mathrm{r}$ & $\mathrm{pf}$ \\
\hline $\begin{array}{l}\text { Mantidae } \\
\text { Neuroptera }\end{array}$ & Thesprotia macilenta Sauss. & 5 & $\mathrm{y}$ & nd & $\mathrm{d}$ & pf \\
\hline $\begin{array}{l}\text { Chrysopidae } \\
\text { Orthoptera }\end{array}$ & Chrysoperla externa (Hagen) & 13 & $\mathbf{w}$ & do & c & $\mathrm{f}$ \\
\hline Acrididae & Orphulella sp. & 11 & $\mathrm{y}$ & do & c & $\mathbf{f}$ \\
\hline
\end{tabular}


As espécies mais freqüentes foram B. xanthophis $(20,9 \%)$ e Alydus sp. $(7,6 \%)$.

Analisando-se os insetos coletados em plantas daninhas durante a entressafra do milho, observou-se que as plantas que hospedaram o maior número de insetos foram apaga-fogo e nabiça. Já rabo-de-foguete e carrapicho-de-carneiro hospedaram o menor número. Apaga-fogo foi a planta daninha em que se coletou o maior número de espécies, ou seja, 39 espécies.

Com relação aos insetos coletados, as pragas predominantes na área foram $D$. speciosa; L. villosa; $P$. significata; $B$. xanthophis; $D$. continua e Xerophloea sp. Quanto aos inimigos naturais, Delphastus sp.; C. sanguinea e Geocoris sp. foram as espécies predominantes.

Quanto as espécies predominantes encontradas nas diferentes plantas daninhas, apaga-fogo, carrapicho-de-carneiro e anileira apresentaram o maior número, com 6 espécies cada. Já a planta daninha que apresentou o menor número de espécies predominantes foi rabo-de-foguete, com apenas 3 espécies.

Nascente et al. (1998) investigaram a riqueza das espécies de artrópodes na cultura do tomate consorciado com plantas daninhas e observaram que entre os herbivoros, $S$. frugiperda; $H$. zea e os coleópteros $D$. speciosa e $L$. villosa, foram os mais abundantes. Já entre os inimigos naturais, C. externa foi o predador mais freqüente.

Dentre as espécies coletadas, $D$. speciosa foi a única espécie que foi predominante em todas as plantas daninhas avaliadas. De um modo geral, as plantas daninhas hospedaram diversos insetos na entressafra da cultura do milho, principalmente insetos-praga, dentre os quais encontraram-se importantes vetores de doenças. Assim, os insetos que ocorreram na entressafra do milho podem estar utilizando as 
plantas daninhas como hospedeiras e mantendo o potencial de ataque na próxima estação.

\subsection{Comparação das áreas de soja e milho com relação aos insetos coletados nas plantas daninhas}

Comparando-se as áreas de soja e milho, com relação aos insetos coletados nas plantas daninhas durante a entressafra, observouse que houve uma diferença numérica muito grande de uma área para a outra, ou seja, enquanto na área de soja coletou-se 5.565 insetos, na área de milho foram 1.775. Assim, pode-se dizer que as plantas daninhas hospedaram mais insetos durante a entressafra da soja que do milho.

De maneira geral, pode-se constatar que plantas daninhas pertencentes a mesma família não hospedam as mesmas espécies de insetos e que insetos considerados pragas de uma determinada cultura, não necessariamente procuram hospedar-se na planta daninha da mesma família da cultura.

Com relação as cigarrinhas, observou-se que na ârea do milho coletou-se mais insetos que na área da soja. Estes merecem especial atenção pois, algumas espécies são vetores potenciais da clorose variegada dos citros, doença causada pela bactéria $X$. fastidiosa que vem causando grandes prejuizos. Yamamoto (1996) relata que as espécies $H$. similis, $B$. xanthophis, $M$. leucomelas e $D$. continua são capturadas também na vegetação invasora do pomar. Assim, estas espécies podem utilizar as plantas daninhas como hospedeiras.

Observou-se a ocorrência da cigarrinha-do-milho, Dalbulus maidis, em bandejas d'água na área da soja e do milho, o que pode ser explicado pelo fato de que esses insetos são atraidos pela coloração 
amarela. Interessante foi a ocorrência deste inseto em apaga-fogo na área do milho e em crotalária, guanxuma e anileira na área da soja, principalmente em guanxuma. Esses insetos foram coletados em número muito pequeno, mas considerando que o milho é o único hospedeiro natural conhecido para este inseto no Brasil (Oliveira, 1996), maiores estudos são necessários, pois talvez eles possam utilizar algumas plantas daninhas como possiveis refúgios naturais durante a entressafra. Power (1987) relatou que a densidade e a diversidade das plantas afetam a abundância e o comportamento de migração deste inseto.

Os percevejos da soja são insetos herbivoros que exploram um grande número de plantas. De acordo com a literatura são pragas típicas de partes reprodutivas de leguminosas (flores, vagens, etc.). Assim, a presença das plantas daninhas, longe de dificultar $o$ estabelecimento dos percevejos, poderia funcionar de maneira inversa, visto que estas plantas florescem e frutificam num menor tempo. Nesta situação, a presença de leguminosas, não só poderia facilitar o encontro da planta hospedeira pelos percevejos, como também, proporcionar condições para que estes permanecessem na área até que a cultura iniciasse o florescimento e frutificação. A densidade populacional destes herbivoros poderia ser alta no momento mais critico da cultura à ação destes insetos, isto poderia não acontecer em áreas onde as plantas daninhas não estivessem presentes durante a entressafra. Fato semelhante também foi observado por Silva (1996).

Podem ocorrer as seguintes situações na interação inseto, plantas daninhas e cultura: a planta daninha funciona como hospedeiro intermediário ou hospedeiro de entressafra para muitas culturas, principalmente as anuais; ao atacar a planta daninha a praga deixa de atacar a cultura e pode surgir a possibilidade de evasão hospedeira; 
dentro dos atuais conceitos de Manejo Integrado de Pragas a planta daninha forneceria alimento aos inimigos naturais atravês do néctar e pólen de suas flores e ao hospedar o inseto-praga facilitaria a criação dos inimigos naturais funcionando como criatório e repositório de inimigos naturais. Assim quando estuda-se esta interação surgem indagações ou interrogações de dificil resposta. A melhor resposta é reconhecer a necessidade de mais pesquisas como meio de aumentar o nivel de conhecimento nesta área.

De um modo geral, as plantas daninhas hospedaram diversos insetos na entressafra da cultura da soja e do milho, tanto pragas como inimigos naturais. Diversas pragas de importância econômica encontraram nas plantas daninhas abrigo durante a entressafra, fato este que merece maiores estudos, pois estas plantas podem exercer um papel de extrema importância, ou seja, abrigam as pragas enquanto a cultura não se encontra no campo, mantendo assim a população destes insetos. No entanto, algumas plantas foram importantes como hospedeiras de inimigos naturais, podendo ser considerada de grande importância no manejo integrado de pragas.

Dessa forma, visando reduzir a aplicação abusiva de herbicidas e os custos de produção, bem como os problemas que vem surgindo de resistência de plantas daninhas aos herbicidas e pensando num manejo integrado de diversas pragas, a área que estuda os insetos em plantas daninhas merece maior atenção, visto que elas podem hospedar diversos insetos, pragas e inimigos naturais, tanto quando a cultura se encontra no campo, como durante a entressafra, servindo de hospedeiras para vários insetos. Além disso, diversos estudos já mostraram que existe um periodo em que as plantas daninhas não competem com a cultura. 


\subsection{Teste do olfatômetro}

Após a realização da análise faunistica para os insetos coletados em plantas daninhas nas áreas de soja e milho durante a entressafra de 97, foram selecionados 4 insetos-praga que se mostraram predominantes. Além destes, T. perditor e Alydus sp. também haviam sido selecionados mas, devido a dificuldade em coletá-los no campo em grande quantidade para a montagem do teste, os mesmos não foram utilizados.

Para a realização do teste foram utilizados 60 insetos para cada repetição, número muito próximo ao utilizado por Branson (1982), que avaliando a resposta olfatória de larvas de $D$. virgifera virgifera a raizes de plantas utilizou 50 larvas.

\subsubsection{Lagria villosa}

Os resultados relativos às médias dos insetos nas plantas daninhas encontram-se na Tabela 19. De acordo com os dados pode-se verificar que houve diferenças estatísticas significativas entre os tratamentos.

Observou-se que $L$. villosa tem maior preferência por crotalária do que por anileira e rabo-de-foguete, uma vez que estes tratamentos mostraram diferenças significativas. Com respeito a apagafogo, guanxuma e guizo-de-cascavel pode-se dizer que o inseto não as distingue das outras plantas testadas já que estas se comportaram igualmente aos demais tratamentos. 
Tabela 19. Média ( $₫$ DPM) do número de insetos da espécie Lagria villosa encontrados nas plantas daninhas através do teste do olfatômetro, Jaboticabal, SP, 1998.

\begin{tabular}{cc}
\hline Tratamentos & Médias $^{1}$ \\
\hline Crotalária & $15,0 \pm 2,2 \mathrm{~A}$ \\
Apaga-fogo & $13,0 \pm 1,3 \mathrm{AB}$ \\
Guanxuma & $9,0 \pm 2,7 \mathrm{AB}$ \\
Guizo-de-cascavel & $9,0 \pm 1,3 \mathrm{AB}$ \\
Rabo-de-foguete & $6,6 \pm 1,8 \mathrm{~B}$ \\
Anileira & $6,0 \pm 1,6 \mathrm{~B}$ \\
\hline Valor de F & 0,01451 \\
CV (\%) & 42,99 \\
\hline
\end{tabular}

${ }^{1}$ Médias seguidas por letras distintas diferem entre si pelo teste de Tukey ao nível de $5 \%$ de probabilidade.

Os resultados, de certa forma, condizem com o que foi observado no campo, ou seja, este inseto ocorreu e foi predominante em praticamente todas as plantas daninhas, exceto para rabo-de-foguete que foi uma das plantas menos preferidas.

Estes insetos se encontravam principalmente nas flores e partes apicais das plantas e se alimentaram de guizo-de-cascavel, guanxuma e principalmente de crotalária. Observou-se que em média $98 \%$ dos insetos utilizados no teste procuraram as plantas daninhas, sendo que os $3 \%$ encontrados na gaiola estavam vivos.

Observou-se que $L$. villosa foi o inseto que mais rápido procurou o alimento, uma vez que todos os insetos foram deixados em jejum por cerca de 15 horas.

\subsubsection{Paranapiacaba significata}

Os resultados relativos às médias dos insetos nas plantas daninhas encontram-se na Tabela 20. De acordo com os dados pode-se 
verificar que houve diferenças estatisticas significativas entre os tratamentos.

Tabela 20. Média $( \pm \mathrm{DPM})$ do número de insetos da espécie Paranapiacaba significata encontrados nas plantas daninhas atravês do teste do olfatômetro, Jaboticabal, SP, 1998.

\begin{tabular}{cc}
\hline Tratamentos & Médias ${ }^{1}$ \\
\hline Anileira & $11,6 \pm 0,9 \mathrm{~A}$ \\
Guizo-de-cascavel & $10,0 \pm 1,3 \mathrm{AB}$ \\
Crotalária & $8,8 \pm 1,6 \mathrm{AB}$ \\
Apaga-fogo & $7,2 \pm 1,3 \mathrm{AB}$ \\
Rabo-de-foguete & $6,2 \pm 1,0 \mathrm{AB}$ \\
Guanxuma & $4,2 \pm 1,8 \mathrm{~B}$ \\
\hline Valor de F & 0,00989 \\
CV (\%) & 37,88 \\
\hline
\end{tabular}

${ }^{1}$ Médias seguidas por letras distintas diferem entre si pelo teste de Tukey ao nivel de $5 \%$ de probabilidade.

Com relaçāo a $P$. significata, os resultados da ANOVA mostraram uma significativa preferência desta espécie em relação a guanxuma, no entanto os tratamentos guizo-de-cascavel, crotalária, apaga-fogo e rabo-de-foguete comportaram-se igualmente e não exercem maior atratividade ao referido inseto quando comparados aos demais tratamentos.

Os resultados não condizem com o que foi observado no campo pois, anileira foi a planta daninha menos preferida pelo inseto no campo e guanxuma que no teste foi a menos preferida mostrou-se predominante no campo. Assim, talvez fosse necessário maior número de repetiçōes para este inseto ou avaliar melhor o efeito que os estimulos químicos e olfatórios destas plantas desempenham neste inseto. 
Observou-se que os insetos se alimentaram de plantas de crotalária e muitos ficaram no solo. Dos insetos utilizados no teste, $80 \%$ em média procuraram as plantas daninhas e dos $20 \%$ que ficaram na gaiola, $15 \%$ estavam mortos.

\subsubsection{Diabrotica speciosa}

Os resultados relativos às médias dos insetos nas plantas daninhas encontram-se na Tabela 21. De acordo com os dados pode-se verificar que houve diferenças estatisticas significativas entre os tratamentos.

Tabela 21. Média ( \pm DPM) do número de insetos da espécie Diabrotica speciosa encontrados nas plantas daninhas através do teste do olfatômetro, Jaboticabal, SP, 1998.

\begin{tabular}{cc}
\hline Tratamentos & Médias $^{1^{*}}$ \\
\hline Apaga-fogo & $14,2 \pm 1,9 \mathrm{~A}$ \\
Crotalária & $12,0 \pm 1,9 \mathrm{AB}$ \\
Guizo-de-cascavel & $8,2 \pm 1,3 \mathrm{ABC}$ \\
Anileira & $6,1 \pm 0,4 \mathrm{BC}$ \\
Guanxuma & $5,9 \pm 0,8 \mathrm{C}$ \\
Rabo-de-foguete & $5,6 \pm 0,8 \mathrm{C}$ \\
\hline Valor de F & 0,02217 \\
CV (\%) & 17,19 \\
\hline
\end{tabular}

${ }^{2}$ Dados transformados em $\mathrm{x}^{-1 / 2}$.

${ }^{1}$ Médias seguidas por letras distintas diferem entre si pelo teste de Tukey ao nivel de $5 \%$ de probabilidade.

Para $D$. speciosa a planta que mais exerceu atratividade foi apaga-fogo diferindo significativamente de todos os tratamentos, exceto de crotalária e guizo-de-cascavel. Anileira foi menos atrativa apenas em relação a apaga-fogo, e guanxuma e rabo-de-foguete foram menos atrativas que apaga-fogo e crotalária. 
Os resultados estão de acordo como o que foi observado no campo, ou seja, crotalária, guizo-de-cascavel e apaga-fogo foram as plantas daninhas mais preferidas pelo inseto. No entanto, $D$. speciosa é uma praga polifaga que se mostrou predominante em todas as plantas.

Os insetos se alimentaram de crotalária, guizo-de-cascavel e apaga-fogo. Observou-se que em média $92 \%$ dos insetos utilizados no teste, procuraram as plantas daninhas. Dos insetos que ficaram na gaiola a maioria estava morta.

\subsubsection{Piezodorus guildinii}

Os resultados relativos às médias dos insetos nas plantas daninhas encontram-se na Tabela 22. De acordo com os dados pode-se verificar que não houve diferenças estatísticas significativas entre os tratamentos.

Comparando-se as médias, verifica-se que crotalária e anileira foram as plantas daninhas que apresentaram as maiores médias, embora não tenha ocorrido diferença entre os tratamentos. Isto, de certa forma, condiz com o que foi observado no campo.

Observou-se postura desse percevejo em plantas de crotalária. Assim, pelos resultados pode-se dizer que as leguminosas são boas hospedeiras para os percevejos, fato este já citado por Maruyama, 1994; Panizzi, 1987 e Panizzi \& Slansky Jr., 1985.

Dos insetos utilizados no teste, $57 \%$ em média procuraram o alimento, sendo que dos $43 \%$ que ficaram na gaiola a maioria estava morta. Estes insetos foram os menos eficientes na procura do alimento, pois muitos morreram sem encontrá-lo e os que encontraram demoraram um tempo relativamente longo. 
Tabela 22. Média ( $\pm \mathrm{DPM}$ ) do número de insetos da espécie Piezodorus guildinii encontrados nas plantas daninhas através do teste do olfatômetro, Jaboticabal, SP, 1998.

\begin{tabular}{cc}
\hline Tratamentos & Médias $^{1}$ \\
\hline Crotaläria & $6,4 \pm 0,5 \mathrm{~A}$ \\
Anileira & $6,2 \pm 1,0 \mathrm{~A}$ \\
Apaga-fogo & $6,0 \pm 1,4 \mathrm{~A}$ \\
Guizo-de-cascavel & $6,0 \pm 0,7 \mathrm{~A}$ \\
Guanxuma & $5,0 \pm 0,4 \mathrm{~A}$ \\
Rabo-de-foguete & $4,6 \pm 0,7 \mathrm{~A}$ \\
\hline Valor de F & 0,61592 \\
CV $(\%)$ & 33,44 \\
\hline
\end{tabular}

${ }^{1}$ Médias seguidas por letras distintas diferem entre si pelo teste de Tukey ao nível de $5 \%$ de probabilidade.

Muitos herbivoros são surpreendentemente ineptos na procura das plantas hospedeiras, e podem morrer nas proximidades do local em que os hospedeiros são abundantes (Kareiva, 1986).

Os insetos avaliados apresentaram preferência por determinadas espécies de plantas daninhas. Esta preferência pode ter grande implicação no controle destes insetos no campo uma vez que a ocorrência de plantas hospedeiras e não hospedeiras numa mesma área pode causar inibição olfatória e visual nos herbivoros, ou seja, os estimulos visuais e químicos podem confundir o inseto, dificultando assim a localização da planta hospedeira. 


\section{CONCLUSÕES}

- As áreas de soja e milho apresentam indices de diversidade semelhantes, e baixa similaridade em relação as espécies encontradas em cada cultura.

- Dos insetos coletados durante a entressafra da soja e do milho, a maioria são insetos-praga.

- Durante a entressafra da soja, as pragas predominantes nas plantas daninhas são: Diabrotica speciosa; Lagria villosa; Paranapiacaba significata; Xerophloea sp.; Scaphitopius sp.; Alydus sp.; Piezodorus guildinii e Thyanta perditor e os inimigos naturais são: Cycloneda sanguinea; Delphastus sp.; Eriopis connexa; Hyperaspis notata; Geocoris sp.; Polybia sp. e Chrysoperla externa.

- Durante a entressafra do milho, as pragas predominantes nas plantas daninhas são: $D$. speciosa; L. villosa; P. significata; Bucephalogonia xanthophis; Diedrocephala continua e Xerophloea sp. e os inimigos naturais são: Delphastus sp.; C. sanguinea e Geocoris sp.

- D. speciosa é a única espécie predominante em todas as plantas daninhas avaliadas e nas duas áreas. 
- Os insetos $L$. villosa, $P$. significata e $D$. speciosa têm preferência por determinadas espécies de plantas daninhas através do teste do olfatômetro. 


\section{REFERÊNCIAS BIBLIOGRÁFICAS}

ALI, A.D.; REAGAN, T.E. Vegetation manipulation impact on predator and prey populations in Louisiana sugarcane ecosystems. Journal of Economic Entomology, v.78, n.6, p.1409-1414, Dec. 1985.

ALTIERI, M.A. Weeds may augment biological control of insects. California Agriculture, p.22-24, May/June 1981.

ALTIERI, M.A.; LETOURNEAU, D.K. Vegetation management and biological control in agroecosystems. Crop Protection, v.1, n.4, p.405-430, 1982 .

ALTIERI, M.A.; TODD, J.W. Some influences of vegetational diversity on insect communities of Georgia soybean fields. Protection Ecology, v.3, p.333-338, 1981.

ALTIERI, M.A.; WHITCOMB, W.H. The potential use of weeds in the manipulation of beneficial insects. HortScience, v.14, n.1, p.12-18, Feb. 1979.

ALTIERI, M.A.; SCHOONHOVEN, A.V.; DOLL, J.D. The ecological role of weeds in insect pest management systems: a review illustrated with bean (Phaseolus vulgaris L.) cropping systems. PANS, v.23, p.195205, 1977. 
ALTIERI, M.A.; TODD, J.W.; HAUSER, E.W.; PATTERSON,M.; BUCHANAN, G.A.; WALKER, R.H. Some effects of weed management and row spacing on insect abundance in soybean fields. Protection Ecology, v.3, p.339-343, 1981.

ATKINSON, A.C. Plots, transformations, and regression. New York: Oxford University Press, 1985. 282p.

BELARMINO, L.C.; GATTI, M.M. Entomofauna da soja em coexistência com plantas daninhas: III - caruru, Amaranthus spp. (Cariophylaceae). In: CONGRESSO BRASILEIRO DE ENTOMOLOGIA, 14., Piracicaba, 1993. Resumos. Piracicaba: SEB, 1993. p.143.

BRANSON, T.F. Olfactory response of larvae of Diabrotica virgifera virgifera to plant roots. Entomologia Experimentalis et Applicata, v.31, p.303-307, 1982 .

BUSCHING, M.K.; TURPIN, F.T. Oviposition preferences of black cutworm moths among various crop plants, weeds, and plant debris. Journal of Economic Entomology, v.69, n.5, p.587-590, 1976.

CHRISTOFFOLETI, P.J. Dinâmica de populaçōes de plantas daninhas e manejo de herbicidas para a cultura da soja. In: CÂMARA, G.M.S. (Ed.) Soja: tecnologia da produção. Piracicaba: ESALQ, Depto. de Agricultura, 1998. cap.9, p. 121-138. 
3 CORREAA, B.S.; PANIZZI, A.R.; NEWMAN, G.G.; TURNIPSEED, S.G. Distribuição geográfica e abundância estacional dos principais insetos-pragas da soja e seus predadores. Anais da Sociedade Entomológica do Brasil, v.6, n.1, p.40-50, 1977.

DAZA, E.; PANTOJA, A. Hospederos alternos en pentatómido: implicaciones en el manejo de plagas. Turrialba, v.42, n.3, p.408410, jul/sep. 1992.

- DEUBER, R. Ciência das plantas infestantes: manejo. Campinas: Ed. Degaspari, 1997. v.2, 285p.

- FAIFER, W.O. Insetos associados a espécies de plantas daninhas em Jaboticabal. Jaboticabal, 1986. 51p. Monografia (Graduação) Faculdade de Ciências Agrárias e Veterinárias, Universidade Estadual Paulista "Júlio de Mesquita Filho".

FAZOLIN, M. Análise faunistica de insetos coletados com armadilha luminosa em seringueira no Acre. Piracicaba, 1991. 236p. Tese (Doutorado) - Escola Superior de Agricultura "Luiz de Queiroz", Universidade de São Paulo.

FONTES, E.M.G. Ervas daninhas como reguladoras das populações de inimigos naturais das pragas de culturas: o exemplo da erva-lanceta. Ciência e Cultura, v.38, n.10, p.1709-1713, out. 1986.

๑ FORNASIERI FILHO, D. A cultura do milho. Jaboticabal: FUNEP, 1992. 273p. 
FORSTER, R.; ALVES, A. Os herbicidas na lavoura da soja. A granja, v.32, p.32-38, 1976.

FOSTER, M.A.; RUESINK, W.G. Influence of flowering weeds associated with reduced tillage in corn on a black cutworm (Lepidoptera: Noctuidae) parasitoid, Meteorus rubens (Nees von Esenbeck). Environmental Entomology, v.13, n.3, p.664-668, June 1984.

FRIZZAS, M.R. Manejos da vegetação natural e seus efeitos na população de inimigos naturais na cultura do algodão (Gossypium hirsutum L.). Jaboticabal, 1996. 68p. Monografia (Graduação) Faculdade de Ciências Agrárias e Veterinárias, Universidade Estadual Paulista "Júlio de Mesquita Filho".

HERZOG, D.C.; TODD, J.W. Samplig valvetbean caterpillar on soybean. In: KOGAN, M.; HERZOG, D.C. (Ed.) Samplig methods in soybean entomology. New York: Springer-Verlag, 1980. p.107-140.

HORTON, D.R.; CAPINERA, J.L. Effects of plant diversity, host density, and host size on population ecology of the colorado potato beetle (Coleoptera: Chrysomelidae). Environmental Entomology, v.16, n.4, p.1019-1026, Aug. 1987.

KAREIVA, P. Trivial movement and foraging by crop colonizers. In: KOGAN, M. (Ed.) Ecological theory and integrated pest management practice. New York: John Wiley, 1986. p.59-82.

- KOGAN, M.; TURNIPSEED, S.G. Ecology and management of soybean arthropods. Annual Review of Entomology, v.32, p.507-538, 1987. 
LEVINS; R.; WILSON, M. Ecological theory and pest management. Annual Review of Entomology, v.25, p.287-308, 1980.

LEWIS, T. Thrips: their biology, ecology and economic importance. New York: Academic Press, 1973. 349p.

LIMA, M.G.A. Espécies de tripes (Thysanoptera: Thripidae) associadas às plantas daninhas na entressafra do amendoim (Arachis hypogaea L.) no Câmpus de Jaboticabal. Jaboticabal, 1997. 50p. Tese (Doutorado)Faculdade de Ciências Agrárias e Veterinárias, Universidade Estadual Paulista "Júlio de Mesquita Filho".

MACHADO, R.M. Utilidades das plantas daninhas no manejo integrado das pragas. Informe Agropecuário, v.13, n.150, p.33-35, 1988.

MARUCCI, R.C. Influência do manejo da vegetação natural sobre a população de pragas na cultura do algodão (Gossypium hirsutum L.). Jaboticabal, 1996. 61p. Monografia (Graduação) - Faculdade de Ciências Agrárias e Veterinárias, Universidade Estadual Paulista “Júlio de Mesquita Filho".

- MARUYAMA, W.I. Ocorrência natural de parasitóides sobre lagartas e ovos de percevejos em soja e plantas daninhas, em Jaboticabal - SP. Jaboticabal, 1994. 66p. Monografia (Graduação) - Faculdade de Ciências Agrárias e Veterinárias, Universidade Estadual Paulista “Júlio de Mesquita Filho". 
MATUO, T. Inovações tecnológicas na aplicação de produtos fitossanitários na cultura da soja. In: REUNIÃO DE PESQUISA DE SOJA DA REGIÃO CENTRAL DO BRASIL, 19., Jaboticabal, 1997. Ata e resumos. Londrina: EMBRAPA, CNPSo, 1997. p.47-48.

NASCENTE, A.S.; MEDEIROS, M.A.; PEREIRA, W.; FRANÇA, F.H. Abundância e riqueza de espécies de herbivoros, predadores e parasitóides em cultivo de tomate consorciado com plantas daninhas. In: CONGRESSO BRASILEIRO DE ENTOMOLOGIA, 17., Rio de Janeiro, 1998. Resumos. Rio de Janeiro: SEB, 1998. p.477.

NIELSON, M.W. A revision of the genus Xerophloea (Homoptera, Cicadellidae). Annals of the Entomological Society of America, v. 55, p.234-244, 1962.

NIELSON, M.W. Leafhopper systematics. In: NAULT, L.R.; RODRIGUEZ, J.G. (Ed.) The leafhoppers and planthoppers. New York: John Wiley, 1985. cap.2, p.11-39.

OLIVEIRA, C.M. Variação morfológica entre populações de Dalbulus maidis (DeLong \& Wolcott, 1923) (Hemiptera, Cicadellidae) de algumas localidades do Brasil. Piracicaba, 1996. 69p. Dissertação (Mestrado) - Escola Superior de Agricultura "Luiz de Queiroz", Universidade de São Paulo.

OLIVEIRA, L.J.; PANIZZI, A.R. Desenvolvimento e viabilidade de Anticarsia gemmatalis (Hübner) em diversas leguminosas. In: CONGRESSO BRASILEIRO DE ENTOMOLOGIA, 17., Rio de Janeiro, 1998. Resumos. Rio de Janeiro: SEB, 1998. p.107. 
OLOUMI-SADEGHI, H.; ZAVALETA, L.R.; LAMP, W.O.; ARMBRUST, E.J.; KAPUSTA, G. Interactions of the potato leafhopper (Homoptera: Cicadellidae) with weeds in an alfalfa ecosystem. Environmental Entomology, v.16, n.5, p.1175-1180, oct. 1987.

OTERO, P.R.; BELARMINO, L.C. Entomofauna de soja em coexistência com plantas daninhas: V - picão preto, Bidens pilosa (Compositae). In: CONGRESSO BRASILEIRO DE ENTOMOLOGIA, 14., Piracicaba, 1993. Resumos. Piracicaba: SEB, 1993. p.140.

PANIZZI, A.R. Impacto de leguminosas na biologia de ninfas e efeito da troca de alimento no desempenho de adultos de Piezodorus guildinii (Hemiptera: Pentatomidae). Revista Brasileira de Biologia, v.47, n.4, p.585-591, nov. 1987.

PANIZZI, A.R.; ROSSI, C.E. Hábitos alimentares de Euschistus heros e Nezara viridula (Hemiptera: Pentatomidae) em carrapicho-de-carneiro, Acanthospermum hispidum. In: EMPRESA BRASILEIRA DE PESQUISA AGROPECUÁRIA. Resultados de pesquisa de soja 1988/1989. Londrina, 1989. p.37-41.

PANIZZI, A.R.; SLANSKY JÚNIOR, F. Legume host impact on performance of adult Piezodorus guildinii (Westwood) (Hemiptera: Pentatomidae). Environmental Entomology, v.14, n.3, p. 237-242, June 1985. 
PINAZZA, L.A. Perspectivas da cultura do milho e sorgo no Brasil. In: SIMPÓSIO SOBRE FATORES QUE AFETAM A PRODUTIVIDADE DO MILHO E DO SORGO, Vitória, 1990. Cultura do milho. Piracicaba: Potafós, 1990. p.1-10.

PITELLI, R.A. Interferência das plantas daninhas em culturas agricolas. Informe Agropecuário, v.11, n.129, p.16-27, 1985.

PITRE, H.N.; BOYD, F.J. A study of the role of weeds in corn fields in the epidemiology of corn stunt disease. Journal of Economic Entomology, v.63, n.1, p.195-197, Feb. 1970.

POWER, A.G. Plant community diversity, herbivore movement, and an insect - transmitted disease of maize. Ecology, v.68, n.6, p.16581669, Dec. 1987.

RAMIRO, Z.A.; SOUZA FILHO, M.F.; RAGA, A. Plantas daninhas associadas ao percevejo-castanho Scaptocoris castanea em cultura de soja. In: REUNIÃO DE PESQUISA DE SOJA DA REGIÃO CENTRAL DO BRASIL, 19., Jaboticabal, 1997. Ata e resumos. Londrina: EMBRAPA,CNPSo, 1997. p.194.

RODINI, E.S.O.; GRAZIA, J. Abundância de algumas espécies de insetos (Coleoptera e Hemiptera) em soja (Glycine max (L.) Merrill) no municipio de Aguaí, SP. In: SEMINÁRIO NACIONAL DE PESQUISA DE SOJA. Anais. 1979. v.2, p. 17-22. 
SANTOS, G.M.M.; MARQUES, O.M. Análise faunistica de comunidades de formigas epigéias (Hymenoptera, Formicidae) em dois agroecossistemas em Cruz das Almas - Bahia. Insecta, v.5, n.1, p.117, mar. 1996.

SCHULTZ, B.B. Reduced oviposition by green lacewings (Neuroptera: Chrysopidae) on cotton intercropped with corn, beans, or weeds in Nicaragua. Environmental Entomology, v.17, n.2, p.229-232, Apr. 1988.

SHELTON, M.D.; EDWARDS, C.R. Effects of weeds on the diversity and abundance of insects in soybeans. Environmental Entomology, v.12, n.2, p.296-298, Apr. 1983.

SILVA, A.L. Levantamento populacional das principais pragas da cultura de soja em Goiânia. Anais da Escola de Agricultura e Veterinária Universidade Federal de Goiânia, n.1, p.99-115, 1977.

SILVA, V.T.A. Efeitos da comunidade de plantas daninhas sobre a artropodofauna da cultura da soja (Glycine max (L.) Merril). Botucatu, 1996. 104p. Tese (Doutorado) - Faculdade de Ciências Agronômicas de Botucatu, Universidade Estadual Paulista "Júlio de Mesquita Filho".

SILVEIRA NETO, S.; NAKANO, O.; BARBIN, D.; VILLA NOVA, N.A. Manual de ecologia dos insetos. São Paulo: Agronômica Ceres, 1976. 419p. 
SILVEIRA NETO, S.; BRAZ, A.J.B.P.; ZUCCHI, R.A.; CHAGAS, E.F.; MENEZES, M. Levantamento de insetos sugadores em citros com coletor de sucção costal. Anais da Sociedade Entomológica do Brasil, v.12, n.2, p.165-173, 1983.

SLANSKY JÚNIOR, F. Early season weedy legumes: potential larval food plants for the migratory velvetbean caterpillar (Lepidoptera: Noctuidae). Journal of Economic Entomology, v.82, n.3, p.819-824, June 1989.

SOUTHWOOD, T.R.E. Ecological methods. London: Chapman and Hall, 1971. 391p.

SOUZA, C.E.P.; AMARAL FILHO, B.F. Uma nova planta hospedeira de Leptoglossus zonatus Dallas, 1892 (Heteroptera, Coreidae). In: CONGRESSO BRASILEIRO DE ENTOMOLOGIA, 17., Rio de Janeiro, 1998. Resumos. Rio de Janeiro: SEB, 1998. p.565.

SOUZA, I.F. Controle biológico de plantas daninhas. Informe Agropecuário, v.15, n.167, p.77-82, 1991.

TAMO, M.; BAUMGÄRTNER, J.; DELUCCHI, V.; HERREN, H.R. Assessement of key factors responsible for the pest status of bean flower thrips Megalurothrips sjostedti (Thysanoptera: Thripidae) in west Africa. Bulletin of Entomological Research, v.83, p.251-258, 1993. 
¿ TANAKA, R.T. Relatos por Estado sobre o comportamento da cultura da soja na safra 1996/97 - São Paulo. In: REUNIÃO DE PESQUISA DE SOJA DA REGIÃO CENTRAL DO BRASIL, 19., Jaboticabal, 1997. Ata e resumos. Londrina: EMBRAPA, CNPSo, 1997. p.15-22.

TINGLE, F.C.; ASHLEY, T.R.; MITCHELL, E.R. Parasites of Spodoptera exigua, S. eridania (Lep.: Noctuidae) and Herpetogramma bipunctalis (Lep.: Pyralidae) collected from Amaranthus hybridus in field corn. Entomophaga, v.23, n.4, p.343-347, 1978.

VELINI, E.D. Avaliação dos efeitos de comunidades infestantes naturais, controladas por diferentes periodos, sobre o crescimento $\mathrm{e}$ produtividade da cultura da soja (Glycine $\max ($ L.) Merril). Jaboticabal, 1989. 153p. Dissertação (Mestrado) - Faculdade de Ciências Agrárias e Veterinárias, Universidade Estadual Paulista "Júlio de Mesquita Filho".

WALLIS, R.L.; TURNER, J.E. Burning weeds in drainage ditches to suppress populations of green peach aphids and incidence of beet western yellows disease in sugarbeets. Journal of Economic Entomology, v.62, n.2, p.307-309, Apr. 1969.

WARDLE, D.A.; NICHOLSON, K.S.; YEATES, G.W. Effect of weed management strategies on some soil-associated arthropods in maize and asparagus ecosystems. Pedobiologia, v.37, n.5, p.257-269, 1993.

YAMAMOTO, P.T. Cigarrinhas em citros no Estado de São Paulo. Laranja, v.17, n.1, p.237-239, 1996. 
YAMAMOTO, P.T.; GRAVENA, S. Espécies de cigarrinhas (Hemiptera, Cicadellidae) em pomares citricos no Estado de São Paulo. In: CONGRESSO BRASILEIRO DE ENTOMOLOGIA, 17., Rio de Janeiro, 1998. Resumos. Rio de Janeiro: SEB, 1998. p.386.

ZANDSTRA, B.H.; MOTOOKA, P.S. Beneficial effects of weeds in pest management - a review. PANS, v.24, n.3, p. 333-338, Sept. 1978. 